\title{
The digestive tract as an essential organ for water acquisition in marine teleosts: lessons from euryhaline eels
}

Yoshio Takei@

\begin{abstract}
Adaptation to a hypertonic marine environment is one of the major topics in animal physiology research. Marine teleosts lose water osmotically from the gills and compensate for this loss by drinking surrounding seawater and absorbing water from the intestine. This situation is in contrast to that in mammals, which experience a net osmotic loss of water after drinking seawater. Water absorption in fishes is made possible by (1) removal of monovalent ions (desalinization) by the esophagus, (2) removal of divalent ions as carbonate $\left(\mathrm{Mg} / \mathrm{CaCO}_{3}\right)$ precipitates promoted by $\mathrm{HCO}_{3}{ }^{-}$secretion, and (3) facilitation of $\mathrm{NaCl}$ and water absorption from diluted seawater by the intestine using a suite of unique transporters. As a result, 70-85\% of ingested seawater is absorbed during its passage through the digestive tract. Thus, the digestive tract is an essential organ for marine teleost survival in the hypertonic seawater environment. The eel is a species that has been frequently used for osmoregulation research in laboratories worldwide. The eel possesses many advantages as an experimental animal for osmoregulation studies, one of which is its outstanding euryhalinity, which enables researchers to examine changes in the structure and function of the digestive tract after direct transfer from freshwater to seawater. In recent years, the molecular mechanisms of ion and water transport across epithelial cells (the transcellular route) and through tight junctions (the paracellular route) have been elucidated for the esophagus and intestine. Thanks to the rapid progress in analytical methods for genome databases on teleosts, including the eel, the molecular identities of transporters, channels, pumps and junctional proteins have been clarified at the isoform level. As 10 y have passed since the previous reviews on this subject, it seems relevant and timely to summarize recent progress in research on the molecular mechanisms of water and ion transport in the digestive tract in eels and to compare the mechanisms with those of other teleosts and mammals from comparative and evolutionary viewpoints. We also propose future directions for this research field to achieve integrative understanding of the role of the digestive tract in adaptation to seawater with regard to pathways/mechanisms including the paracellular route, divalent ion absorption, metabolon formation and cellular trafficking of transporters. Notably, some of these have already attracted practical attention in laboratories.

(Continued on next page)
\end{abstract}

\footnotetext{
Correspondence: takei@aori.u-tokyo.ac.jp

All transporters have both common names and those derived from the solute carrier (SLC) family. In this review, the SLC family names are shown in addition to the common names at first appearance to indicate similar transport characteristics and susceptibility to common inhibitors. The number after the common name is not hyphenated, and the acronyms are capitalized (e.g., PAT1).

Laboratory of Physiology, Department of Marine Bioscience, Atmosphere and Ocean Research Institute, The University of Tokyo, 5-1-5 Kashiwanoha,

Kashiwa, Chiba 277-8564, Japan
}

C C The Author(s). 2021 Open Access This article is licensed under a Creative Commons Attribution 4.0 International License, which permits use, sharing, adaptation, distribution and reproduction in any medium or format, as long as you give appropriate credit to the original author(s) and the source, provide a link to the Creative Commons licence, and indicate if changes were made. The images or other third party material in this article are included in the article's Creative Commons licence, unless indicated otherwise in a credit line to the material. If material is not included in the article's Creative Commons licence and your intended use is not permitted by statutory regulation or exceeds the permitted use, you will need to obtain permission directly from the copyright holder. To view a copy of this licence, visit http://creativecommons.org/licenses/by/4.0/ The Creative Commons Public Domain Dedication waiver (http://creativecommons.org/publicdomain/zero/1.0/) applies to the data made available in this article, unless otherwise stated in a credit line to the data. 
(Continued from previous page)

Keywords: Osmoregulation, Seawater adaptation, Anguilla spp., Esophageal desalinization, Biomineralization, Epithelial transport, Transcellular transport, Paracellular transport, Tight junction protein, Hormonal regulation, Metabolon, Vesicle trafficking

\section{Background}

1.1 Diverse body fluid regulation in marine fishes

Extant vertebrates inhabit three different types of habitats in terms of osmoregulation: water- and ion-deficient land habitats, water-sufficient and ion-deficient inland freshwater (FW) habitats, and water- and ion-sufficient seawater $(\mathrm{SW})$ habitats. Because of the high osmolality of SW, however, the ocean is generally a desiccative environment for marine teleost fishes. To address this issue, marine fishes use three different strategies for body fluid regulation (Fig. 1). The first strategy is adopted by the most primitive extant vertebrate group, the hagfishes, which conform their plasma to environmental SW in terms of both ion concentrations and osmolality (acting as iono- and osmoconformers), similar to marine invertebrates (Fig. 1). Thus, they exert little osmoregulation effort and incur little expense. The ions involved are monovalent ions $\left(\mathrm{Na}^{+}\right.$and $\left.\mathrm{Cl}^{-}\right)$, as divalent ions $\left(\mathrm{Mg}^{2+}\right.$ and $\left.\mathrm{SO}_{4}{ }^{2-}\right)$ are maintained at levels lower than those in plasma [63]. The second strategy is employed by elasmobranchs and a lobe-finned bony fish, the coelacanth, whose plasma ion concentrations are lower than the concentrations in SW but whose plasma osmolality is maintained at a level similar to that in SW via accumulation of urea in the plasma (acting as ionoregulators and osmoconformers). Thus, they need only to excrete excess ions and retain urea at the kidneys, as osmotic forces on water diffusion are nearly abolished. Marine teleosts use a third strategy like that of marine mammals, birds and reptiles, which have plasma ion concentrations and osmolality approximately one-third that of SW (making them iono- and osmoregulators) (Fig. 1). Thus, they must counter osmotic water loss and excess ion gain. To address this hydromineral challenge, marine teleosts drink SW and absorb water together with ions in the intestine. Ions also enter the body via the body surfaces driven by their concentration gradients. Then, excess monovalent ions are excreted mostly by the gills, and excess divalent ions are excreted by the kidneys [127, 144].

Gill ionocytes (mitochondrion-rich cells) are responsible for active $\mathrm{Na}^{+}$and $\mathrm{Cl}^{-}$excretion (see [36, 51]). As acquisition of ionocytes appeared to be one of the cues for teleosts to re-enter the marine environment after the teleost-specific whole-genome duplication that occurred ca. 300 mya [91], gill ionocytes have been the most intensively studied tissue in osmoregulation research. Consequently, the molecular mechanisms of transcellular and paracellular ion transport have been elucidated, and these mechanisms have been summarized in several reviews (e.g., $[30,85,86$, 90]). SW contains high

\section{1. iono- and osmoconformer hagfishes \\ $\mathrm{Na} \quad \mathrm{Cl} \mathrm{K} \mathrm{Ca} \mathrm{Mg} \mathrm{SO} \mathrm{Urea}_{4}$ Osm \\ $\begin{array}{llllllll}485 & 508 & 10 & 6 & 26 & 18 & 3 & 1034\end{array}$}

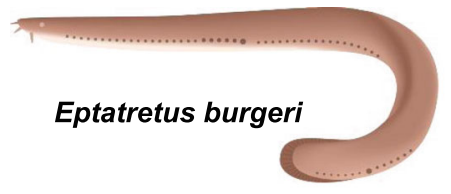

2. ionoregulator, osmoconformer elasmobranchs/coelacanth

$\mathrm{Na} \quad \mathrm{Cl} \quad \mathrm{K} \quad \mathrm{Ca} \mathrm{Mg} \mathrm{SO}_{4}$ Urea Osm

$\begin{array}{llllllll}247 & 221 & 8 & 3 & 5 & 2 & 342 & 1030\end{array}$

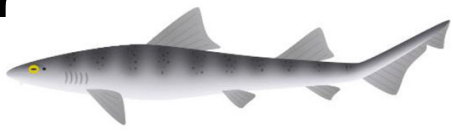

Triakis scyllium

3. iono- and osmoregulator teleosts

$\begin{array}{cccccccc}\mathrm{Na} & \mathrm{Cl} & \mathrm{K} & \mathrm{Ca} & \mathrm{Mg} & \mathrm{SO}_{4} & \text { Urea } & \text { Osm } \\ 175 & 155 & 3 & 2 & 3 & 1 & 3 & 377\end{array}$

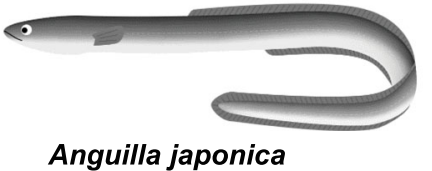

Fig. 1 Diverse strategies for adaptation of fishes to a hypertonic seawater environment. The ion concentrations are in mM, and osmolality (Osm) is in $\mathrm{mOsm} / \mathrm{l}$. The values for eels are for eels acclimated to seawater. The values for seawater are shown in Table 1. All marine mammals, birds and reptiles are iono- and osmoregulators, while the only amphibian that can acclimate to seawater, the crab-eating frog (Fejervarya cancrivora), is an ionoregulator and osmoconformer, as are elasmobranchs. Illustrated by Mari Kawaguchi of Sophia University (https://www.ginganet.org/mari) 
concentrations of the divalent ions $\mathrm{Mg}^{2+}$ and $\mathrm{SO}_{4}{ }^{2-}$ in addition to monovalent ions (Table 1), and the sites of $\mathrm{MgSO}_{4}$ excretion are the proximal tubules of the kidneys $[18,19]$. Transporters involved in transcellular $\mathrm{Mg}^{2+}$ transport have been suggested to exist in the euryhaline pufferfish mefugu, Takifugu obscurus [96, 97], and those for $\mathrm{SO}_{4}{ }^{2-}$ transport have been proposed to exist in the mefugu [107] and eel [256]. However, the whole picture of divalent ion transport in the kidneys has not yet been revealed. The urinary bladder also serves as a site for final water absorption before excretion in marine teleosts [134].

It has been known since the early 1900s that marine teleosts drink copiously to compensate for water lost osmotically across the body surface [207]. The mechanisms for eliciting drinking have been investigated in various teleost species and have been summarized in a few reviews $[69,218,221,259]$. Relatively recently, the roles of cerebral mechanisms regulating drinking (thirst) in teleosts were suggested after the mechanisms were compared between fully aquatic eels and semiterrestrial mudskippers [11, 105]. After SW is consumed, it enters the digestive tract, which is an intracorporeal but external environment in relation to body fluids. Only after absorption by the intestine does the ingested water join the body fluids. In this sense, intestinal water absorption is critical for body fluid regulation and thus for survival of marine teleosts in hypertonic SW.

\subsection{Role of the digestive tract in adaptation to marine environments}

For terrestrial vertebrates such as mammals, drinking SW results in severe loss of body fluids. Water is lost by osmosis in the esophagus and stomach when hypertonic $\mathrm{SW}$ enters the lumen. $\mathrm{NaCl}$ is absorbed significantly by the intestine and $\mathrm{NaCl}$ absorption may be accompanied by absorption of some water. However, as $\mathrm{Mg}^{2+}$ and $\mathrm{SO}_{4}{ }^{2-}$ in $\mathrm{SW}$ are scarcely absorbed by the intestine, the luminal fluid osmolality increases after water absorption, which hinders further water absorption. Thus, severe diarrhea occurs after SW drinking in mammals. Moreover, as urine $\mathrm{NaCl}$ concentrations of terrestrial mammals are usually lower than $\mathrm{SW} \mathrm{NaCl}$ concentrations, water is further lost in the urine for $\mathrm{NaCl}$ excretion. Although there is a report showing that whale kidneys can concentrate $\mathrm{Cl}^{-}$to a concentration of 820 $\mathrm{mM}$ [189], urine $\mathrm{NaCl}$ concentrations are usually much lower than SW concentrations [20]. Marine birds and reptiles possess salt glands that concentrate $\mathrm{NaCl}$ above SW levels through a mechanism similar to that in teleost ionocytes, which are localized in different parts of the body [189].

On the other hand, marine teleosts can absorb 70$85 \%$ of ingested SW across the intestine and excrete excess $\mathrm{NaCl}$ from gill ionocytes $[127,144]$. This is due to the excellent ability of the teleost digestive tract to process ingested SW along its segments for final absorption in the intestine (see $[69,259])$. As detailed below, ingested SW is first diluted in the esophagus by removal of $\mathrm{Na}^{+}$and $\mathrm{Cl}^{-}$(desalinization) without water loss [83, 166]. The ingested $\mathrm{SW}$ is further diluted in the anterior intestine by bicarbonate ion $\left(\mathrm{HCO}_{3}{ }^{-}\right)$secretion into the lumen, which is followed by reductions in $\mathrm{Mg}^{2+}$ and $\mathrm{Ca}^{2+}$ concentrations via precipitation of these ions as carbonates [70, 73, 264]. Finally, water is absorbed in parallel with $\mathrm{Na}^{+}$and $\mathrm{Cl}^{-}$by the intestine, either transcellularly via the suite of transporters unique to marine teleosts $[69,133,259]$ or paracellularly via tight junctions (TJs).

Thanks to the recent development of gene technology and bioinformatics together with the establishment of genome databases for various fish species, it is possible to identify transport molecules responsible for ion and water absorption along the digestive tract. The progress made in this decade is evident: molecular mechanisms have been elucidated at the isoform (paralog) level for transporters, channels, pumps and $\mathrm{TJ}$ proteins. In response to such progress and because almost $10 \mathrm{y}$ have passed since the previous reviews on teleost intestinal function for osmoregulation were published [69, 213, 259], we decided to summarize current knowledge about the molecular mechanisms in order to gain insights into the future directions. In this review, we focus on the

Table 1 lon concentrations and osmolality of luminal fluid along the digestive tract of eel. Ion concentrations of eel plasma and of seawater are also shown

\begin{tabular}{lllllllll}
\hline Segment & Osmolality $(\mathbf{m O s m} / \mathbf{l})$ & $\mathbf{N a}^{+}(\mathbf{m M})$ & ${ }^{*} \mathbf{K}^{+}(\mathbf{m M})$ & $\mathbf{C l}^{-}(\mathbf{m M})$ & $\mathbf{H C O}_{\mathbf{3}}{ }^{-}(\mathbf{m M})$ & $\mathbf{M g}^{\mathbf{2 +}}(\mathbf{m M})$ & $\mathbf{C a}^{\mathbf{2 +}}(\mathbf{m M})$ & $\mathbf{S O}_{\mathbf{4}}{ }^{2-}(\mathbf{m M})$ \\
\hline Esophagus & 449 & 211 & 10 & 225 & - & 40 & - & 8 \\
Stomach & 460 & 222 & 14 & 255 & - & 41 & 10 & - \\
Intestine & 295 & 40 & 14 & 68 & 100 & 150 & 12 & 133 \\
Rectum & 300 & 4 & 11 & 59 & 105 & 188 & 14 & 105 \\
SW & 1029 & 450 & 10 & 524 & 2 & 50 & 30 \\
Plasma & 377 & 175 & 4 & 155 & 14 & 3 & 2 & 1 \\
\hline
\end{tabular}

- , not measured. The data are based on Tsukada et al. [241]

*Data of Pleuronectes platessa [74] 
recently identified transport molecules in relation to the specific function of each segment of the digestive tract. Although molecular studies have been performed in several teleost species, we describe the mechanisms mainly in eels (genus Anguilla) for reasons explained in the next section. We include data obtained in mammals wherever appropriate to compare the mechanisms of waterretaining and ion-excreting marine teleosts with those of water- and ion-retaining mammals [225].

\subsection{Contribution of eels to osmoregulation research}

Among eels in the order Anguilliformes, the eel discussed here is a euryhaline, migratory (catadromous) species that can readily adapt to both hypotonic and hypertonic environments. Eels are SW species in origin, and some eels do not undergo upstream migration but rather stay in coastal SW areas throughout their lives, as shown by the presence of strontium in whole otoliths [242]. Thus, they have an excellent hypo-osmoregulation ability and can easily survive in concentrated SW. Accordingly, they can be used to examine how osmoregulatory mechanisms are altered after direct transfer from FW to SW seemingly without severe disturbances in other homeostatic mechanisms. For these reasons, the European eel ( $A$. anguilla), Japanese eel (A. japonica) and American eel (A. rostrata) have often been used for osmoregulation researches since the time of Smith [207]. These researches include research on gill function $[100,103,108,186]$, drinking regulation $[82,141$, $161,223]$, and digestive tract function $[5,83,114$, $138,165,206,238]$. In contrast, another family of euryhaline migratory (anadromous) species, the salmonids, are FW species in origin, and some live their whole lives in FW (land-locked subspecies). As a result, the osmoregulatory mechanisms of eels differ considerably from those of salmonids and from those of stenohaline sedentary marine teleosts [224]. Thus, it is worthwhile to compare the roles of the digestive tract in SW adaptation among the three groups with different osmoregulatory mechanisms.

Another advantage of the eel as an experimental fish for studying intestinal function is that this fish can survive normally for several months without food. We acclimated eels in FW aquaria for 1 week after purchase and then transferred them to SW aquaria for 2 weeks to prepare SW-acclimated eels. We used them for intestinal experiments thereafter, and we obtained a full response to hormones in terms of sensitivity and efficacy for a few months thereafter (see Sect. 5), although in killifish (Fundulus heteroclitus), the water permeability of the intestine appears to decrease within $24 \mathrm{~h}$ after feeding [274]. The major function of the intestine is nutrient absorption, and ions and water in the food and in the digestive juice secreted after feeding significantly influence salt and water balance in fish [273]. We can exclude such influences when eels are used as experimental fish. In addition, we can exclude the influences of nutrientcoupled ion absorption on water and ion balance when unfed eels are used. It is known that $~ 50 \%$ of water is absorbed in parallel with $\mathrm{Na}^{+}$-glucose cotransport in the human intestine [132]. Furthermore, whole-genome sequencing of three Anguilla species has been completed, and the results are publicly available [79, 101, 168]. Thus, mining of transporter genes at the paralog level is possible with the database. In this review, data for eels are primarily introduced with particular emphasis on the molecular mechanism to serve as a basis for comparison with the molecular mechanisms of other teleosts. This review updates the previous reviews on the role of the intestine in osmoregulation $[69,213,259]$ and extends our previous review on the regulation of drinking in fishes, i.e., ingestion from the environment into the digestive tract [220]. Ion transport by the digestive tract significantly affects acid-base balance, which is referred to only when necessary in this review. Readers can find several reviews on this topic elsewhere [76, 232, 272]. A detailed account of osmoregulation in invertebrates and vertebrates can be found in Larsen et al. [127].

\section{The esophagus as an organ for desalinization}

The class Teleostei is the most diverse group of vertebrates in terms of ecology and physiology and contains more than half of the total number of vertebrate species [159]. Unsurprisingly, the morphology of the digestive tract is also diverse among teleost species [261]. Most teleost digestive tracts include an esophagus, stomach, intestine, and rectum; some lack the stomach, such as that of medaka (Oryzias spp.), and some have pyloric caeca at the anterior part of the intestine, as observed in salmonids. The esophagus is the first segment of the digestive tract that directly receives ingested SW. There are sphincters at the entrance and exit of the esophagus to regulate inflow from the buccal cavity and outflow to the stomach. Therefore, ingested SW is kept in the esophagus for some time to allow modifications to its composition. The eel is an excellent experimental fish with which to study esophageal function because this fish has a long and distensible esophagus that is suitable for use in sac experiments [83, 114, 157, 227]. A morphological study has shown that the eel esophageal epithelium becomes thinner and that blood vessels develop beneath the epithelium after SW acclimation, supporting the occurrence of facilitated desalinization [275].

As shown in Table 1, ingested SW is processed gradually according to its passage through the digestive tract of eels [113, 207, 241, 257]. Similar results have been reported in the digestive tract of the winter flounder, Pseudopleuronectes americanus [166]. In both species, 
profound decreases in $\mathrm{Na}^{+}$and $\mathrm{Cl}^{-}$concentrations (desalinization) occur in the esophagus. In contrast, the decreases in $\mathrm{Mg}^{2+}$ and $\mathrm{SO}_{4}{ }^{2-}$ concentrations are small, suggesting that esophageal epithelia are scarcely permeable to divalent ions and water; thus, osmotic influx of water from the serosal side is negligible [83]. In vitro studies using esophageal sac preparation have shown that $\mathrm{NaCl}$ efflux increases while water influx decreases dramatically after SW acclimation in eels when SW is on the luminal side and isotonic Ringer solution is on the serosal side [83, 227]. Unidirectional (mucosa-to-serosa)

${ }^{22} \mathrm{Na}$ fluxes have also been examined using esophageal epithelia in Ussing chambers for the winter flounder [166] and the gulf toadfish, Opsanus beta [49]; the results show that ${ }^{22} \mathrm{Na}$ efflux is elevated in fish kept in hypersaline media.

The transporters involved in transepithelial $\mathrm{Na}^{+}$and $\mathrm{Cl}^{-}$ transport have been examined using various transporterspecific inhibitors (Table 2). Although the efficacy of inhibition varies among species, consistent effects are obtained with mucosal application of DMA/EIPA and DIDS/ DNDS and with serosal application of ouabain and DPC, suggesting the involvement of the apical $\mathrm{Na}^{+} / \mathrm{H}^{+}$exchanger (NHE) and $\mathrm{Cl}^{-} / \mathrm{HCO}_{3}{ }^{-}$exchanger (anion exchanger, $\mathrm{AE}$ ) and of basolateral $\mathrm{Na}^{+} / \mathrm{K}^{+}$-ATPase (NKA) and $\mathrm{Cl}^{-}$ channels (ClCs) [49, 157, 166, 227]. HCTZ is effective in the eel [227] but not effective in the toadfish [49]. We initially thought that HCTZ inhibits the SLC12 family of transporters, such as the $\mathrm{Na}^{+}-\mathrm{Cl}^{-}$cotransporter (NCC), found in the intestine (see 4.4.1), but HCTZ also inhibits carbonic anhydrase (CA), which supplies $\mathrm{H}^{+}$and $\mathrm{HCO}_{3}{ }^{-}$ for NHE and AE to facilitate their combined activity [205].

\subsection{Molecular mechanisms of desalinization}

Transporter molecules involved in desalinization have been assessed by transcriptome analysis (RNA-seq) using the esophagi of FW- and SW-acclimated eels [227]. Among the candidates implied by the inhibitor studies, the candidates were further narrowed down with criteria of (1) sufficient expression in the esophagus and (2) upregulation in SW-acclimated eels. Since RNA-seq can hardly distinguish the expressed genes at the isoform level, all paralogs were mined from the eel genome database, and real-time $\mathrm{qPCR}$ was performed using paralog-specific primers after transfer of eels from FW to SW [227]. The final candidate transport proteins that met the criteria are shown in Fig. 2 together with the changes in the transcript levels after SW acclimation.

\section{Mucosal side}

For transcellular $\mathrm{NaCl}$ absorption, the major route on the mucosal side is via coupled NHE3 (SLC9a3) and AE on the apical membranes of epithelial cells in exchange for $\mathrm{H}^{+}$and $\mathrm{HCO}_{3}{ }^{-}$excretion into the lumen (Fig. 2). Several AE genes of the SLC26 and SLC4 families are expressed in the esophagus, of which apically located SLC26a3a/b (also called downregulated in adenoma, DRA) and SLC26a6a (also called putative anion transporter 1, PAT1) are candidates, but their expression levels are low and not upregulated after SW acclimation. DIDS-sensitive SLC4a2a (AE2a) is another candidate, as its gene is abundantly expressed in the eel esophagus as in the mammalian intestine [244]. Both apical and basolateral localization of $\mathrm{AE} 2$ have been reported in the mammalian intestine [174]. NHE3 and SLC26a3/6 may be bound together to the scaffolding protein NHERF1 (NHE regulatory factor 1 ) via the PDZ-binding motif to form a metabolon (see 6.3). Their activities may be regulated by NHERF1 through phosphorylation and/or vesicle trafficking of the complex to the apical membrane (see 6.4). The NHERF1 gene (slc9a3r1) is expressed significantly in the eel esophagus [227]. As various second messengers (cAMP, $\mathrm{Ca}^{2+}$ and cGMP) regulate the activity of the metabolon, hormonal regulation of esophageal desalinization most likely occurs.

The activity of coupled NHE3 and AE should be enhanced by the production of $\mathrm{H}^{+}$and $\mathrm{HCO}_{3}{ }^{-}$from $\mathrm{CO}_{2}$ hydration by cytosolic CAII, which is expressed abundantly in the esophagus in SW eels [227]. CAII is also known to bind to NHERF and to form a metabolon for its regulation (see 6.3). Two CAII genes ( $c a 2 a$ and $c a 2 b)$ are expressed in the eel esophagus, and $c a 2 a$ is more abundant and upregulated after SW acclimation (Fig. 2). Thus, CAIIa plays a major role in the production of $\mathrm{H}^{+}$ and $\mathrm{HCO}_{3}{ }^{-}$for activation of NHE3 and AE. This is in contrast to the eel intestine, where CAIIb is a major

Table 2 Effects of inhibitors on desalinization in the esophagus of teleosts

\begin{tabular}{|c|c|c|c|c|c|c|c|c|c|}
\hline \multirow[t]{2}{*}{ Species } & \multicolumn{6}{|c|}{ Mucosal side } & \multicolumn{2}{|c|}{ Serosal side } & \multirow[t]{2}{*}{ Reference } \\
\hline & $\begin{array}{l}\text { Amiloride } \\
\text { (ENaC) }\end{array}$ & $\begin{array}{l}\text { DMA/EIPA } \\
\text { (NHE) }\end{array}$ & $\begin{array}{l}\text { DIDS/DNDS } \\
\text { (AE, NBC) }\end{array}$ & $\begin{array}{l}\text { Bumet/Furo } \\
\text { (NKCC) }\end{array}$ & $\begin{array}{l}\text { HCTZ } \\
\text { (NCC) }\end{array}$ & $\begin{array}{l}\text { DPC } \\
\text { (CIC) }\end{array}$ & $\begin{array}{l}\text { Ouabain } \\
\text { (NKA) }\end{array}$ & $\begin{array}{l}\text { DPC } \\
\text { (CIC) }\end{array}$ & \\
\hline Winter flounder & + & ND & ND & - & ND & ND & ++ & ND & [166] \\
\hline Japanese eel & ND & ND & + & + & + & ND & ++ & ND & [157] \\
\hline Gulf toadfish & - & + & ND & ND & - & ND & ND & ND & [49] \\
\hline Japanese eel & ND & ++ & + & - & ++ & - & ++ & ++ & [227] \\
\hline
\end{tabular}

+, effective; -, ineffective. Number of + indicates strength of the effect. In parenthesis is target transporter of the inhibitor. For details, see text and abbreviation list. Bumet bumetanide, Furo furosemide, ND not determined 


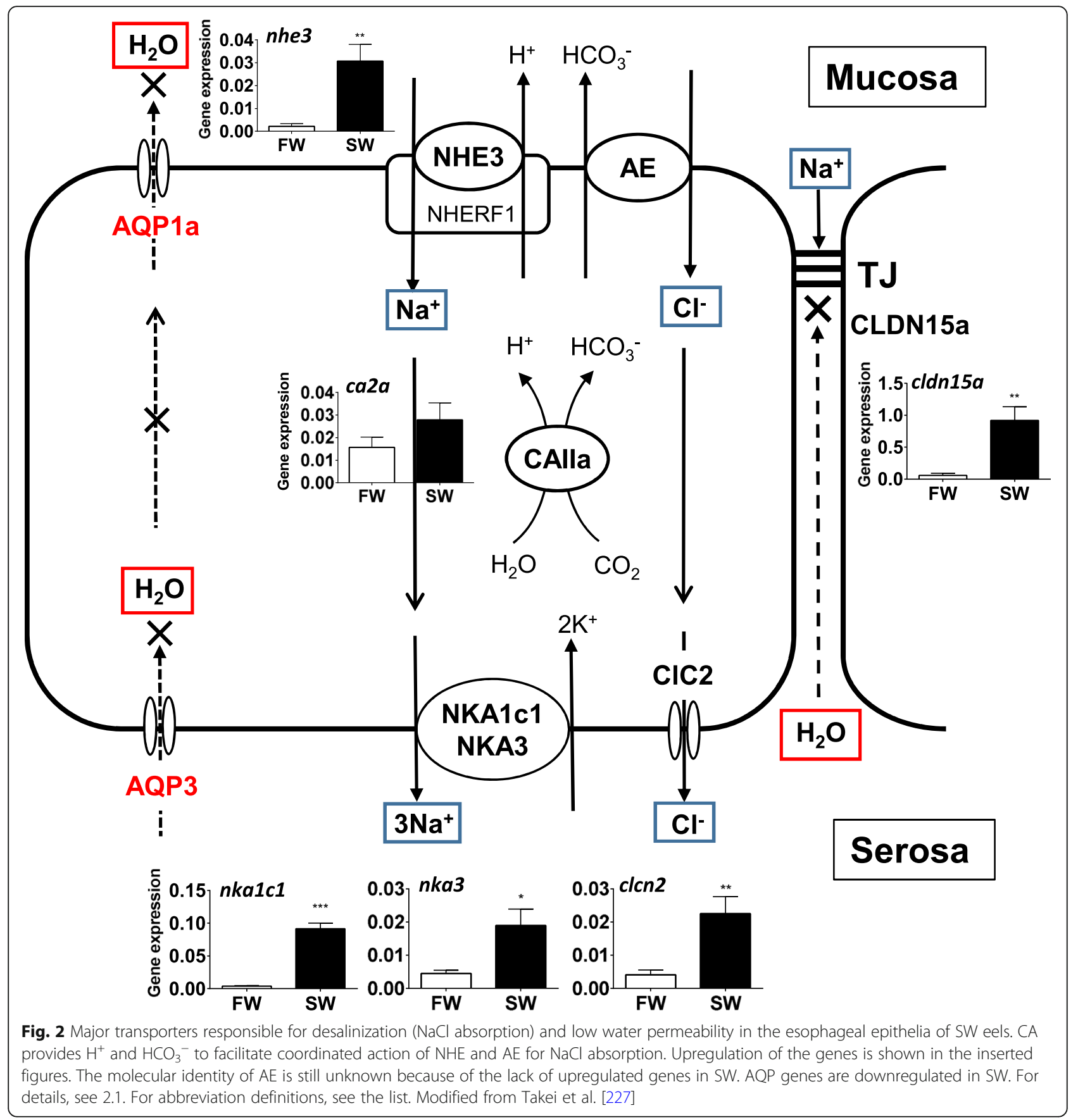

cytosolic CAII that produces $\mathrm{HCO}_{3}{ }^{-}$for its secretion into the lumen and carbonate precipitation (see 4.4.1 and 4.4.2).

In the gulf toadfish, the NHE1 (SLC9a1), NHE2 (SLC9a2), NHE3, CAII, SLC26a6 and AE2 genes are expressed in the esophagus, but none of the genes are upregulated after transfer of the fish from SW to concentrated 60 ppt SW [49]. EIPA inhibits desalinization, and among EIPA-sensitive NHEs, NHE2 is likely responsible for $\mathrm{Na}^{+}$uptake given the reduced expression of the NHE3 gene in concentrated SW. On the other hand, nhe 2 is constitutively expressed in the esophagus in both FW and SW eels. Thus, NHE2 may also function to take up $\mathrm{Na}^{+}$irrespective of environmental salinity, while upregulated NHE3 is specifically involved in the enhanced $\mathrm{Na}^{+}$uptake in the SW eel esophagus. Recruitment of NHE3-tagged vesicles to the apical membrane has been reported to occur in response to 
stimuli via intracellular messengers in mammals (see 6.4). The differences in the major transporters used for esophageal desalinization may reflect the differences in osmoregulatory mechanisms among euryhaline migratory eels and stenohaline, sedentary marine toadfish [224].

\section{Serosal side}

On the serosal side of epithelial cells, $\mathrm{Na}^{+}$and $\mathrm{Cl}^{-}$that enter the cells are extruded into the extracellular interstitial fluid by the coordinated action of ouabainsensitive NKA (NKA1c1 and NKA3) and DPCsensitive $\mathrm{Cl}^{-}$channel $2(\mathrm{ClC} 2)$ on the basolateral membrane (Fig. 2). NKA1c1 and NKA3 are catalytic $\alpha$-subunits of NKA, and these genes (atpla1c1 and atp1a3) are profoundly upregulated after SW acclimation (Fig. 2). The NKA1c2 and NKA1c3 genes are also expressed significantly in the esophagus, but no upregulation occurs after SW acclimation [227]. Thus, these NKAs may play a maintenance role in $\mathrm{Na}^{+}$absorption in the esophagus in both FW and SW eels. Eels have no NKA1a and NKA1b subunits like those found in salmonid gills [85], but the NKA1c subunit is present and diversified into 3 isoforms in eels [270]. The $\mathrm{K}^{+}$$\mathrm{Cl}^{-}$cotransporter 1 (KCC1, SLC12a4) gene is also expressed significantly in both the FW and SW eel esophagus; this gene may be responsible for $\mathrm{Cl}^{-}$extrusion and recycling of $\mathrm{K}^{+}$accumulated by NKA in the cell on the serosal side. It is also possible that AE2 is involved in $\mathrm{Cl}^{-}$extrusion in exchange for $\mathrm{HCO}_{3}{ }^{-}$, as is suggested to occur in the toadfish [49], as both apical and basolateral localization has been reported for mammalian SLC4-type AEs [174].

\subsection{Water transport}

Another feature of the SW eel esophagus is low water permeability [83]. The low water permeability through the epithelial cells is accounted for by the low expression levels of the two aquaporin genes aqp1a and $a q p 3$, which are further downregulated after SW acclimation (Fig. 2). AQP1 may be on the apical membranes of epithelial cells, and AQP3 may be on the basolateral membrane, as suggested by the localization of these AQPs in the intestine (see 4.2.1). The amount of aqp1a transcripts in the esophagus is $1 / 50$ that in the intestine. On the other hand, aqp1dup, most likely $a q p 1 b$, is expressed weakly in the esophagus in European eels and upregulated after cortisol treatment [149]. Plasma cortisol concentrations increase transiently after SW transfer, and cortisol administration increases intestinal water absorption in eels [84].

\subsection{Paracellular pathway}

The TJ protein genes cldn1, cldn3b, cldn5b, cldn $7 b$, cldn11b, cldn11b, cldn12, cldn15 and cldn23a are expressed in the esophagus, as detected by RNA-seq, of which $c l d n 3 b$, cldn5b, and $c l d n 15$ are upregulated in SW-acclimated eels [227]. TJs are composed of proteins from the claudin (CLDN) family and of TJ-associated MARVEL proteins such as occludin and tricellulin, but CLDNs are the primary proteins that determine paracellular ion and water permeability [78]. Among the expressed CLDN genes, cldn15a is exceptionally highly expressed, and its expression is profoundly upregulated (> 80-fold) after SW acclimation, as detected by RNA-seq; this upregulation has been confirmed by qPCR (Fig. 2). As CLDN15 is known to act as a cation channel in mammals [121], it may serve not only as a barrier for water movement but also as a paracellular route for $\mathrm{Na}^{+}$uptake (Fig. 2) if it is also $\mathrm{Na}^{+}$-permeable in teleosts (see 6.1). The same sets of CLDN genes are expressed in the esophagus and intestine except that $c l d n 3 b$ is additionally expressed in the esophagus. All CLDNs expressed in the esophagus other than CLDN15 are barrier-forming CLDNs [121], and the amounts of all transcripts are much greater $(\sim 10$ fold) in the esophagus than in the intestine. Thus, these CLDNs form a barrier and inhibit paracellular water transport in the SW eel esophagus (Fig. 2). Paracellular tightness can also be confirmed by the much higher transepithelial resistance of the esophagus than of the intestine in SW eels.

\subsection{Do the stomach and pyloric caeca play roles in SW acclimation?}

There is a sphincter at the exit of the stomach that keeps SW for further dilution in the stomach for some time before it is sent out to the anterior intestine [261]. The resultant stomach expansion inhibits further drinking in the eel [82]. Measurement of the drinking rate in the eel by the esophageal fistula method with reintroduction of ingested water into the stomach [226] has revealed that SW eels do not drink constantly but rather drink in a rhythmic pattern, i.e., with repeated increases and decreases in intervals of 15-30 min. This indicates that the sphincter is relaxed after the interval, which relieves stomach expansion and restores vigorous drinking in SW.

In some species, such as salmonids and sparids, diverticula grow from the anterior intestine to form small blind-end tubes known as pyloric caeca. The number of pyloric caeca varies among species, ranging from 5 to 6 in sea bream to $>200$ in salmonids. The function of pyloric caeca has attracted attention since Aristotle's era, and it was shown that this tissue serves as an extension of the intestine to increase the surface area for nutrient absorption [25]. Vigorous water absorption 
has been demonstrated to occur in the pyloric caeca of the chinook salmon, Oncorhynchus tshawytscha, and the uptake capacity is sixfold higher than that of the intestine in SW-acclimated fish [250]. In the gilthead sea bream, Sparus aurata, isolated enterocytes from pyloric caeca possess higher NKA activity than those from the intestine [45]. High NKA activity has also been found in the pyloric caeca of chinook salmon, and cortisol treatment further augments NKA activity and the capacity for water absorption [248]. In addition to NKA, high expression of $a q p 8 b$ has been found in the pyloric caeca of the Atlantic salmon, Salmo salar, supporting the role of water absorption from imbibed SW in this tissue [235]. Epithelial conductance is higher in the pyloric caeca than in the anterior intestine in the rainbow trout Oncorhynchus mykiss [75], suggesting that precipitation of divalent ions could occur not only in the intestine but also in the pyloric caeca (see 4.4). The pyloric caeca may perform both desalinization and water absorption, but further studies are required to clarify the osmoregulatory roles of this intriguing tissue.

\section{The intestine is an essential organ for water acquisition}

After desalinization in the esophagus and subsequent minor processing in the stomach, ingested SW becomes only slightly hypertonic to body fluids when it enters the intestine. The major task of the intestine for osmoregulation is to absorb water together with $\mathrm{NaCl}$ using a suite of transporters, of which $\mathrm{Na}^{+}-\mathrm{K}^{+}-2 \mathrm{Cl}^{-}$cotransporter 2 (NKCC2, SLC12a1) is unique to marine teleosts (see 4.1). As SW contains high concentrations of divalent ions (Table 1) and as these ions are hardly absorbed by the intestine [166, 207], water absorption results in increased divalent ion concentrations in the luminal fluid. As $74-85 \%$ of water is absorbed by the intestine in $\mathrm{SW}$ eels [207], the concentrations of $\mathrm{Mg}^{2+}$ and $\mathrm{SO}_{4}{ }^{2-}$ in the luminal fluid become $250 \mathrm{mM}$ and $150 \mathrm{mM}$, respectively, if $80 \%$ of the water is absorbed from SW. As a result, the osmolality produced only by these ions almost equals that of plasma, although the osmotic coefficient of $\mathrm{MgSO}_{4}(0.58)$ is lower than that of $\mathrm{NaCl}(0.93)$. The high osmolality produced by the divalent ions certainly inhibits additional water absorption. To overcome this problem, the marine teleost intestine secretes $\mathrm{HCO}_{3}{ }^{-}$ into the lumen and decreases $\mathrm{Ca}^{2+}$ and $\mathrm{Mg}^{2+}$ concentrations via precipitation of these ions as carbonates (see 4.4). In addition, $\mathrm{Mg}^{2+}$ and $\mathrm{SO}_{4}{ }^{2-}$ appear to be absorbed meaningfully by the intestine, as discussed in 6.2.

\section{1 $\mathrm{NaCl}$ absorption}

Initial studies have shown that $\mathrm{K}^{+}$in the luminal fluid is essential for $\mathrm{NaCl}$ absorption in the intestine in winter flounder [156] and SW-acclimated eels [6]. The stoichiometry of absorbed ions is $1 \mathrm{Na}^{+}: 1 \mathrm{~K}^{+}: 2 \mathrm{Cl}^{-}$and thus electroneutral [164]. Furthermore, $\mathrm{NaCl}$ absorption is completely blocked by mucosal application of furosemide or bumetanide, each of which is an NKCC inhibitor, in the intestines of SW-acclimated eels [7, 12]; red drum, Sciaenops ocellatus [50]; and other marine teleosts (see $[69,133])$. These results suggest that the major transporter on the apical membrane responsible for $\mathrm{NaCl}$ absorption is an NKCC, probably NKCC2. As NKCC2 takes up four ions (osmolytes) into the epithelial cell at a time, water efficiently moves in parallel into the cell through AQPs (see 4.2). Mucosal application of $\mathrm{Ba}^{2+}$, a $\mathrm{K}^{+}$channel inhibitor, also blocks $\mathrm{NaCl}$ absorption so that recycling of $\mathrm{K}^{+}$back into the lumen via a $\mathrm{K}^{+}$channel is necessary for continuous functioning of NKCC2 [57]. A shortage of $\mathrm{K}^{+}$in the lumen easily develops because of the low concentration of $\mathrm{K}^{+}$in SW compared with the concentrations of $\mathrm{Na}^{+}$and $\mathrm{Cl}^{-}$(Table 1). $\mathrm{K}^{+}$efflux at the mucosal side and $\mathrm{Cl}^{-}$efflux at the serosal side produce a serosa-negative transepithelial potential difference (PD), which is characteristic of the marine teleost intestine (Fig. 3). In mammalian intestines, dominant $\mathrm{Na}^{+}$influx at the mucosal side by epithelial $\mathrm{Na}^{+}$channels (ENaCs) produces serosa-positive PD [106]. In the distal intestine, including the rectum, NCC, more accurately $\mathrm{NCC} 1$ (SLC12a3), is also involved in $\mathrm{NaCl}$ absorption in the eel intestine (see 4.1.1).

As observed in the esophagus, $\mathrm{Cl}^{-}$is also taken up by $\mathrm{AE}$ in exchange for $\mathrm{HCO}_{3}{ }^{-}[68,69]$. This mechanism is supported by the fact that removal of $\mathrm{Cl}^{-}$from the mucosal fluid inhibits $\mathrm{NaCl}$ absorption (which also inhibits NKCC2) and the fact that AE is responsible for $\mathrm{HCO}_{3}{ }^{-}$secretion into the lumen for carbonate precipitation (see 4.4). However, mucosal application of DIDS, an AE inhibitor, minimally inhibits $\mathrm{NaCl}$ absorption in the intestine in SW-acclimated eels [7] and the goby Gillichthys mirabilis [43]. In addition, more than $50 \%$ of $\mathrm{Cl}^{-}$absorption is accounted for by $\mathrm{AE}$ function in the toadfish and some other marine teleosts $[68,73]$. To complete $\mathrm{NaCl}$ uptake by $\mathrm{AE}, \mathrm{Na}^{+}$is taken up in exchange for $\mathrm{H}^{+}$by NHE, as observed in the esophageal epithelium (Fig. 2) and in the intestines of mammals (see 4.1.1). Collectively, the major apical transporters responsible for $\mathrm{NaCl}$ absorption are NKCC2 in the intestines of SW eels and other marine (euryhaline) teleosts, while the combination of $\mathrm{AE}$ and NHE plays a significant role in some marine species. This variation in responsible transporters also illustrates the diversity of osmoregulatory mechanisms among teleost species [224].

On the serosal side of the intestinal epithelium, ouabain, an NKA inhibitor, has been found to significantly block $\mathrm{NaCl}$ absorption in all teleost species examined thus far (see $[69,133])$. Thus, a low cytoplasmic $\mathrm{Na}^{+}$ concentration produced by NKA is essential for the 


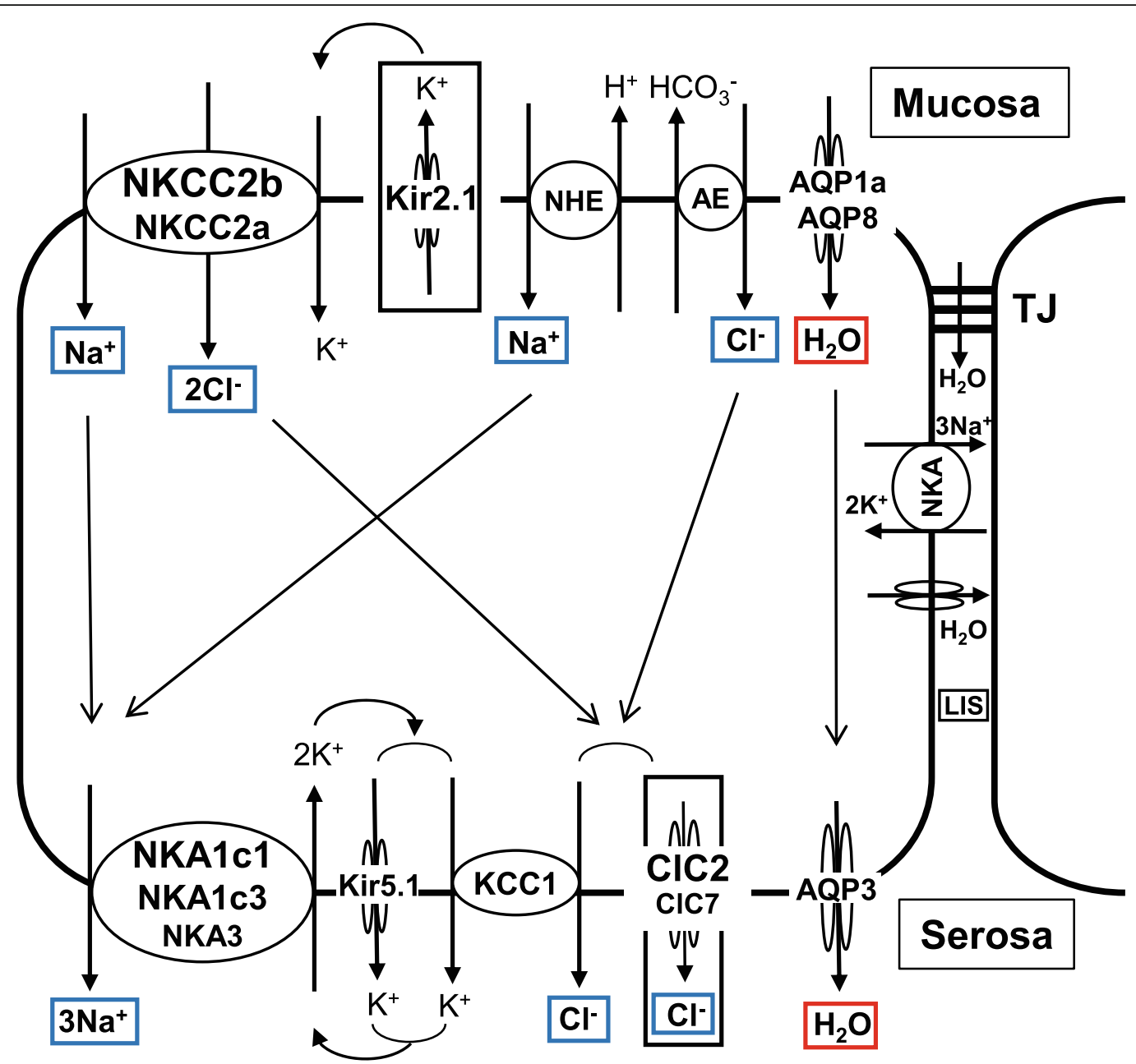

Fig. 3 Major transporters responsible for $\mathrm{Na}^{+}$and $\mathrm{Cl}^{-}$absorption (blue rectangles) and water absorption (red rectangle) in the intestinal epithelia of SW eels. $\mathrm{K}^{+}$extrusion at the mucosal side and $\mathrm{Cl}^{-}$extrusion at the serosal side (black rectangles) produce the serosa-negative potential difference typical of the marine teleost intestine. For the molecular identities of NHE and AE, see Fig. 6. The local increase in osmolality in the lateral interspace (LIS) produced by NKA stimulates water flux into the space through the AQP and tight junction (TJ). The flows of ions and water within the cell are shown by arrows. The text size for the transporters indicates the relative abundance and upregulation of the transporters in SW. For details, see 4.1.1. For abbreviation definitions, see the list

activity of NKCC2, NCC1 and NHE and important not only for $\mathrm{NaCl}$ absorption but also for $\mathrm{HCO}_{3}{ }^{-}$secretion [71]. NKA is an electrogenic pump that extrudes $3 \mathrm{Na}^{+}$ in exchange for $2 \mathrm{~K}^{+}$across the basolateral membrane. As a result, the resting membrane potential of enterocytes becomes negative, and $\mathrm{K}^{+}$ia maintained in the cytosol. The accumulated $\mathrm{K}^{+}$is recycled into the extracellular space via a $\mathrm{K}^{+}$channel for continuous functioning of NKA, as the $\mathrm{K}^{+}$concentration in teleost plasma is in the low millimolar range (Fig. 1). $\mathrm{Cl}^{-}$channels have been suggested to be present on the basolateral membrane for $\mathrm{Cl}^{-}$efflux into the extracellular space [135] to complete transcellular $\mathrm{NaCl}$ transport with NKA. This $\mathrm{Cl}^{-}$efflux is the cause of serosa-negative PD in the marine teleost intestine, as mentioned above. The presence of $\mathrm{KCC}$ on the basolateral membrane, which extruces $\mathrm{Cl}^{-}$and $\mathrm{K}^{+}$to the extracellular fluid at the same time, has also been suggested [208].

$\mathrm{Na}^{+}$and $\mathrm{Cl}^{-}$are also transported via the paracellular pathway of the intestinal epithelium, which will be discussed in detail in section 6.1. The intestinal epithelia of marine teleosts are leaky and exhibit low transepithelial resistance (Rt), and the Rt increases from the anterior to posterior direction and is highest in the rectum in the eel [12] and in other teleosts [133].

\subsubsection{Molecular mechanisms of $\mathrm{NaCl}$ absorption}

Mucosal side Although only one NKCC2 exists in mammals, two isoforms, NKCC2a and NKCC2b, exist in 
the eel $[37,255]$, of which NKCC2b is the major isoform in the intestine (Fig. 3). Of the two NKCC2 genes, slc12a1b is expressed at a much higher level than slc12a1a and is upregulated in all intestinal segments in eels after acclimation to SW (Fig. 4): [12, 268]. The upregulation of slc12a1b occurs after transfer to SW or hypertonic medium in the intestines of all euryhaline and marine teleost species examined thus far, including the Mozambique tilapia, Oreochromis mossambicus [130]; olive flounder, Paralichthys olivaceus [111]; gilthead sea bream [66]; red drum [50]; and spotted sea bass, Lateolabrax maculatus [282]. The slc12a1b expression decreases gradually in the posterior direction in the intestine, while the NCC1 gene slc12a3 expression increases gradually and is highest in the rectum in both European and Japanese eels [38, 255]. Thus, NCC1 may play a role in $\mathrm{NaCl}$ absorption in the rectum. However, slc12a3 expression is lower in SW eels than in FW eels, and it is much lower than that of $s l c 12 a 1 b$ even in the posterior intestine (Fig. 4). The expression of slc12a3 is also much lower than that of slc12a1 in the intestines of Mozambique tilapia [130] and the three-spine stickleback, Gasterosteus aculeatus [140]. On the other hand, the NCC2 gene (slc12a10) is significantly expressed in the eel intestine, and the expression increases in the posterior direction (Fig. 4). NCC2 is involved in $\mathrm{NaCl}$ absorption in the gills of Mozambique tilapia and killifish [224] and probably in the NCC cells of the zebrafish, Danio rerio [90].

As mentioned above, active NKCC2 on the apical membrane causes $\mathrm{K}^{+}$shortage in the luminal fluid, which inhibits continuous NKCC2 function. To compensate for $\mathrm{K}^{+}$in the luminal fluid, $\mathrm{K}^{+}$is recycled by a $\mathrm{K}^{+}$channel, and Kir2.1 is the candidate (Fig. 3). The Kir2.1 gene (kcnj2) is expressed substantially in the eel intestine and upregulated after SW acclimation (Fig. 4). $\mathrm{Na}^{+}$and $\mathrm{Cl}^{-}$are also absorbed from the lumen into enterocytes via the coordinated action of $\mathrm{AE}$ and NHE. The molecular identities of $\mathrm{AE}$ and NHE are discussed in the $\mathrm{HCO}_{3}{ }^{-}$secretion section (see 4.4).

Serosal side Concerning basolateral transporters for $\mathrm{NaCl}$ absorption, NKA1c1 (atp1a1c1), NKA1c3 (atp1a1c3) and NKA1c3 (atp1a3) are responsible for $\mathrm{Na}^{+}$absorption, as they are expressed at considerable levels in the eel intestine [270]. The atpla1c1 and atpla3 expression are upregulated in the anterior intestine after SW acclimation (Fig. 4). These NKAs may work together to extrude $\mathrm{Na}^{+}$into the interstitial fluid in SW eels (Fig. 3).

To ensure the constant activity of NKA, $\mathrm{K}^{+}$should be recycled into the extracellular fluid via a basolateral $\mathrm{K}^{+}$ channel, and Kir5.1 is the candidate (Fig. 3). Kir5.1 was first identified as a partner of NKA in the ionocytes of
SW eel gills [216]. In fact, two Kir5.1 genes (kcnj16a and $k c n j 16 b)$ are expressed in the eel intestine, and $k c n j 16 b$ is upregulated in all intestinal segments of SWacclimated eels (Fig. 4). In the small intestines of mammals, Kir7.1 is involved in recycling of $\mathrm{K}^{+}$for continuous activity of NKA [167], while Kir5.1 and Kir4.1 are responsible for $\mathrm{K}^{+}$recycling for NKA activity in the distal convoluted tubules of the kidneys [258].

Concerning $\mathrm{Cl}^{-}$efflux on the serosal side, $\mathrm{ClC} 2$ and $\mathrm{ClC} 7$ appear to be responsible (Fig. 3) because their genes ( $c l c n 2$ and $c l c n 7)$ are expressed in the eel intestine and upregulated in the anterior segment after SW acclimation (unpublished data). The clcn 2 expression is particularly substantial and profoundly upregulated in SW. The clcn 3 is also expressed in the intestine, but its expression is much lower than that of $c l c n 2$ and does not increase after $\mathrm{SW}$ acclimation. In mammals, $\mathrm{ClC} 2$ is responsible for $\mathrm{Cl}^{-}$efflux at the serosal side of the intestinal epithelium [170], but the cell polarity of localization changes depending on various factors (see 4.3.1). Notably, $\mathrm{ClC} 2$ is localized on the lateral membrane close to the $\mathrm{TJ}$ and regulates the paracellular permeability of ions and water in the intestinal epithelium in mammals [160]. In addition, the KCC1 gene (slc12a4) is expressed in the eel intestine, and its expression tends to increase after SW acclimation (Fig. 4). It seems likely, therefore, that $\mathrm{KCC} 1$ on the basolateral membrane is responsible for $\mathrm{K}^{+}$recycling for NKA and $\mathrm{Cl}^{-}$efflux into the interstitial fluid (Fig. 3). Notably, the suite of transporters for $\mathrm{NaCl}$ absorption develops in the intestine during smoltification in the Atlantic salmon, when the fish are still in FW but preparing for downstream migration to the sea [215].

Knowledge from mammals In mammals, the major routes for $\mathrm{NaCl}$ absorption are (1) electroneutral absorption via combined activity of NHE and $\mathrm{AE}$ and (2) electrogenic absorption via $\mathrm{ENaC}$ at the mucosal side of the intestinal epithelium [61, 106, 199]. ENaC transports only $\mathrm{Na}^{+}$, which is the major source of serosa-positive $\mathrm{PD}$ in the mammalian intestine. The ortholog of $\mathrm{ENaC}$ is not identifiable in the teleost genome. Instead, a member of the acid-sensing ion channel (ASIC) family, a subfamily of the $\mathrm{ENaC} /$ degenerin superfamily, exists in teleosts. ASIC, which is localized on the apical membranes of ionocytes in FW trout gills, takes up $\mathrm{Na}^{+}$from environmental FW in exchange for $\mathrm{H}^{+}$through vacuolar-type $\mathrm{H}^{+}$-ATPase (VHA) [46]. The transcript of ASIC is not detectable in the intestines of eels even by transcriptome analysis (unpublished data).

Two NHE genes (NHE2 and NHE3) are expressed in the mammalian intestine, of which NHE3 is dominant, and $\mathrm{Nhe}^{-/-}$mice exhibit decreased $\mathrm{NaCl}$ absorption and mild diarrhea [192]. In addition, only NHE3, not 


\section{A. Apical $\mathrm{NaCl}$ absorption}
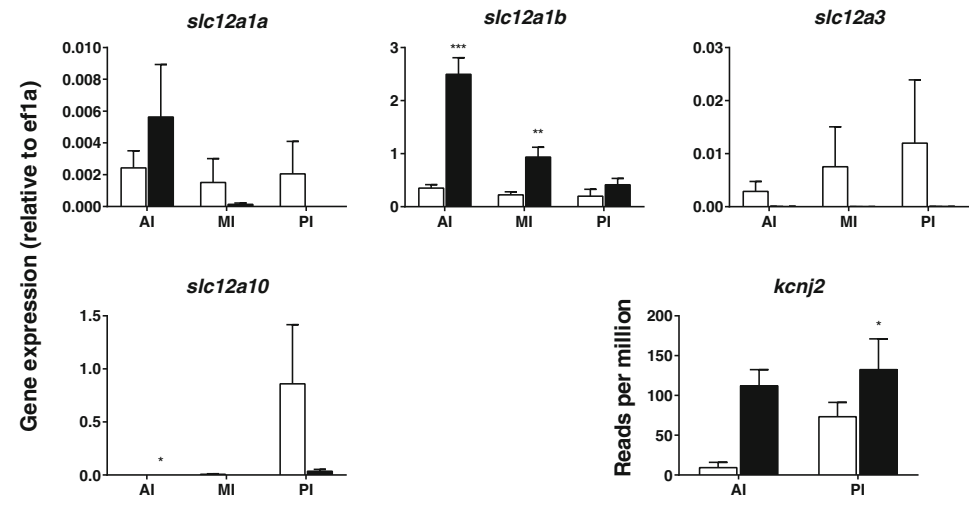

\section{B. Basolateral $\mathrm{NaCl}$ absorption}
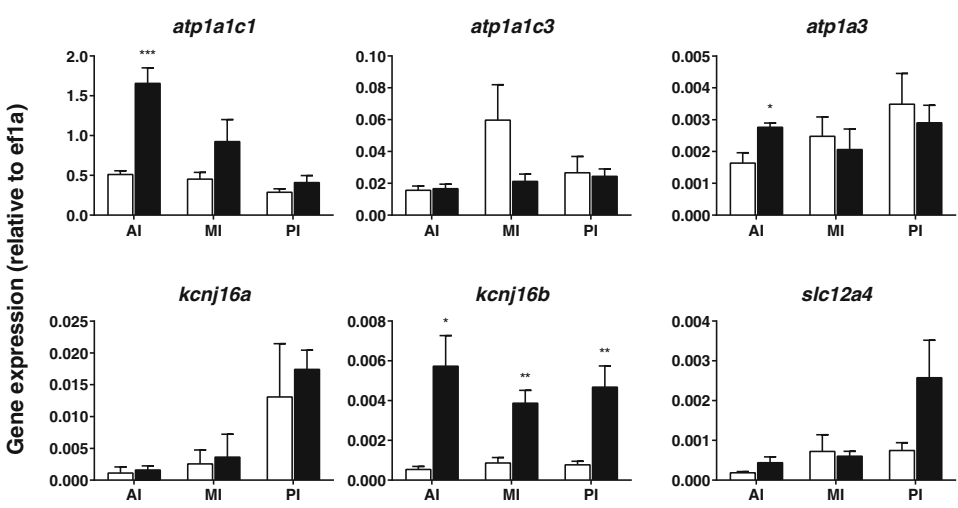

\section{Water absorption}
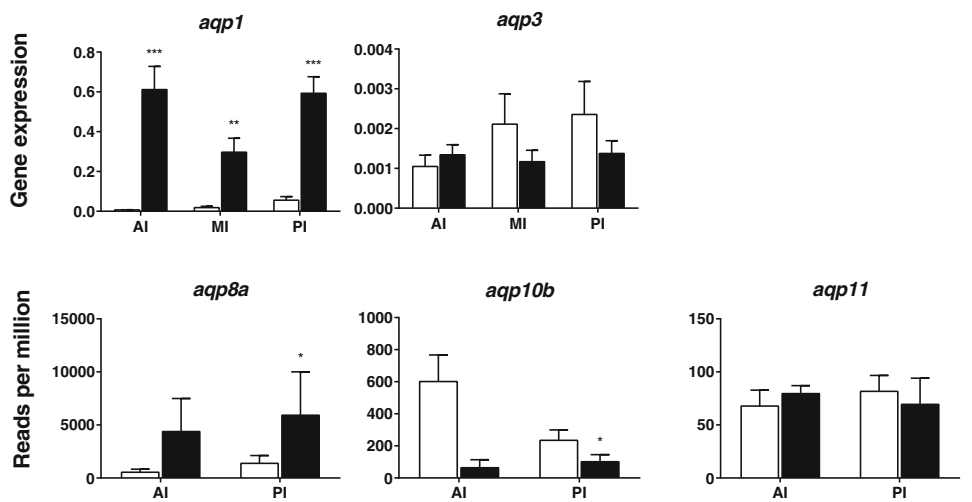

\section{Cl secretion}
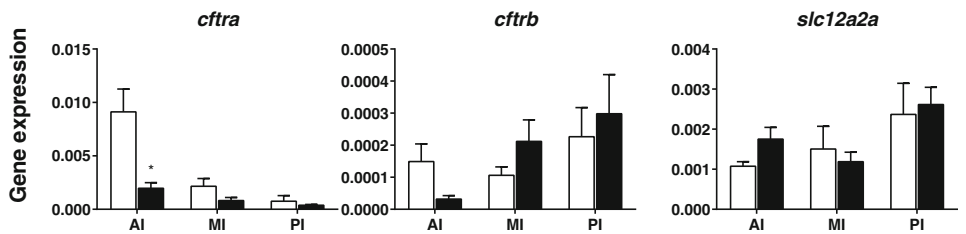

Fig. 4 (See legend on next page.) 
(See figure on previous page.)

Fig. 4 Expression of the genes responsible for $\mathrm{NaCl}(\mathbf{A}$ and $\mathbf{B})$ and water absorption $(\mathbf{C})$ in the anterior intestine (Al), middle intestine (MI) and posterior intestine (PI) in FW-acclimated (plain column) and SW-acclimated (filled column) eels as determined by real-time qPCR. The expression of the genes related to $\mathrm{Cl}^{-}$secretion suggested in mammals and other marine teleosts is also shown in (D). The expression levels are corrected by those of elf1 $a$ and thus indicate the relative abundance values of the genes. The atp1, kcnj2 and kcnj16 are the genes for NKA, Kir2.1 and Kir5.1, respectively. The figures with 'Reads per million' on the ordinate were created from RNA-seq data $(n=5)$. The figures are depicted based on the data in Ando et al. [12], Wong et al. [270], and Takei et al. [228] and on unpublished data. The primers for real-time PCR, including those for the unpublished data, are listed in Supplementary Table 1. ${ }^{*} p<0.05,{ }^{* *} p<0.01,{ }^{* * *} p<0.001$. For details, see 4.1 .1 and 4.2.1. For abbreviation definitions, see the list

NHE2, responds to intracellular messengers such as cAMP for recruitment of transporter-tagged vesicles to the apical membrane (see 6.4), which demonstrates a regulatory role of NHE3 [44]. The major AE genes expressed in the intestinal epithelium are Slc26a3 and Slc26a6. Slc26a3 is expressed throughout the whole length of the intestine, while the Slc26a6 transcript is not detectable in the distal colon [106]. It has been suggested that SLC26a3 exchanges $2 \mathrm{Cl}^{-} / 1 \mathrm{HCO}_{3}{ }^{-}$and that SLC26a6 exchanges $1 \mathrm{Cl}^{-} / 2 \mathrm{HCO}_{3}{ }^{-}$in culture cells with transient expression, but the stoichiometry is still under debate [195]. SLC26a3 plays a major role in $\mathrm{NaCl}$ absorption, as $\mathrm{Slc} 26 \mathrm{a} 3^{-/-}$mice suffer from severe chloridelosing diarrhea [193]. The effect of Slc26a6 knockout on the intestine is not as strong as the effect on the kidneys [200]. NHE and AE form a metabolon with other transporters and enzymes, as discussed in 6.3.

The transporters involved in intestinal $\mathrm{NaCl}$ absorption in mammals are similar to those of some marine teleosts but different from those of other teleosts, including eels, in which NKCC2 plays a dominant role (Fig. 3). Interestingly, $\mathrm{NKCC} 2$-based $\mathrm{NaCl}$ absorption is similar to the absorption in the thick ascending limb of Henle's loop (TAL) in the mammalian kidneys, in which NKCC2 and renal outer medullary potassium channel (ROMK) on the apical membrane and NKA, ClC-Kb and $\mathrm{KCC} 4$ on the basolateral membrane are involved in transcellular $\mathrm{NaCl}$ absorption [16]. The advantage of the NKCC2-based method in teleosts is the efficient transport of $\mathrm{NaCl}$ and water, as mentioned above, but NKCC2 has no regulatory role in acid-base balance, unlike the combination of $\mathrm{AE}$ and NHE. It is possible that teleosts acquired the NKCC2 system in the intestine during the evolution of their habitat toward the ocean; this is particularly applicable to migratory/euryhaline fishes, which must cope with abrupt changes in environmental salinity.

\subsection{Water absorption}

In parallel with $\mathrm{NaCl}$ transport, water moves from the intestinal lumen into the body fluid through the epithelium if the luminal fluid is almost isotonic to the body fluid [259]. The transcellular and paracellular routes are possible routes for water absorption. As the plasma membrane consists of a lipid bilayer that is almost impermeable to water, AQPs on the apical and basolateral membranes greatly facilitate transcellular water absorption [95]. The possibility of water cotransport by transporters such as $\mathrm{KCC}$ and the $\mathrm{Na}^{+}$-glucose cotransporter has been suggested [281], but this idea is still under debate. Regarding the paracellular route, it is known that some TJ proteins have channel-like activity [121], and CLDN2 has been suggested to serve as a water channel (see 6.1). However, paracellular water flux seems to be minor in the intestine of the killifish [274].

The marine teleost intestine can absorb water from slightly hypertonic luminal fluid $[62,68,194]$, which is also true in SW-acclimated eels [206]. However, a high $\mathrm{MgSO}_{4}$ concentration in the luminal fluid certainly limits water absorption and survival in the hypersaline environment in the toadfish [62]. The luminal fluid close to the apical membrane exists in a microenvironment covered by mucus and thus may be made hypotonic to the body fluid by $\mathrm{H}_{2} \mathrm{O}$ formation and carbonate precipitation catalyzed by extracellular CAIV (see 4.4.2). On the basolateral side, NKA extrudes $3 \mathrm{Na}^{+}$in exchange for $2 \mathrm{~K}^{+}$, which generates an osmotic gradient between the intracellular fluid and extracellular fluid. If this occurs in the lateral space between the adjacent enterocytes just below the TJ (called the lateral interspace, LIS), the fluid in the LIS becomes hypertonic to both the luminal and intracellular fluids. Then, water moves from both compartments into the interstitial fluid passively $[42,126]$. Although ion fluxes precede that of water to produce a driving force, the fluid transported across the epithelium is isotonic, which generates the solute $\left(\mathrm{Na}^{+}\right)$-recirculation model [125]. It is now known that $\mathrm{Na}^{+}$recirculation is achieved by NHE on the basolateral membrane, not NKCC1, in the eel (see 4.4.1). The mechanisms of water absorption across intestinal epithelia have been discussed in detail by Whittamore [259].

\subsubsection{Molecular mechanisms of transcellular water absorption}

Transcellular water movement is achieved through AQPs. At least four AQPs are expressed in the eel 
intestine, AQP1, AQP3, AQP8, and AQP10 [13, 110, 149], of which AQP3 and AQP10 are glyceroaquaporins that allow passage not only of water but also of glycerol, urea, etc. [95]. Two isoforms usually exist for AQP1 (AQP1a and AQP1b) in the eel and other teleosts. The expression of aqpla has been found to be upregulated in all segments of the eel intestine [13] and in vascular endothelial cells [149]. The tissue distribution of $a q p 1 b$ transcripts has not yet been examined in eels. The aqp1 expression is most abundant in the rectum, where water absorption may be enhanced by increased hydrostatic pressure [109]. A valve-like structure exists between the posterior intestine and the rectum in eels, which blocks backflow when the luminal pressure in the rectum increases. AQP1 is localized on the apical membranes of intestinal epithelial cells, as indicated by immunohistochemistry of the intestines of SW-acclimated Japanese and European eels [13, 149]. Our recent study using transcriptome analysis (RNA-seq) showed that aqpla, aqp3, aqp $8 a, a q p 10 b$ and $a q p 11$ were expressed in the eel intestine, of which $a q p 1 a$ and aqp $8 a$ were expressed at high levels (Fig. 4). Isoforms were identified by a reverse-BLAST best hit approach in our eel transcriptome data (DDBJ accession number: DRA004258) using annotations in the zebrafish database (https://zfin.org/). From the RNA-seq data, the expression of $a q p 1 a$, aqp3 and $a q p 8 a$ was significantly upregulated after SW acclimation, but real-time qPCR showed that aqp3 expression did not change after SW acclimation (Fig. 4), suggesting the possible presence of isoforms. On the other hand, our qPCR analysis showed that aqp1a was expressed in all intestinal segments and profoundly upregulated after SW acclimation in the eel (Fig. 4).

In the Atlantic salmon [236] and gilthead sea bream [172], both $a q p 1 a$ and $a q p 1 b$ are expressed in the intestine, with aqp1a exhibiting higher expression than $a q p 1 b$, and the expression of these genes is higher in fish acclimated to SW than in those acclimated to FW. Immunoreactive AQP1a is localized on both the apical and lateral membranes of sea bream enterocytes, while it is found on the basolateral membrane in the Atlantic salmon. It has been suggested that the direction of trafficking of transporter-tagged vesicles to either the apical or basolateral membrane is dependent on environmental salinity (see 6.4). Upregulation of aqp1 has also been reported in the intestine of the silver sea bream, Sparus sarba [40], and the European sea bass, Dicentrarchus labrax [64].

The aqp3 is most abundantly expressed in the gills of teleost fishes, but significant expression has also been detected in the intestine of the eel [149], and the expression level is higher in the rectums of SW-acclimated fish than in those of FW fish [110]. The aqp3 expression is low in the intestines of Mozambique tilapia [254] and sea bass [64]. Among AQPs expressed in the eel intestine, AQP3 is the only AQP that has been found to localize on the basolateral membranes of epithelial cells $[39,254]$, although AQP3 also localizes to the apical membrane in killifish [181]. In mammals, apical AQP2 and basolateral AQP3 are responsible for transcellular water absorption at the renal collecting duct [102].

AQP8 is another candidate apical membrane AQP (Fig. 3). The aqp 8 is expressed in the eel intestine, and the transcript levels increase after SW acclimation [110, 149]. We have also observed upregulation of aqp $8 a$ in the posterior intestines of SW eels (Fig. 4). Immunohistochemical analysis showed that AQP8 exists on the apical membranes of intestinal cells. Three AQP8 genes (aqp8aa, aqp8ab and $a q p 8 b)$ are expressed in the intestine in Atlantic salmon, of which $a q p 8 a b$ has the highest transcript levels in the intestine, and $a q p 8 a b$ is upregulated after SW acclimation [236]. The salmon AQP8ab is also localized on the mucosal (apical) side in enterocytes and appears to play important roles in water absorption [47], as is the case for mammalian AQP8 [240].

The aqp10 expression is observed in the intestines of eels and is upregulated in SW-acclimated fish [110, 149]. However, our transcriptome data suggest that $a q p 10 b$ is downregulated in the SW eel intestine (Fig. 4). The aqp10 expression has also been reported in the intestines of Atlantic salmon [236] and gilthead sea bream [185]. Cellular localization of AQP10 has not yet been examined in fish, but AQP10 is localized on the apical membranes of enterocytes in humans [154]. Expression of $a q p 3, a q p 8$ and aqp10, including their subtypes, has also been reported in the intestine of the three-spine stickleback [140].

To summarize the possible transcellular pathway for water absorption, the major apical AQP may be AQP1a in the eel intestine, as judged by the expression level of its gene and upregulation after SW acclimation (Fig. 3). In other marine teleosts, AQP8 and AQP10 on the apical membrane are also involved in the uptake of water into epithelial cells. The water taken up into the cells may be transported into the extracellular fluid via AQP3 on the basolateral membrane, although AQP3 gene expression is low compared with that of other AQPs. It seems that AQP1 also plays a role in water absorption at the serosal side in the Atlantic salmon [236]. In the euryhaline medaka, Oryzias latipes, aqp1a, aqp7, aqp8ab and $a q p 10 a$ are downregulated after SW transfer, and immunoreactive AQP1a and AQP10a move from the apical membrane to the subapical region after transfer to SW, indicating decreased transcellular water permeability across the intestinal epithelium [139]. Thus, it is hypothesized that water is transported mostly via the paracellular route after SW acclimation in medaka, 
although paracellular water permeability appears to be suppressed in salmonids after SW acclimation [213]. The water permeability of $\mathrm{TJ}$ proteins is discussed in 6.1 .

\section{$4.3 \mathrm{Cl}^{-}$secretion}

As shown in Table 1, SW contains similar concentrations of $\mathrm{Na}^{+}(450 \mathrm{mM})$ and $\mathrm{Cl}^{-}(524 \mathrm{mM})$. As esophageal desalinization removes $\mathrm{Na}^{+}$and $\mathrm{Cl}^{-}$equally from $\mathrm{SW}$, $\mathrm{Na}^{+}$and $\mathrm{Cl}^{-}$concentrations in the luminal fluid may also be similar when ingested SW enters the intestine for absorption. In the anterior intestine, NKCC2 takes up $1 \mathrm{Na}^{+}$and $2 \mathrm{Cl}^{-}$from the luminal fluid, and $\mathrm{AE}$ further takes up $\mathrm{Cl}^{-}$in exchange for $\mathrm{HCO}_{3}{ }^{-}$(Fig. 3). Accordingly, the amount of $\mathrm{Cl}^{-}$in the luminal fluid decreases much faster than that of $\mathrm{Na}^{+}$during passage along the intestinal tract. However, the concentration of $\mathrm{Cl}^{-}$in the luminal fluid is higher than the $\mathrm{Na}^{+}$concentration in the intestine and rectum in eels (Table 1) and other marine teleosts $[4,69,182]$. This implies that $\mathrm{Cl}^{-}$is secreted into the lumen to maintain the activity of $\mathrm{NKCC} 2$ and AE for constant $\mathrm{NaCl}$ absorption.

In mammals, $\mathrm{Cl}^{-}$secretion has been demonstrated in crypt cells of the intestine (see [61]). The secretory-type cells were once thought to be restricted to the crypt region of the intestine, but it was later shown that they are present more widely along the crypt-villus axis [98]. Accordingly, it is controversial whether the same enterocytes have both absorptive and secretory functions or whether two different cell types exist. In the eel, guanylin has been shown to inhibit NKCC2 and stimulate apical $\mathrm{Cl}^{-}$channels at the same time via a single second messenger, cGMP, resulting in $\mathrm{Cl}^{-}$ secretion [9]. Thus, a single enterocyte seems to be able to change its function from absorption to secretion (see 5). However, a small population of secretory-type enterocytes appear to exist in the killifish intestine [145].

Typical secretory-type cells are characterized by the presence of cystic fibrosis transmembrane regulator anion $\left(\mathrm{Cl}^{-}\right)$channels (CFTRs) on the apical membrane and NKCC1 (SLC12a3) on the basolateral membrane in mammals (Fig. 5). Low cytosolic $\mathrm{Na}^{+}$caused by NKA promotes the activity of NKCC1 to take up $\mathrm{Cl}^{-}$from the extracellular fluid into the cell. Then, increased cytosolic $\mathrm{Cl}^{-}$is secreted into the intestinal lumen via CFTR, which is facilitated by the negative intracellular potential produced by NKA. Anion secretion accompanies parallel fluid secretion into the lumen, resulting in secretory diarrhea in mammals [61]. The suite of transporters for $\mathrm{Cl}^{-}$secretion in the intestine is similar to those of mitochondrion-rich ionocytes of the gills in marine teleosts $[85,86]$ and secretory epithelial cells of the rectal
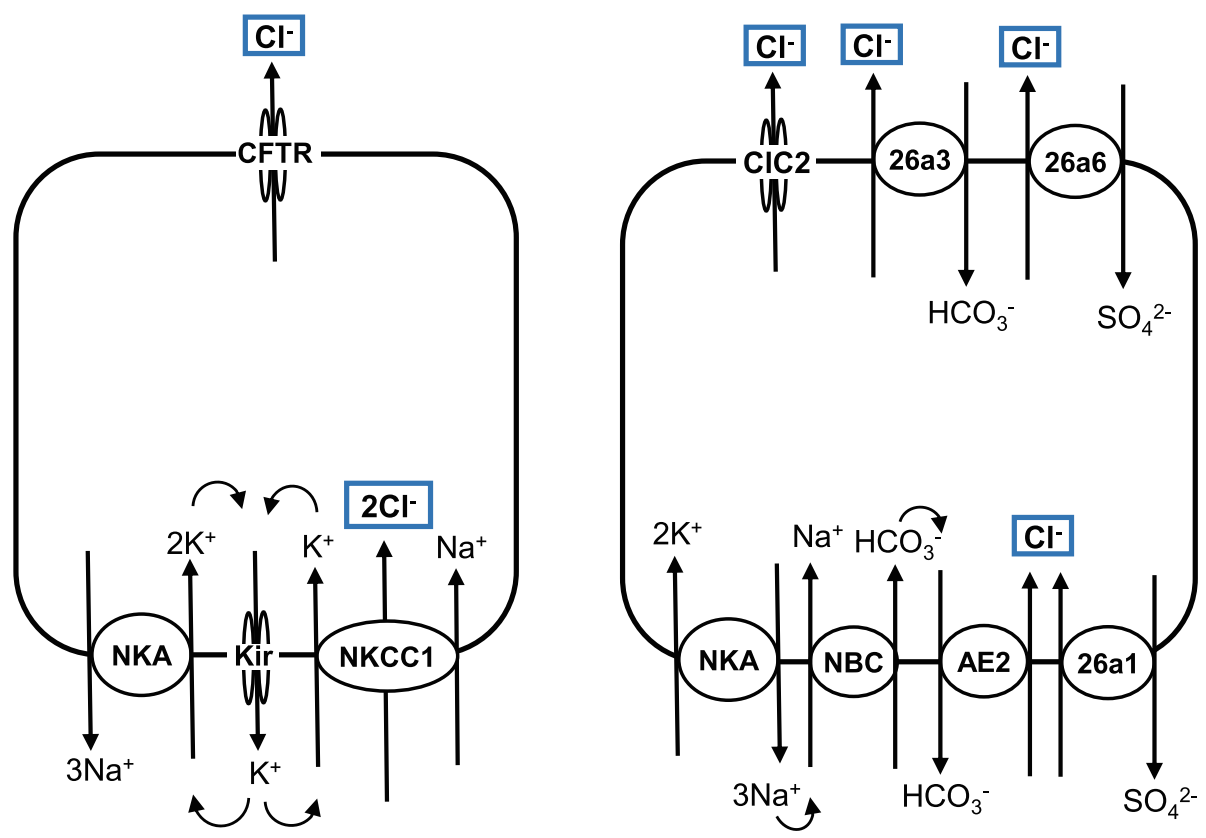

\section{A. Mammals}

\section{B. SW eels}

Fig. 5 Transporters involved in transcellular $\mathrm{Cl}^{-}$secretion (blue rectangles) into the lumen by intestinal epithelial cells in mammals (A) and seawater (SW)-acclimated eels (B). Because of the low expression of NKCC1 and CFTR in the intestines of SW eels, alternative molecular mechanisms are suggested. For details, see 4.3.1. For abbreviation definitions, see the list 
gland in marine elasmobranchs [203]. In this sense, the rectal gland is similar to the crypt cells of the mammalian colon.

\subsubsection{Possible molecular mechanisms}

In the teleost intestine, Marshall et al. [146] found substantial expression of $c f t r$ as high as that in the gills of SW-acclimated killifish. Apical localization of immunoreactive CFTR occurs only in the enterocytes of SW fish [145]. The enterocytes with CFTR immunoreactivity at the brush border membrane compose $20 \%$ of the total enterocyte population, suggesting the presence of secretory-type cells (Fig. 5). As immunoreactive CFTR migrates to the basolateral membrane in FW, the function of CFTR may change from $\mathrm{Cl}^{-}$excretion in SW to $\mathrm{Cl}^{-}$absorption in FW (see 6.4). Substantial expression of cftr has also been detected in the intestines of Mozambique tilapia [130] and spotted sea bass [282], and the expression is enhanced in hypersaline environments in these fishes. The cftr expression has also been reported in the intestines of gilthead sea bream [66], three-spine stickleback [140], and European sea bass [4]. In the sea bream, cftr expression is downregulated in the anterior intestine after transfer from diluted 12-ppt SW to regular SW or to hypertonic 55-ppt SW, but it is upregulated in the rectum.

The partner of apical CFTR for transcellular $\mathrm{Cl}^{-}$secretion is basolateral NKCC1, as mentioned above. This coupling may also be the case in the intestines of some teleost species. The expression of two NKCC1 genes (slc12a2a and slc12a2b) has been demonstrated in the intestine of the spotted sea bass [282]. The expression of both NKCC1 genes in the intestine is much lower than that in other tissues and much lower than that of the CFTR gene. Furthermore, the expression of the major isoform, slc12a $2 a$, does not change after acclimation to a hypersaline medium. Two NKCC1 genes are also expressed in the intestine of the gilthead sea bream [66], three-spine stickleback [140], and European sea bass [4]. Similar to cftr expression, slc12a2 expression is downregulated in the anterior intestine of the sea bream but upregulated in the rectum after transfer from an isotonic to a hypertonic medium.

In contrast to the roles in these teleost species, the roles of CFTR and NKCC1 in $\mathrm{Cl}^{-}$secretion seem to be minor in the eel. The expression of two cftr isoforms (cftra and cftrb) is detectable along the intestinal tract in Japanese eels [269]. However, the expression of cftra, a dominant isoform in the intestine, is low compared with that of $c l c n 2$ and $c l c n 7$, which are upregulated in SWacclimated eels (Fig. 4). Furthermore, the expression of cfrta is downregulated in the anterior intestine in SWacclimated fish (Fig. 4). It is possible that CFTR of the FW eel intestine is localized in the basolateral membrane for $\mathrm{Cl}^{-}$absorption, as suggested in killifish [145]. Gene expression does not always parallel protein abundance in cells, and it is possible that CFTR protein resides on the apical membrane or is stored in vesicles in the subapical region in enterocytes for recruitment after stimulation. In both FW and SW eel intestines, however, immunoreactive CFTR is not found on the apical membrane but rather in cytoplasmic vesicles [269]. Thus, it is likely that apical $\mathrm{Cl}^{-}$channels different from CFTR may exist for $\mathrm{Cl}^{-}$secretion in the eel. The presence of DPC-inhibitable and guanylin-sensitive $\mathrm{Cl}^{-}$ channels has been shown on the apical brush-border membrane of the eel intestine (see 5). $\mathrm{ClC} 2$ is usually localized to the basolateral membrane for $\mathrm{Cl}^{-}$absorption in the intestines of mammals [28], as illustrated in Fig. 3. However, guanylin stimulates $\mathrm{Cl}^{-}$secretion in the intestines of $\mathrm{Cftr}^{-1-}$ mice, where apical $\mathrm{ClC} 2$ is suggested to compensate for CFTR for $\mathrm{Cl}^{-}$secretion (see [56]). As the polarity of vesicle recruitment changes depending on the environmental stimuli, as suggested for CFTR [145], it is possible that $\mathrm{ClC} 2$ is responsible for $\mathrm{Cl}^{-}$secretion stimulated by guanylin (unpublished data). Alternatively, it is also possible that SLC26a6 on the apical membrane excretes $\mathrm{Cl}^{-}$in exchange for $\mathrm{SO}_{4}{ }^{2-}$ driven by its high concentration $(>100 \mathrm{mM})$ in the luminal fluid (see 6.2) or that SLC26a3 excretes $\mathrm{Cl}^{-}$in exchange for $\mathrm{HCO}_{3}{ }^{-}$ driven by its high concentration $(\sim 100 \mathrm{mM})$ in the luminal fluid (see 4.4.1). SLC26a6 in the SLC26 family has a high affinity for $\mathrm{SO}_{4}{ }^{2-}$ [199], and it actively exchanges $\mathrm{SO}_{4}{ }^{2-}$ and $\mathrm{Cl}^{-}$in the renal proximal tubules of eels [256], while SLC26a3 readily exchanges $\mathrm{Cl}^{-}$and $\mathrm{HCO}_{3}{ }^{-}$ [199].

Concerning NKCC1 on the basolateral membrane, only slc12a2a is expressed in the intestines of both European eels [37] and Japanese eels [271]. Compared with that of the NKCC2 gene (slc12a1b), slc12a2a expression is low, and it does not change after SW acclimation (Fig. 4). In addition, slc12a $2 a$ expression is higher in silver eels ready for downstream migration than in river-dwelling yellow eels [37]. Because of the low slc12a2 expression in the eel intestine, sulfate anion transporter 1 (SAT1, SLC26a1) could be a candidate for $\mathrm{Cl}^{-}$uptake at the serosal side in exchange for $\mathrm{SO}_{4}{ }^{2-}$, which is facilitated by uptake of $\mathrm{SO}_{4}{ }^{2-}$ from the luminal fluid by SLC26a6 (Fig. 5, see 6.4). $\mathrm{Cl}^{-} / \mathrm{SO}_{4}{ }^{2-}$ exchange activity has been demonstrated to occur in the basolateral membrane of the rabbit intestine [191].

When all the data obtained thus far are taken together, it seems that secretory-type enterocytes, which have CFTR on the apical membrane and NKCC1 on the basolateral membrane, may exist in the marine teleost intestine for $\mathrm{Cl}^{-}$secretion into the lumen (Fig. 5). This $\mathrm{Cl}^{-}$compensation in the luminal fluid allows constant activity of $\mathrm{NKCC} 2$ and $\mathrm{AE} / \mathrm{NHE}$ to be 
maintained for $\mathrm{NaCl}$ absorption and thus water absorption. This mechanism enables marine teleosts to absorb $>80 \%$ of water from ingested SW and explains why the luminal fluid $\mathrm{Cl}^{-}$concentration is higher than the $\mathrm{Na}^{+}$concentration in the luminal fluid of marine teleost intestine. However, knowledge from the eel intestine suggests that an alternative set of transporters is responsible for $\mathrm{Cl}^{-}$secretion, which requires further clarification. Intestine-specific knockdown of a transporter gene can be performed evaluate the genes responsible for SW acclimation. The use of membranepermeable antisense oligonucleotides injected directly into the intestinal lumen enables intestine-specific gene knockdown.

\section{4 $\mathrm{HCO}_{3}{ }^{-}$secretion and carbonate precipitation}

The high $\mathrm{CO}_{2}$ concentration and high $\mathrm{pH}$ of the rectal fluid in marine teleosts were recognized 90 years ago by Homer W. Smith [207]. It was shown later that the high $\mathrm{pH}$ is caused by active $\mathrm{HCO}_{3}{ }^{-}$secretion into the lumen by epithelial cells (see $[68,69,259])$. Luminal fluid alkalization is more profound after fish are acclimated to hypertonic SW [264], suggesting a role of $\mathrm{HCO}_{3}{ }^{-}$secretion in SW acclimation. As will be discussed in detail below (see 4.4.2), the secreted $\mathrm{HCO}_{3}{ }^{-}$helps precipitate carbonates of divalent ions $\left(\mathrm{Mg}^{2+}\right.$ and $\left.\mathrm{Ca}^{2+}\right)$, which are present in SW at concentrations higher than those in plasma (Table 1) and further concentrated by water absorption. Precipitate formation decreases luminal fluid osmolality and further enhances water absorption [73]. It is important to note that carbonate precipitate formation by marine teleost intestines explains $3-15 \%$ of the total oceanic carbon cycle and contributes to the amelioration of ocean acidification via fixation of $\mathrm{CO}_{2}$ in the ocean [265]. Because of its important role in global sustainability, $\mathrm{HCO}_{3}{ }^{-}$secretion by the marine teleost intestine is one of the recent topics of interest in fish physiology $[48,67,80,87]$.

The involvement of apical $\mathrm{AE}$ in $\mathrm{HCO}_{3}{ }^{-}$secretion has been suggested by in vitro experiments using $\mathrm{Cl}^{-}$-deficient Ringer solution or application of DIDS on the mucosal side of the intestinal epithelium. Consistently, mucosal application of DIDS inhibits $\mathrm{HCO}_{3}{ }^{-}$secretion in the sanddab, Citharichthys sordidus, and the rainbow trout $[74,75]$. However, DIDS is more potent in inhibiting $\mathrm{HCO}_{3}{ }^{-}$secretion when applied to the serosal side than to the mucosal side; it is only slightly inhibitory when applied to the mucosal side in the eel [7] and other teleost species $[43,52]$. Such species differences may be due to the differences in major transporters used among species [224] and the different sensitivities of AEs to DIDS among teleost species, as shown in mammals (see below). $\mathrm{HCO}_{3}{ }^{-}$secretion is significantly inhibited when $\mathrm{Cl}^{-}$-deficient Ringer solution is on the mucosal side [73, 263], and the presence of $\mathrm{AE}$ on the apical membrane is now widely recognized [68]. Concerning inhibition by serosal DIDS, as removal of serosal $\mathrm{Na}^{+}$profoundly decreases $\mathrm{HCO}_{3}{ }^{-}$secretion in the eel [7], $\mathrm{Na}^{+}-\mathrm{HCO}_{3}{ }^{-}$cotransporter (NBC), a member of the DIDS-sensitive SLC4 family of $\mathrm{HCO}_{3}{ }^{-}$ transporters [174], may be involved in $\mathrm{HCO}_{3}{ }^{-}$uptake from the serosal side for secretion into the lumen.

Two sources of $\mathrm{HCO}_{3}{ }^{-}$in the cell are conceivable for $\mathrm{HCO}_{3}{ }^{-}$secretion into the lumen. One is $\mathrm{HCO}_{3}{ }^{-}$taken up from the serosal side by NBC [231] as mentioned above, facilitated by NKA-induced low cytosolic $\mathrm{Na}^{+}[68$, $69,71]$. The other is endogenous $\mathrm{HCO}_{3}{ }^{-}$produced in the enterocyte by hydration of $\mathrm{CO}_{2}$ catalyzed by cytosolic CAII [230]. Because of the high metabolic activity of the cells, $\mathrm{CO}_{2}$ production in intestinal epithelial cells is high. In fact, both sources contribute to the increase in cytosolic $\mathrm{HCO}_{3}{ }^{-}$in the teleost intestine, while their relative contributions differ considerably among species [69]. Since serosal DIDS and removal of $\mathrm{HCO}_{3}{ }^{-}$in the serosal fluid profoundly decrease $\mathrm{HCO}_{3}{ }^{-}$secretion in the goby [43], eel [7] and other marine teleosts [262], the contribution of serosal $\mathrm{HCO}_{3}{ }^{-}$is significant in these species. On the other hand, almost all $\mathrm{HCO}_{3}{ }^{-}$is supplied by $\mathrm{CO}_{2}$ hydration in $\mathrm{SW}$-acclimated rainbow trout [75]. $\mathrm{CA}$ is one of the enzymes that has the fastest reaction rate and catalyzes the following reaction: $\mathrm{CO}_{2}+\mathrm{H}_{2} \mathrm{O} \rightleftharpoons$ $\mathrm{HCO}_{3}{ }^{-}+\mathrm{H}^{+}$. The forward reaction is much faster than the reverse reaction, and in high- $\mathrm{CO}_{2}$ environments such as intestinal epithelial cells. Thus, the presence of cytosolic CAII greatly enhances $\mathrm{HCO}_{3}{ }^{-}$production. Under high- $\mathrm{HCO}_{3}{ }^{-}$and high-pH conditions, such as in the intestinal lumen, however, the reverse reaction occurs, which is accelerated by membrane-bound CAIV (see below).

\subsubsection{Molecular mechanisms of $\mathrm{HCO}_{3}{ }^{-}$secretion}

The molecular mechanisms of $\mathrm{HCO}_{3}{ }^{-}$secretion have been investigated for more than a decade in several teleost species, and ample data have been accumulated [66, $69,122,231,259]$. In this section, however, we will first describe the data obtained in eels for comparison with those obtained in preceding studies on other teleost species.

Mucosal side Three SLC26a6 genes (slc26a6a, slc26a6b, slc26a6c) are expressed at significant levels in the eel intestine, as assessed by transcriptomic analyses followed by real-time $\mathrm{qPCR}$ for differentiation of the isoforms (Figs. 6 and 7A). Among the isoforms, slc6a6a exhibits the most abundant transcripts in the posterior intestine, and the transcript levels decrease in the anterior direction; in contrast, slc26a1b transcripts are most abundant in the anterior intestine, and the transcript levels 


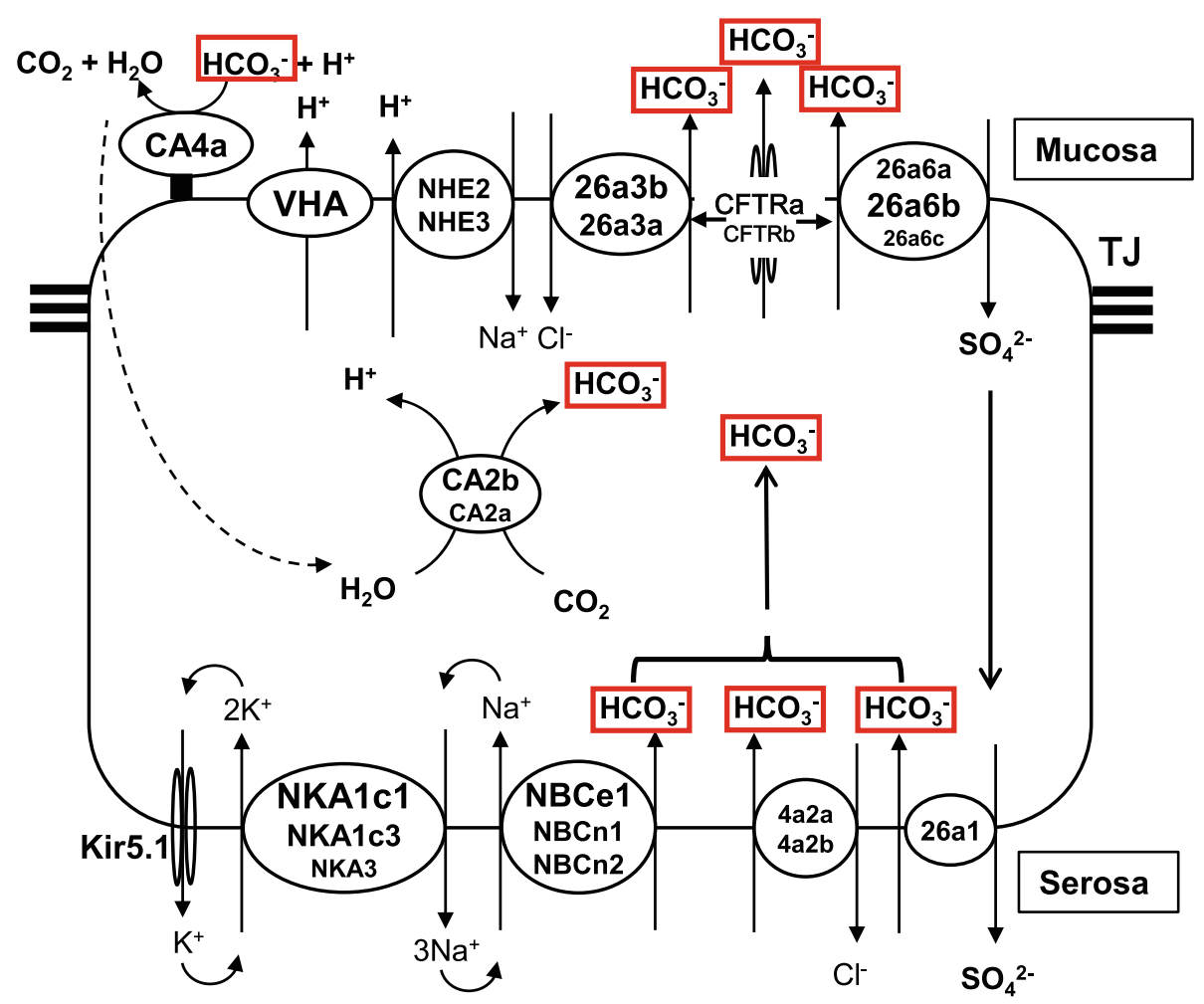

Fig. 6 Major transporters responsible for $\mathrm{HCO}_{3}{ }^{-}$secretion (red rectangles) into the lumen by the intestinal epithelial cells of SW eels. These transporters also function in $\mathrm{NaCl}$ absorption (see Fig. 3) and $\mathrm{Mg} / \mathrm{CaCO}_{3}$ precipitation (see Fig. 8). NHEs, SLC26a3/6 s and CFTRs are combined as a metabolon for mutual activity regulation (see 6.3 and Fig. 8). The text size for the transporters is related to the relative abundance and upregulation of the transporters in SW. For details, see 4.4.1. For abbreviation definitions, see the list

decrease in the posterior direction. The $s l c 26 a 6 c$ expression is the lowest among these isoforms in all intestinal segments. The slc6a6a expression is upregulated in all segments of the intestine during the course of SW acclimation [228], although the expression returns to the FW level after SW acclimation (Fig. 7A). The stoichiometry of SLC26a6 has been suggested to be electrogenic, exchanging $2 \mathrm{HCO}_{3}{ }^{-}$with $1 \mathrm{Cl}^{-}$, in the mefugu [107], while variable stoichiometry has been reported in mammals $[1$, 106]. The electrogenic nature of SLC26a6 has also been shown in mefugu [122] and toadfish [76].

In addition, two SLC26a3 genes (slc26a3a and $s l c 26 a 3 b)$ are expressed abundantly in the eel intestine, and their expression is upregulated profoundly after SW transfer until the eels are fully acclimated to SW (Fig. 6 and $7 \mathrm{~A})$. The $s l c 26 a 3 b$ expression is most abundant in the anterior intestine and decreases in the posterior direction, while slc26a3a expression is most abundant in the posterior intestine and decreases in the anterior direction. In this way, two SLC26a3 isoforms and two SLC26a6 isoforms appear to compensate for each other in different segments of the intestine. The expression level of $s l c 26 a 3 a / b$ is several-fold higher than that of $s l c 26 a 6 a / b$ (Fig. 7A). The stoichiometry of SLC26a3 is reported to be $\mathrm{HCO}_{3}{ }^{-} / 2 \mathrm{Cl}^{-}$in mammals (see [106]), but it has not yet been examined in teleosts. As mentioned above, however, mucosal DIDS fails to decrease $\mathrm{HCO}_{3}{ }^{-}$ secretion in the eel intestine [7, 228]. Although DIDS is generally an effective inhibitor of AE of the SLC26 family in mammals, it fails to block SLC26a3 in some species $[15,260]$, showing species specificity of DIDS for SLC26a3. Among teleosts, DIDS effectively blocks SLC26a6 in the rainbow trout [22], but its effect on SLC26a3 has not been confirmed in any teleost species. Supposing that DIDS is effective for SLC26a6 but ineffective for SLC26a3 in eels, the major apical AE of the SLC26 family responsible for $\mathrm{HCO}_{3}{ }^{-}$secretion and $\mathrm{Cl}^{-}$ absorption might be SLC26a3 in eels.

Other candidate transporters for $\mathrm{HCO}_{3}{ }^{-}$secretion are anion channels on the apical membrane, and cftra expression has been detected in the eel intestine (Fig. 4). CFTR is known to readily pass $\mathrm{HCO}_{3}{ }^{-}$in mammals [204] and couple with SLC26a3/6 to stimulate $\mathrm{HCO}_{3}{ }^{-}$ secretion [212] (Fig. 8). The polarity (apical or basolateral) of CFTR localization seems to be variable depending on the environmental salinity and other conditions 


\section{A. SLC26 family AEs}
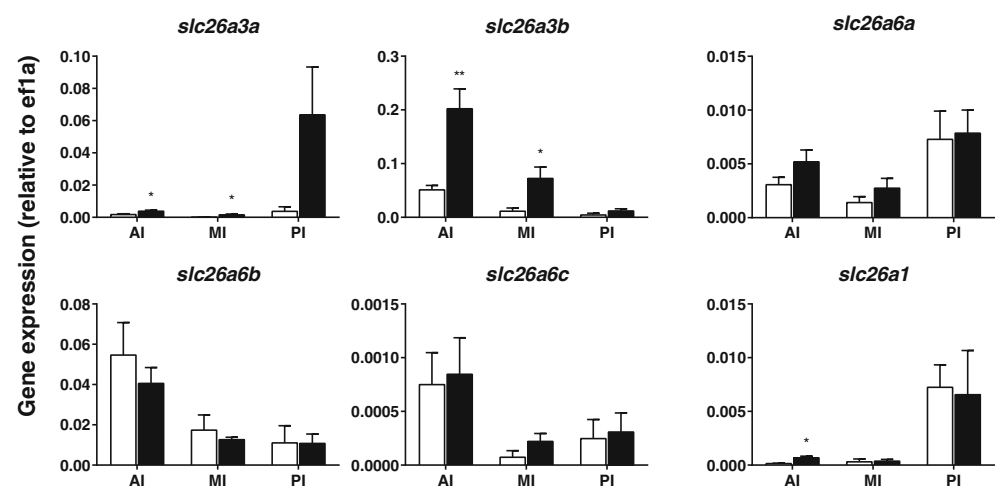

\section{B. SLC9 family NHEs}
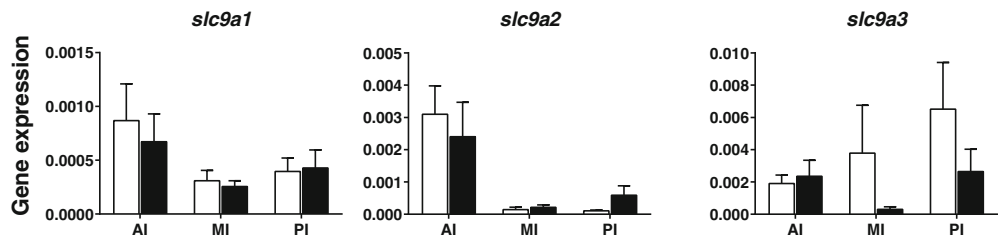

\section{SLC4 family AEs}
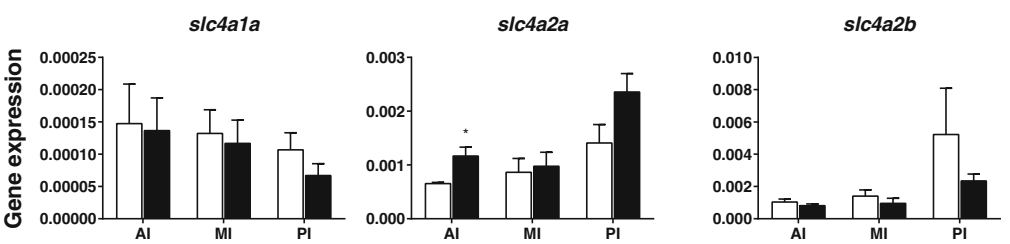

\section{SLC4 family NBCs}
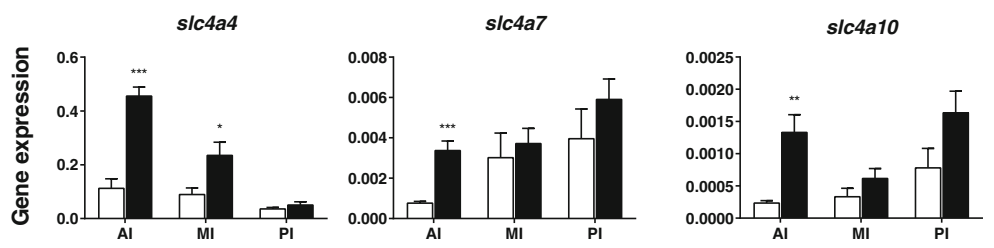

\section{E. Carbonic anhydrases}
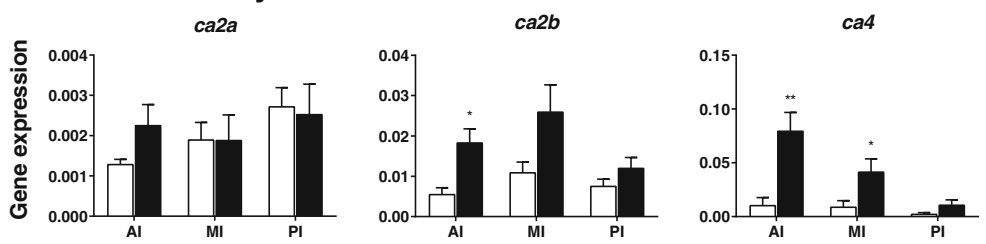

\section{F. V-ATPases}
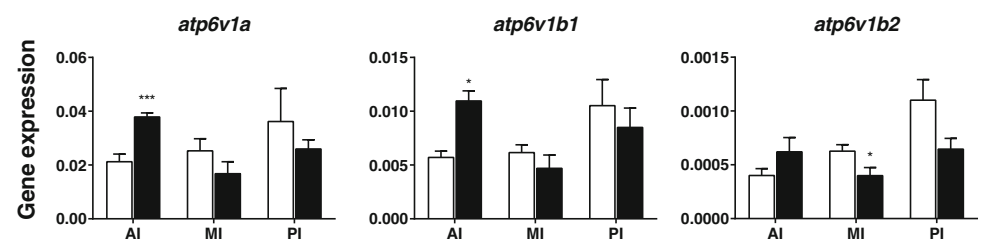

Fig. 7 (See legend on next page.) 
(See figure on previous page.)

Fig. 7 Expression of the genes responsible for $\mathrm{HCO}_{3}{ }^{-}$secretion in the anterior (Al), middle (MI) and posterior (PI) intestine in FW-acclimated (plain column) and SW-acclimated (filled column) eels as determined by real-time GPCR. The genes are grouped by SLC family and function. The atp6s are the genes for of VHA subunits. The figures are based on the data in Takei et al. [228] and Wong et al. [269] and on unpublished data. The primers for real-time $\mathrm{GPCR}$, including those for the unpublished data, are listed in Supplementary Table $1 .{ }^{*} p<0.05,{ }^{* *} p<0.01,{ }^{* * *} p<0.001$. For details, see 4.4 .1 . For abbreviation definitions, see the list

[145]. clcn 2 and $c l c n 3$ are expressed significantly in the eel intestine (unpublished data). Significant expression of $c l c n 3$ has also been reported in the cod intestine [87]. However, the major role of apical ClCs appears to be for $\mathrm{Cl}^{-}$secretion in teleost fishes (see 4.3.1).

The involvement of SLC26a6 was first suggested in the euryhaline mefugu, in which slc26a6 expression is profoundly upregulated after transfer from FW to SW [122]. Similar results have been reported in the rectum in gulf toadfish [179] and gilthead sea bream [66] transferred from diluted SW to concentrated SW. In contrast, slc26a6 expression in the anterior intestine of Mozambique tilapia is suppressed after transfer from FW to SW [183]. In addition, slc26a3 expression has also been detected in the intestines of several teleost species, and upregulation of the transcripts has been found in sea bream [66] and tilapia [183] after hyperosmotic stimulation. The slc26a3 and slc26a6 expression has also been detected in the intestine of the European sea bass [4]. It seems that the relative contributions of SLC26a3 and SLC26a6 to $\mathrm{HCO}_{3}{ }^{-}$secretion differ among teleost species.

As partners of SLC26a3 and SLC26a6 for coupled uptake of $\mathrm{Na}^{+}$and $\mathrm{Cl}^{-}$and excretion of $\mathrm{H}^{+}$and $\mathrm{HCO}_{3}{ }^{-}$, three NHE genes, NHE1 (slc9a1), NHE2 (slc9a2) and NHE3 (slc9a3), are expressed in the eel intestine (Fig. 6 and 7B). NHE1 and NHE2 are resident-type, while NHE3 is a mobile-type transporter that is stored in cytoplasmic vesicles and inserted into the plasma membrane (see 6.4). The expression of NHE genes does not change in the eel intestine after SW transfer (Fig. 7B). AE and NHE are thought to be physically associated in the

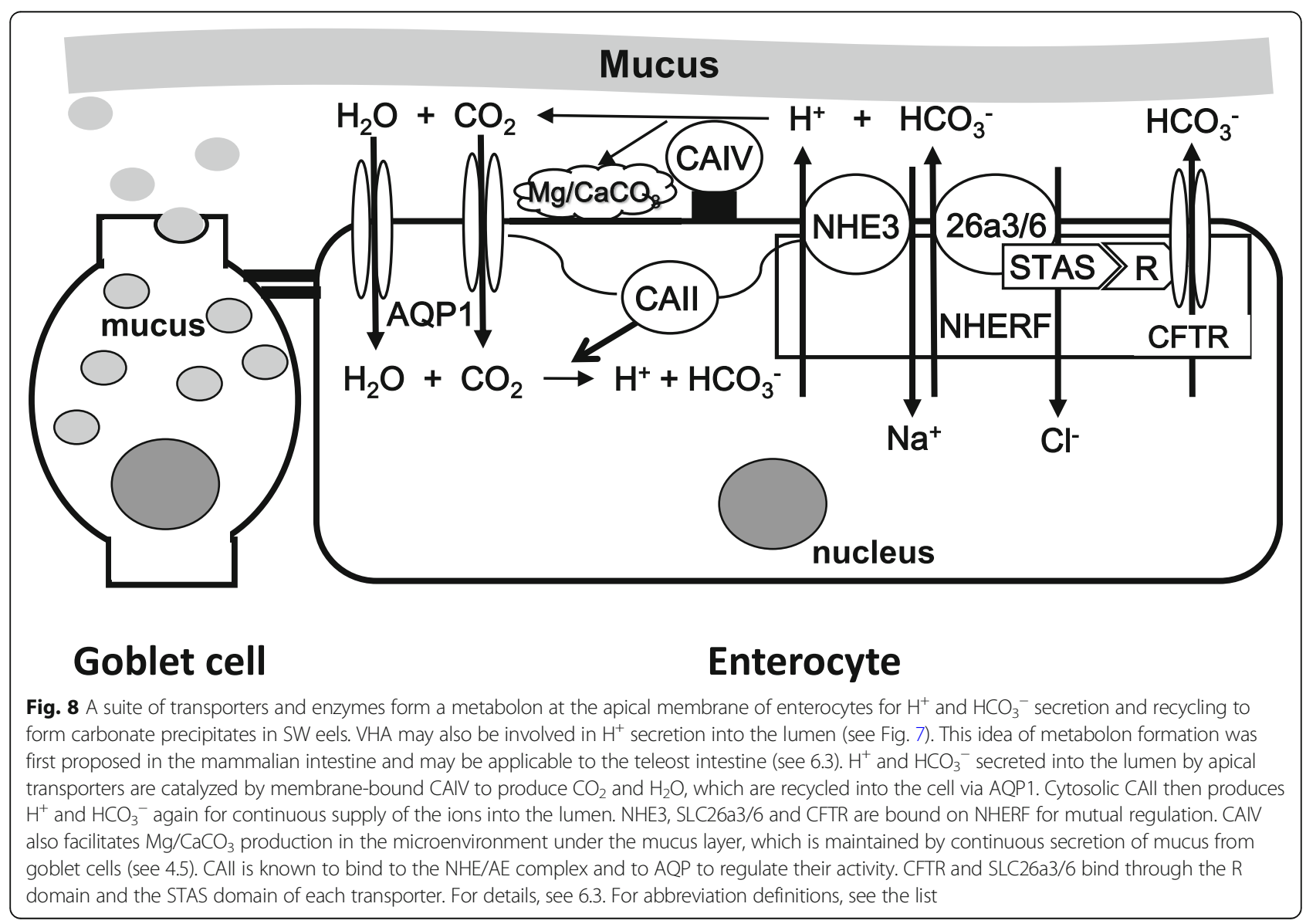


anchor protein (see 6.3). The gene of the anchor protein for NHE3, NHERF1 (slc9a3r1), is expressed significantly in the intestine, and its expression is upregulated twofold after SW acclimation, as demonstrated by RNA-seq (unpublished data). NHE3 and AE in the anchor protein are recruited from the cytoplasmic vesicles to the apical membrane upon phosphorylation (see 6.4). NHE3 is an electroneutral exchanger of $1 \mathrm{Na}^{+} / 1 \mathrm{H}^{+}$. With regard to other teleosts, nhe3 expression has been detected in the intestines of rainbow trout [72] and cod [87].

Serosal side On the basolateral membrane, SLC26a1 may be a major $\mathrm{AE}$ for $\mathrm{HCO}_{3}{ }^{-}$uptake into the cell, as its gene expression is consistently upregulated in all segments of the eel intestine after SW transfer [228], although the upregulation is not significant in the middle and posterior intestine after full acclimation to SW (Fig. 7A). As SLC26a1 exhibits high affinity for $\mathrm{SO}_{4}{ }^{2-}$, it is possible that apical SLC26a6 and basolateral SLC26a1 work in concert for transcellular secretion of $\mathrm{HCO}_{3}{ }^{-}$in exchange for $\mathrm{SO}_{4}{ }^{2-}$ absorption in the $\mathrm{SW}$ eel intestine (see 6.2). Cooperation of the two sulfate transporters has been observed in the proximal tubules of SW eel kidneys [257]. The SLC4 family of AEs also contains candidates for $\mathrm{HCO}_{3}{ }^{-}$secretion: two AE2 genes (slc4a2a and $s l c 4 a 2 b$ ) are expressed in the eel intestine, and slc4a2a tends to be upregulated after SW transfer (Fig. 7C). AE2 may be localized on the basolateral membrane, as assumed from its location in the intestines of mammals [174] and by the lack of inhibition of $\mathrm{HCO}_{3}{ }^{-}$secretion by apical application of DIDS in the eel intestinal epithelium [228].

Among other $\mathrm{HCO}_{3}{ }^{-}$transporters, three $\mathrm{NBC}$ genes, NBCe1a (slc4a4a), NBCn1 (slc4a7) and NBCn2 (slc4a10a), are expressed in the SW eel intestine, of which slc4a4a is expressed most profoundly (Fig. 7D). All the NBC genes are upregulated in different segments of the eel intestine after SW transfer [228]. Thus, $\mathrm{HCO}_{3}{ }^{-}$may be taken up with $\mathrm{Na}^{+}$from the extracellular fluid by electrogenic NBCela and electroneutral NBCn1 and NBCn2a. The stoichiometry of NBCe1 is $1 \mathrm{Na}^{+} /$ $2 \mathrm{HCO}_{3}{ }^{-}$in mammals [174] and electrogenic in toadfish [231]. However, the external $\mathrm{Na}^{+}$concentration affects the stoichiometry of mefugu $\mathrm{NBCe} 1$, and the ratio becomes $1 \mathrm{Na}^{+} / 4 \mathrm{HCO}_{3}{ }^{-}$at $120 \mathrm{mM} \mathrm{Na}{ }^{+}$, which is similar to the concentration in the extracellular fluid of teleosts [29]. NBCe1 activity is facilitated by the low levels of cytosolic $\mathrm{Na}^{+}$produced by NKAs on the basolateral membranes of enterocytes $[69,133]$. The slc4a4 is also expressed in the intestines of mefugu [122], toadfish [231], and sea bream [66], and its expression is upregulated after transfer to hyperosmotic environments. The inhibition of $\mathrm{HCO}_{3}{ }^{-}$secretion by serosal DIDS coincides with the DIDS sensitivity of NBCs [7, 43, 69]. Given all the results obtained thus far, it seems that transcellular $\mathrm{HCO}_{3}{ }^{-}$transport occurs principally via apical SLC26a3 and SLC26a6 and basolateral NBCe1 and SLC26a1/AE2 in marine teleosts (Fig. 6).

Carbonic anhydrases and proton ATPase In addition to uptake from the serosal side, cytosolic $\mathrm{HCO}_{3}{ }^{-}$is provided by hydration of $\mathrm{CO}_{2}$ in epithelial cells, which is catalyzed by cytosolic CAII (CAc), as suggested in several teleost species $[66,75,187] . \mathrm{CO}_{2}$ is produced by active metabolism of enterocytes and is taken up from the luminal fluid (Fig. 8). Two cytosolic CAII genes (ca2a and $c a 2 b$ ) and a membrane-bound CAIV gene (ca4a) are expressed at high levels in the eel intestine, and $c a 2 b$ and ca4a expression is upregulated after SW transfer (Fig. 7E). CAIV has a catalytic site on the luminal side and may produce $\mathrm{H}_{2} \mathrm{O}$ and $\mathrm{CO}_{2}$ from $\mathrm{H}^{+}$and $\mathrm{HCO}_{3}{ }^{-}$ secreted into the microenvironment between the mucus layers and the apical membranes of epithelial cells (Fig. 8 ), as observed in rainbow trout [72]. $\mathrm{H}_{2} \mathrm{O}$ and $\mathrm{CO}_{2}$ production decrease luminal fluid osmolality to facilitate water absorption, and the generated $\mathrm{CO}_{2}$ is recycled into the cell for hydration by CAII (see 4.4.2). It is likely that $\mathrm{CO}_{2}$ is recycled efficiently via AQP1 on the apical membrane, as suggested in zebrafish [31] and mammals [171]. As $\mathrm{HCO}_{3}{ }^{-}$secretion is inhibited to different degrees by mucosal application of acetazolamide, which blocks both CAII and CAIV at the same time, the relative contributions of the CAs to $\mathrm{HCO}_{3}{ }^{-}$secretion differ among teleost species $[69,259]$. The role of CAII in $\mathrm{HCO}_{3}{ }^{-}$secretion has been documented in the rainbow trout [72] and other marine teleosts [69].

$\mathrm{HCO}_{3}{ }^{-}$secretion is mediated by mutual activation of SLC26-family AEs and CFTR on the apical membrane (see 6.3). As SLC26a6 exchanges $1 \mathrm{Cl}^{-} / \mathrm{n} \mathrm{HCO}_{3}{ }^{-}$in teleosts [107], additional $\mathrm{H}^{+}$secretion into the lumen neutralizes the secreted $\mathrm{HCO}_{3}{ }^{-}$to support the activity of coupled SLC26a6 and NHE3, which exchanges $1 \mathrm{Na}^{+} /$ $1 \mathrm{H}^{+}[69,76]$. In fact, $\mathrm{H}^{+}$secretion facilitates $\mathrm{HCO}_{3}{ }^{-}$secretion and increases the production of $\mathrm{CO}_{2}$ and $\mathrm{H}_{2} \mathrm{O}$ by CAIV (see below). $\mathrm{H}^{+}$secretion also helps protect against cellular acidification [76]. The candidate $\mathrm{H}^{+}$ transporter is VHA, which is expressed in the intestines of various teleost species, such as rainbow trout [72], toadfish [76], sea bream [66], cod [87], tilapia [183], Senegalese sole [182], and sea bass [4]. VHA is a large protein complex consisting of two domains, V0 and V1, that consist of six and eight subunits, respectively. Significant expression of the A subunit and $2 \mathrm{~B}$ subunits in the V1 domain (atp6v1a, atp6v1b1, atp6v1b2) has been detected in the eel intestine. Among these subunits, atp6v1a and atp6v1b1 are highly expressed, and their expression is upregulated after SW transfer (Fig. 7F). VHA also appears to be localized on the basolateral 
membrane to help maintain the resting potential and neutral $\mathrm{pH}$ of the cell [69]. The CAs and VHA appear to be physically coupled to the $\mathrm{AE} / \mathrm{NHE}$ complex to form a metabolon (see 6.3).

\subsubsection{Mechanisms of carbonate production}

Formation of white precipitates consisting of $\mathrm{Ca} / \mathrm{Mg}$ carbonate within the intestinal lumen has been reported in various marine teleosts for more than 50 years; for example, such precipitates have been observed in southern flounder [81], rainbow trout [201], eels [88, 153, 207], toadfish [253], European flounder [262] and mefugu [122]. The solubilities of $\mathrm{MgCO}_{3}$ and $\mathrm{CaCO}_{3}$ in water are 1.65 and $0.13 \mathrm{mmol} / \mathrm{l}$ at $25^{\circ} \mathrm{C}$, respectively, while luminal fluid $\mathrm{Mg}^{2+}$ and $\mathrm{Ca}^{2+}$ concentrations are 188 and $14 \mathrm{mmol} / \mathrm{l}$, respectively, in the eel intestine (Table 1). Although solubility changes greatly according to $\mathrm{pH}$ and the presence of other ions, concentrated $\mathrm{HCO}_{3}{ }^{-}$in the luminal fluid certainly promotes the formation of carbonates [70, 265]. The chemical compositions of carbonate precipitates have been examined in teleost intestines. The carbonate precipitate consists of $\mathrm{Ca}$ carbonate and/or calcite in the flounder [81] and eel [88], and the calcite contains one-third (by weight) $\mathrm{Mg}$ and a small amount of $\mathrm{Mn}$, producing a substance called calcian kutnohorite, in the gulf toadfish [253]. On the other hand, the carbonate precipitate contains $22.6 \mathrm{~mol} \%$ $\mathrm{Mg}, 76.9 \mathrm{~mol} \% \mathrm{Ca}$ and small amounts of $\mathrm{P}$ and $\mathrm{S}$ and is called magnesian calcite ( $\mathrm{Mg}$ calcite) in the eel [153]. Chemical and structural analyses have been performed on the crystalline products in the intestinal lumens of various tropical fishes and have revealed that $\mathrm{Mg}$ calcite contains 0.5 to more than $40 \mathrm{~mol} \%$ $\mathrm{MgCO}_{3}$ [184]. The precipitate of the sea bream intestine contains $54 \mathrm{~mol} \% \mathrm{Mg}^{2+}$, and $\mathrm{Mg}^{2+}$ may be responsible for stabilizing the unstable mineral crystals [54]. The mechanisms of $\mathrm{Mg}$ calcite formation have been investigated in marine organisms, and high- $\mathrm{Mg}$ calcite that contains $>4 \mathrm{~mol} \% \mathrm{MgCO}_{3}$ is naturally formed by calcite-coated animals such as foraminifera, echinoids and corals [131]. The ratio of $\mathrm{MgCO}_{3}$ increases in proportion to the relative $\mathrm{Mg}^{2+}$ concentration in the medium. Recently, a protein-based matrix with strong $\mathrm{Ca}^{2+}$-binding properties was found in the teleost intestine; this matrix facilitates carbonate precipitation [188]. The proteins were purified from the Ca precipitates in the toadfish intestine and analyzed by proteomics. Many matrix proteins were found to be highly acidic, which may provide negatively charged domains for immobilization of $\mathrm{Ca}^{2+}$. Immobilization increases the local $\mathrm{Ca}^{2+}$ concentration in the microenvironment and facilitates the precipitation of divalent ions with secreted $\mathrm{HCO}_{3}{ }^{-}$.
As mentioned above, the space between the mucus layer and the apical membrane of enterocytes is a microenvironment different from the central lumen, which is maintained by constant secretion of mucus by goblet cells (Fig. 8). $\mathrm{H}^{+}$and $\mathrm{HCO}_{3}{ }^{-}$are secreted into the microenvironment, where not only $\mathrm{CO}_{2}$ and $\mathrm{H}_{2} \mathrm{O}$ production but also carbonate production are efficiently facilitated by membrane-bound CAIV via the following reaction: $\mathrm{Ca}^{2+} / \mathrm{Mg}^{2+}+2 \mathrm{HCO}_{3}{ }^{-} \rightleftharpoons \mathrm{Ca} /$ $\mathrm{MgCO}_{3}+\mathrm{H}_{2} \mathrm{O}+\mathrm{CO}_{2}$ [89]. This reaction not only removes divalent ions and produces $\mathrm{H}_{2} \mathrm{O}$ to decrease osmolality but also supplies $\mathrm{CO}_{2}$ through AQP1 for hydration to produce $\mathrm{HCO}_{3}{ }^{-}$via cytosolic CAII for constant operation of apical AE (Fig. 8).

\section{Hormonal control}

The effects of hormones are governed by the presence of receptors in the tissue. Thus, it is important to examine the presence of hormone receptors in the digestive tract using a sensitive detection method such as RNA-seq. It is known that the gut is one of the organs that produces the greatest variety of hormones, and it synthesizes unique hormones such as guanylin in addition to those produced by other tissues such as brain-gut peptides [151, 222]. Considering the data obtained thus far, it is apparent that hormones that increase cAMP or cGMP as a second messenger inhibit $\mathrm{NaCl}$ and water absorption [8].

\subsection{Hormones that inhibit $\mathrm{NaCl}$ transport}

The most potent hormone that inhibits $\mathrm{NaCl}$ absorption is the cardiac hormone atrial natriuretic peptide (ANP), which almost nullifies short-circuit current (Isc) in the isolated intestinal epithelium of the eel when it is applied to the serosal side [10] and in the intestine of winter flounder [163]. The minimum effective dose of homologous eel ANP for inhibition of Isc is as low as $10^{-11} \mathrm{M}$ in vitro, which is much lower than those of other inhibitory hormones examined thus far [11] and much lower than the reported effective doses of ANP in the mammalian intestine [219]. The natriuretic peptide (NP) family is highly diversified in teleost fishes, and at least 7 members, ANP, B-type NP (BNP), ventricular NP (VNP), and 4 types of C-type NPs (CNP1 4), exist in the eel [93, 94]. Biological NP receptors (GC-A and GC-B) are single-stranded receptors with a cytosolic guanylyl cyclase (GC) domain that produces cGMP as an intracellular second messenger consequent to ligand binding [14]. Similar to the ligands, NP receptors are diversified in fishes compared with mammals [222]. The increased cGMP after ligand binding activates protein kinase GII (PKGII), which inhibits NKCC2 and decreases Isc by inhibiting $\mathrm{K}^{+}$efflux on the mucosal side and $\mathrm{Cl}^{-}$efflux on the serosal side (see Fig. 3), resulting in inhibition of 
$\mathrm{NaCl}$ absorption [10, 163]. As ANP and VNP are synthesized locally in the intestine, these hormones may act in a paracrine fashion as well as in an endocrine fashion [137].

Other hormones that potently inhibit $\mathrm{NaCl}$ absorption are the guanylin-family peptides, which are highly expressed locally in the intestine. The family members (guanylin, uroguanylin and renoguanylin) and their receptors (GC-C1 and GC-C2) are more diversified in the eel $[34,35,278,279]$ than in mammals, in which they have two ligands and one receptor. The guanylin family and its receptors form the only known hormonal system whose genes are all upregulated after transfer to SW. GC-C is another type of single-stranded membrane receptor with intracellular GC domain in addition to the NP receptors GC-A and GC-B. Homologous eel guanylin profoundly decreases Isc or even reverses it when applied to the mucosal side of the eel intestine [12, 277]. The Isc inhibition is due to inhibition of NKCC2, as is the case for ANP. Similar effects have been observed in the toadfish using eel renoguanylin, a heterologous hormone that is similar to toadfish guanylin [177]. The minimum effective dose for inhibition is $10^{-9} \mathrm{M}$ [12], which is higher than that for ANP [11]. This may be due to the paracrine action of guanylin from the lumen, into which it is secretedwith mucus from goblet cells and where it acts on GC-C localized on the apical membranes of enterocytes (acting in a luminocrine manner) [278]. Guanylin is more effective on the mucosal side than on the serosal side of the intestinal epithelium in vitro. Thus, guanylin is a local hormone in the intestine, although it is also secreted into the circulation. Guanylin and uroguanylin secreted into the circulation may act directly on the kidneys to inhibit NKCC2 at the TAL and induce diuresis/natriuresis [56].

More recent studies have shown that guanylin not only inhibits NKCC2 but also stimulates $\mathrm{Cl}^{-}$channels on the apical membrane for $\mathrm{Cl}^{-}$secretion into the lumen in the eel [9] and toadfish [177], resulting in reversal of Isc. In the eel, this effect is only detectable when fish Ringer solution on the mucosal side is replaced with a simulated luminal fluid in vivo that contains low $\mathrm{NaCl}$ and high $\mathrm{MgSO}_{4}$ and when NKCC2 activity is inhibited. The enhanced $\mathrm{Cl}^{-}$secretion by guanylin occurs via DPCsensitive $\mathrm{Cl}^{-}$channels, not CFTR, in the apical membrane. In the toadfish, on the other hand, guanylininduced $\mathrm{Cl}^{-}$secretion appears to be mediated by apical CFTR and basolateral NKCC1, as in mammals [177, 180]. In the mammalian intestine, where NKCC2 is scarcely present on the apical membrane, guanylin induces $\mathrm{Cl}^{-}$and $\mathrm{HCO}_{3}{ }^{-}$secretion into the lumen through activation of apical CFTR [14,56]. Guanylin inhibits $\mathrm{Na}^{+}$ absorption in mammals through inhibition of NHE3 and the scaffolding protein NHERF2, which are the major players in $\mathrm{Na}^{+}$absorption in mammals (see 4.1.1). In toadfish, where AE and NHE play important roles in $\mathrm{NaCl}$ absorption, renoguanylin inhibits $\mathrm{AE}$ (SLC26a6) to decrease $\mathrm{Cl}^{-}$absorption and $\mathrm{HCO}_{3}{ }^{-}$secretion [178]. In contrast, guanylin stimulates $\mathrm{HCO}_{3}{ }^{-}$secretion in the $\mathrm{SW}$ eel intestine, not through direct action on apical $\mathrm{AE}$ but through inhibition of NKCC2 [228]. NKCC2 inhibition decreases cytosolic $\mathrm{Na}^{+}$and $\mathrm{Cl}^{-}$, which stimulate apical $\mathrm{AE}$ and/or basolateral $\mathrm{NBC}$, resulting in increased $\mathrm{HCO}_{3}{ }^{-}$secretion. Thus, guanylin supplies $\mathrm{Cl}^{-}$to the lumen for continuous NKCC2 activity, increases $\mathrm{HCO}_{3}{ }^{-}$ secretion for carbonate precipitation, and flushes out carbonate precipitates from the rectum [12, 177], all of which facilitate SW acclimation, although inhibition of NKCC2 is certainly disadvantageous for SW acclimation. As reported recently, transfer of rainbow trout to SW stimulates intestinal motility [24]. As guanylin is upregulated after SW transfer in the eel and toadfish intestine and activates intestinal motility in mammals [55], the increased motility could be due to guanylin.

It has been suggested that guanylin-induced Isc inhibition is mediated not by cGMP but by cAMP in mammals [14]. This is because the cGMP increased by guanylin inhibits cAMP-specific phosphodiesterase 3 (PDE3), resulting in increased cAMP levels in enterocytes. Transcriptome analysis has shown that the PDE3 gene is also expressed in the eel intestine (unpublished data). Notably, the effect of renoguanylin on intestinal $\mathrm{Cl}^{-}$and $\mathrm{HCO}_{3}{ }^{-}$secretion is suggested to be mediated by PKA in the toadfish [180]. Thus, hormones that increase cytosolic cAMP inhibit Isc and therefore $\mathrm{NaCl} /$ water absorption in teleost fishes. This indicates that hormones that bind to G protein-coupled receptors (GPCRs) associated with the Gos subunit are inhibitory to transport. Such hormones include vasoactive intestinal peptide, whose inhibitory action has been demonstrated in the intestines of winter flounder [162], Mozambique tilapia [143] and eels [11]. Urotensin I is also inhibitory in the goby [136], in which it binds to Gas-associated GPCRs.

On the other hand, stimulation of soluble adenylyl cyclase (sAC) is suggested to be stimulatory for Isc in the toadfish intestine [237]. It has been shown that increased $\mathrm{HCO}_{3}{ }^{-}$concentrations in Ringer solution on both sides of an Ussing chamber increase Isc and that this increase disappears following removal of mucosal $\mathrm{Cl}^{-}$and mucosal application of bumetanide, suggesting an involvement of NKCC2. The findings also suggest that NKCC2 activation is induced by SAC because SAC inhibition abolishes the stimulatory effect of $\mathrm{HCO}_{3}{ }^{-}$on Isc [237]. This idea is interesting and suggests a new role for sAC in the regulation of intestinal function. However, all hormones that increase cytosolic cAMP inhibit Isc. Calvalho et al. investigated this issue and found that transmembrane AC activated by hormones and sAC exert opposite 
effects on Isc in the sea bream intestine, although both ACs produce the same effector, cAMP, in the cytoplasm [26]. As mentioned above, NKCC2 governs the whole transport system in the intestines of most marine teleosts, and inhibition of NKCC2 profoundly affects other transporters and electrical parameters involved in intestinal transport, as exemplified by guanylin-induced $\mathrm{Cl}^{-}$ secretion [9] and $\mathrm{HCO}_{3}{ }^{-}$secretion [228]. More data may be required to define the stimulatory effect of sAC on NKCC2, including data on the specificity of sAC inhibitors in teleosts.

\subsection{Hormones that stimulate $\mathrm{NaCl}$ transport}

In contrast to inhibitory hormones, hormones that decrease cAMP appear to increase Isc and $\mathrm{NaCl}$ absorption in the teleost intestine. Examples are somatostatin [245] and neuropeptide $Y$ [246] in eels, whose receptors are GPCRs associated with the Goi/o subunit that decrease cytosolic cAMP after ligand binding. Urotensin II and AVT also increase Isc in the intestines of tilapia [143] and sea bream [150]. These hormones bind to GPCRs associated with the Goq/11 subunit and increase the levels of the second messengers $\mathrm{IP}_{3} / \mathrm{Ca}^{2+}$ and diacylglycerol (DAG). As the seabream intestine used in the above experiment shows low serosa-negative or serosa-positive $\mathrm{PD}$, unlike the high serosa-negative PD in other marine teleosts [133], NKCC2 may be inhibited before AVT stimulation in the seabream intestine. For instance, the Isc of the intestine in SW-acclimated eels is $\sim 500 \mu \mathrm{A} /$ $\mathrm{cm}^{2}$ [12], while it is less than $5 \mu \mathrm{A} / \mathrm{cm}^{2}$ in the seabream intestine [150]. AVT does not affect Isc in the intestines of tilapia [142] or eels (unpublished data), which exhibit high serosa-negative PD caused by high NKCC2 activity (Fig. 3). It is possible that AVT-induced increases in $\mathrm{IP}_{3} /$ DAG levels release the inhibition of NKCC2 in the seabream intestine. The different effects of AVT also exemplify the diversity of osmoregulatory mechanisms among teleost species [224].

The renin-angiotensin system is activated in the SW environment in teleosts [267], as indicated by elevated circulating levels of angiotensin II (Ang II) in the eel [266]. Ang II appears to inhibit NKA activity in the intestine of the eel to reduce $\mathrm{NaCl}$ absorption [148], and causes a reduction in plasma $\mathrm{Na}^{+}$concentration in concert with an Ang II-dependent increase in NKA activity in the gills and kidneys in SW eels. Ang II also increases water and $\mathrm{Cl}^{-}$absorption in intestinal sac of FW-acclimated tilapia but not in those of SWacclimated fish [142]. It is possible that Ang II, whose

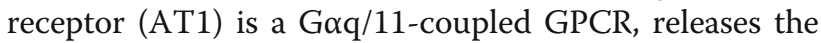
inhibitory effect of $\mathrm{NKCC} 2$ on $\mathrm{NaCl}$ absorption, as discussed above for AVT. Cortisol is known to enhance NKA activity and ion/water absorption in the intestines of eels, salmonids and other model fish species [84, 151,
197, 249]. Cortisol implantation induces dose-dependent increases in NKA activity in the posterior intestine and pyloric caeca of chinook salmon [248]. However, the effect of cortisol on water transport is slow, suggesting that transcriptional activation of transporters occurs [247].

\subsection{Hormones that affect $\mathrm{HCO}_{3}{ }^{-}$transport}

The effects of calciotropic hormones on $\mathrm{HCO}_{3}{ }^{-}$secretion have been investigated in the teleost intestine in relation to $\mathrm{CaCO}_{3}$ precipitation. In teleosts, parathyroid hormone-related peptide (PTHrP) and stanniocalcin 1 (STC1) are the major hypercalcemic and hypocalcemic hormones, respectively, while calcitonin seems to have minor roles in $\mathrm{Ca}^{2+}$ metabolism in teleost fishes. Serosal application of pufferfish PTHrP increases ${ }^{45} \mathrm{Ca}^{2+}$ influx in vitro in the seabream intestine [58], whereas salmon STC1 perfusion into the isolated cod intestine decreases $\mathrm{Ca}^{2+}$ influx [214]. In intestinal epithelia mounted in Ussing chambers, PTHrP decreases $\mathrm{HCO}_{3}{ }^{-}$secretion, while STC1 increases $\mathrm{HCO}_{3}{ }^{-}$secretion in the sea bream [59]. Interestingly, PTHrP decreases water absorption in intestinal sacs of sea bream [27]. As the in vitro experiments revealing these findings used the same fish Ringer solution on both sides of the intestinal epithelium, it would be intriguing to examine the effects of PTHrP using simulated in vivo luminal fluid on the mucosal side, in which carbonate precipitation could occur. As mentioned above, renoguanylin inhibits $\mathrm{HCO}_{3}{ }^{-}$secretion in the toadfish intestine [180], while guanylin stimulates $\mathrm{HCO}_{3}{ }^{-}$secretion in the eel intestine when simulated luminal fluid was used on the mucosal side [228]. In mammals, guanylin stimulates $\mathrm{HCO}_{3}{ }^{-}$secretion from the duodenal epithelium in vitro [77] and in vivo [17] through activation of CFTR. Prolactin decreases $\mathrm{HCO}_{3}{ }^{-}$secretion in the seabream intestine in vitro [53]. Interestingly, incubation of anterior intestinal explants with prolactin for $3 \mathrm{~h}$ downregulates slc4a4 expression but not slc $26 a 6$ or slc $26 a 3$ expression. Expression of the two prolactin receptor genes (prlr1 and prlr2) has been reported in the Mozambique tilapia intestine, and prlr2 expression is upregulated in SW-acclimated fish [198]. A recent review has summarized the osmoregulatory action of prolactin in the gastrointestinal tracts of fishes [23].

Research on hormonal regulation of ion and water transport in the teleost intestine has focused mostly on the transcellular pathway, but paracellular transport through TJ proteins may also be regulated by hormones (see 6.1). ANP has been suggested to affect paracellular ion transport in the eel intestine [239]. In addition, several hormones have been shown to affect $c l d n$ expression in the Atlantic salmon [235]. Among those hormones, cortisol, growth hormone and prolactin 
downregulate the expression of $\operatorname{cldn15}$, the major CLDN in the teleost intestine (see 6.1), in the anterior intestine in FW salmon. This downregulation probably regulates the changes in paracellular permeability by reorganizing intestinal tissues in preparation for downstream migration. There have been several studies on the hormonal regulation of CLDNs in the gills $[116,117]$. In addition to the intestine, hormonal regulation of esophageal desalinization is also likely as mentioned above (see 2.1).

\section{Future directions}

There are a number of important questions that have not yet been answered about the role of the intestine in SW acclimation in teleost fishes. Regarding transporters, major transporters essential for $\mathrm{NaCl}$ and water absorption may have been identified using contemporary molecular techniques, and more will be identified in the near future using newly developed bioinformatics tools that enable detection of trace expression of genes that are important for fine-tuning of physiological responses. A more important goal is to confirm the functions of the identified genes, probably using genetically modified fishes. As discussed above, the molecular mechanisms of transport are considerably different among species, not only between euryhaline and stenohaline species but also within euryhaline species such as catadromous eels and anadromous salmonids [224]. In this regard, it is important to thoroughly establish the molecular mechanism in one species for comparison with the mechanisms in other species. The molecules include not only transporters but also $\mathrm{TJ}$ proteins, the latter of which constitutes the first topic of this section. As a model species, the euryhaline medaka (genus Oryzias) may be advantageous because a reliable genome database is publicly available [104], techniques for gene modification have been established [112], and kin species with different salinity tolerances exist [92]. The second topic of this section is $\mathrm{Mg}^{2+}$ and $\mathrm{SO}_{4}{ }^{2-}$ transport in the intestine. The intestinal epithelium has long been thought to be impermeable to these divalent ions, but they seem to be significantly able to pass through the epithelium, as indicated in eel studies [257]. The third and fourth topics have scarcely been investigated in fishes, so these topics will be discussed based on data obtained in mammals to frame future studies in fishes.

\subsection{Paracellular route}

The sheet-like polarized epithelial cells that transport ions and water are joined by TJs near the apical part of the lateral membrane, which serve as barriers for free movement of ions and water between cells [243]. Junctional proteins consist of several molecules, of which CLDNs are major constituents and play essential roles in the sealing mechanism in terms of the structure and function of TJs $[78,119]$. TJs are not simple barriers for ions and water; rather, they exhibit selectivity for the substances that pass through the junctions according to their concentration gradients, and CLDNs are the major components involved in selectivity [60, 121]. The CLDN family is composed of 27 members, which are divided largely into two groups: barrier-forming CLDNs, such as CLDN1, CLDN3, CLDN4, CLDN5, CLDN6, CLDN8, CLDN12 and CLDN18, and channel-forming CLDNs, such as CLDN2, CLDN10, CLDN15, CLDN16, CLDN17 and CLDN19. The channel-forming CLDNs are further subdivided into cation-selective channel formers, such as CLDN2, CLDN10b, CLDN15, CLDN16 and CLDN19, and anion-selective channel formers, such as CLDN10a and CLDN17 [121]. CLDN10a and CLDN10b are splice variants from the same gene. Among channel-forming CLDNs, only CLDN2 serves as a paracellular water channel [175]. In leaky epithelia such as those of the intestine and renal proximal tubules, paracellular fluid transport plays a significant role in water absorption. In the anterior intestines of rodents, CLDN2 and CLDN15 are abundantly expressed and serve as routes for $\mathrm{Na}^{+}$recruitment between epithelial cells for continuous activity of $\mathrm{Na}^{+}$-coupled nutrient absorption [229]. CLDN15 is the most studied CLDN, and its gene knockout results in an extraordinarily large intestine in terms of length and diameter (megaintestine). Recently, CLDN15 has been suggested to be a paracellular water channel in the small intestine in mammals [176].

The number of CLDN genes increased by more than double in teleost fishes via teleost-specific wholegenome duplication and tandem duplication of genes [117]. Duplicated genes are usually nonfunctionalized as pseudogenes or subjected to posttranscriptional gene silencing, but most of the CLDN genes are retained in teleosts. This retention may be related to aquatic life because the body surfaces of teleosts are exposed directly to environmental water that dissolves various substances and has an osmolality different from that of body fluids. Thus, the epithelial cells of the body surface must cope with these issues via TJs. As a result, the gills have been the major targets of CLDN research in fishes [30]. For instance, cation selectivity and salinity-dependent expression has been examined for duplicated channelforming CLDN10s in killifish gills [147].

The expression levels of cldn1, cldn5b, cldn $7 a$, cldn11a, cldn11b, cldn12, cldn15, and cldn23a have been detected by RNA-seq in the eel intestine, and cldn7a and $c l d n 15$ are upregulated after SW transfer (unpublished data). Real-time qPCR has not yet been performed on cldns expressed in the intestine. In the esophagus, similar sets of cldns are expressed, and the number of expressed genes is much greater in the esophagus than in the intestine, illustrating the watertight nature of the 
esophagus (see 2.1). Among the genes, cldn15 is expressed at the highest level, and its expression is upregulated after SW transfer in the eel intestine, as in the esophagus [227]. Of the CLDNs expressed in the eel esophagus, only CLDN15 is a cation channel type; the others are barrier-forming types. Because of the upregulation of cldn15 after SW acclimation, paracellular $\mathrm{Na}^{+}$ influx through TJs could be accelerated in the esophagus after drinking of SW. In the intestine, by contrast, as the $\mathrm{Na}^{+}$concentration of luminal fluid is much lower than that of extracellular fluid (Table 1), absorbed $\mathrm{Na}^{+}$is recirculated back into the luminal fluid via CLDN15 to maintain NKCC2/NCC activity. Recently, CLDN15 has been suggested to be water-permeable in mammals, but $\mathrm{Na}^{+}$influx blocks water movement through the TJ protein [176]. Thus, even if teleost CLDN15 is also waterpermeable, water efflux may be blocked by vigorous $\mathrm{Na}^{+}$ transport caused by luminal SW in the SW eel esophagus. Although $\mathrm{Na}^{+}$may move through $\mathrm{TJ}, \mathrm{Cl}^{-}$may not move in parallel through the paracellular route because no candidates for anion-specific CLDNs are expressed in the eel esophagus. As CLDNs are highly diversified in teleost fishes, the selectivity of CLDNs for ions and water must be examined in diverse teleost CLDNs in the future. Hormonal regulation of paracellular transport is also an interesting topic for future studies.

In other teleost fishes, $c l d n 15$ and $c l d n 25 b$ are expressed significantly, and their expression is upregulated after SW transfer in the intestine of the Atlantic salmon [235]. However, the expression of cldn 3 is low in this species [233]. The barrier-forming CLDN3 genes were duplicated and are expressed in different intestinal segments of the euryhaline pufferfish, Tetraodon nigroviridis; in addition, the expression levels decrease after transfer to SW [33]. The cldn15a, cldn15b and cldn 25 are expressed in the medaka intestine, and cldn15b expression is profoundly downregulated in SW [21]. As the aqp genes are downregulated in the medaka intestine after SW transfer [139], the decreased cldn15 expression in SW may be related to increased water permeability of the paracellular route (see 4.2.1). Recently, Tipsmark et al. [234] suggested that CLDN15 in the medaka intestine may be water-permeable because the density of immunoreactive CLDN15 at TJs did not change in SW despite downregulation of $c l d n 15$ transcripts.

\subsection{Absorption of $\mathrm{Mg}^{2+}$ and $\mathrm{SO}_{4}{ }^{2-}$}

It is generally accepted that $\mathrm{Mg}^{2+}$ and $\mathrm{SO}_{4}{ }^{2-}$ are hardly absorbed by the intestine in teleosts [166, 262]; thus, changes in their amounts and concentrations in the luminal fluid are sometimes used as markers to estimate the amounts of ingested SW and subsequent water absorption by the intestine, respectively. However, $\mathrm{Mg}^{2+}$ and $\mathrm{SO}_{4}{ }^{2-}$ may be absorbed significantly by the intestine because these ions are secreted into the urine at high concentrations in marine teleosts [18, 173, 257], although the fraction of renal excretion of absorbed ions appears to be small in the toadfish [69]. The $\mathrm{Mg}^{2+}$ transporters SLC41a1 and Cyclin M3 (Cnnm3) have been identified in the renal proximal tubules of SWacclimated mefugu, and they have been suggested to be involved in $\mathrm{Mg}^{2+}$ secretion into the lumen [96, 97]. $\mathrm{Mg}^{2+}$ seems to be concentrated in cytoplasmic vesicles and secreted into the lumen via exocytotic delivery of vesicle contents [18]. The $\mathrm{SO}_{4}{ }^{2-}$ transporters SLC26a6 (apical) and SLC26a1 (basolateral) exist in renal proximal tubule cells of SW eels [256] and SW mefugu [107], and these AEs secrete $\mathrm{SO}_{4}{ }^{2-}$ transcellularly from the serosa to the mucosa in exchange for $\mathrm{Cl}^{-}$. As a result, $\mathrm{Mg}^{2+}$ and $\mathrm{SO}_{4}{ }^{2-}$ concentrations in the urine of SW-acclimated eels are $116.1 \mathrm{mM}$ and $36.5 \mathrm{mM}$, respectively, higher than the concentrations in SW. In contrast, $\mathrm{SO}_{4}{ }^{2-}$ is actively absorbed in exchange for $\mathrm{HCO}_{3}{ }^{-}$in the proximal tubules of FW eels, where apical SLC13a1 and basolateral SLC26a1 transport $\mathrm{SO}_{4}{ }^{2-}$ and $\mathrm{HCO}_{3}{ }^{-}$in the opposite direction from that in SW eels [158]. Thus, the direction of $\mathrm{SO}_{4}{ }^{2-}$ transport by SLC26a1 is concentration-dependent. As $\mathrm{Mg}^{2+}$ is precipitated with $\mathrm{Ca}^{2+}$ as carbonates to decrease its concentration in the luminal fluid, $\mathrm{SO}_{4}{ }^{2-}$ may be absorbed to a greater extent than $\mathrm{Mg}^{2+}$.

Genes involved in $\mathrm{Mg}^{2+}$ transport are significantly expressed in the intestines of SW mefugu [96, 97]. In mammals, transient receptor potential melastatin types 6 [252] and 7 [190], Cnnm4 [276], and $\mathrm{Mg}^{2+}$ transporter 1 [65] are expressed in the intestine [41]. Furthermore, some TJ proteins, such as cation channel-type CLDN16 and CLDN19, are known to selectively pass $\mathrm{Mg}^{2+}$ through the paracellular route $[118,202]$. As the $\mathrm{Mg}^{2+}$ concentration in the luminal fluid is extremely high (> $150 \mathrm{mM}$ ), the paracellular pathway needs to be taken into account. However, expression of cldn16 and cldn19 in the SW eel intestine is undetectable by RNA-seq. Although research on $\mathrm{Mg}^{2+}$ transport across the intestinal epithelium in teleost fishes is still in its infancy, this is certainly an intriguing topic for future research.

Concerning $\mathrm{SO}_{4}{ }^{2-}$ transport, a pair of SLC26-family transporters, apical SLC26a3/6 and basolateral SLC26a1, are substantially expressed in the intestinal epithelia of marine teleosts (see 4.4.1). These transporters have been suggested to absorb $\mathrm{Cl}^{-}$and secrete $\mathrm{HCO}_{3}{ }^{-}$, as discussed above [69]. We also suggest that SLC26a3/6 may exchange these monovalent ions in opposing directions, i.e., via $\mathrm{Cl}^{-}$secretion and $\mathrm{HCO}_{3}{ }^{-}$absorption, as judged by the high $\mathrm{HCO}_{3}{ }^{-}$concentration and low $\mathrm{Cl}^{-}$concentration in the luminal fluid (see 4.3.1). In addition, we further suggest that this pair of SLC26 transporters may absorb $\mathrm{SO}_{4}{ }^{2-}$ and secrete $\mathrm{HCO}_{3}{ }^{-}$or $\mathrm{Cl}^{-}$(Figs. 5 and 6). This exchange is possible because of the high 
concentration of $\mathrm{SO}_{4}{ }^{2-}$ in the luminal fluid of the distal intestine (Table 1) and the high affinity of these SLC26 AEs for $\mathrm{SO}_{4}{ }^{2-}$ [1]. This anion exchange also increases luminal $\mathrm{HCO}_{3}{ }^{-}$and $\mathrm{Cl}^{-}$concentrations to facilitate carbonate precipitation and to maintain NKCC2 activity for water and $\mathrm{NaCl}$ absorption, respectively. It has been shown that $\mathrm{SO}_{4}{ }^{2-}$ is absorbed in exchange for $\mathrm{Cl}^{-}$in the winter flounder intestine in vitro under high $\mathrm{SO}_{4}{ }^{2-}$ and low $\mathrm{Cl}^{-}$in the mucosal fluid, while $\mathrm{SO}_{4}{ }^{2-}$ secretion occurs when both mucosal and serosal fluid contain $1 \mathrm{mM}$ $\mathrm{SO}_{4}{ }^{2-}$ [169]. When ${ }^{35} \mathrm{SO}_{4}{ }^{2-}$ is added to the environmental SW, $15 \%$ of the $\mathrm{SO}_{4}{ }^{2-}$ that enters the blood enters via intestinal absorption, as demonstrated by esophageal ligation in SW eels [257]. ${ }^{35} \mathrm{SO}_{4}{ }^{2-}$ injected into the blood is secreted gradually into the environment; the ${ }^{35} \mathrm{SO}_{4}{ }^{2-}$ appears in the urine as ions soon after injection, while it is taken up by the liver and gills. Much more ${ }^{35} \mathrm{~S}$ than ${ }^{35} \mathrm{SO}_{4}{ }^{2-}$ is secreted slowly from the digestive tract and gills as bile compounds and mucus. Thus, more $\mathrm{SO}_{4}{ }^{2-}$ is absorbed by the intestine than is indicated by its urine concentration. Mefugu SLC26a6 can exchange $\mathrm{SO}_{4}{ }^{2-}$ with $\mathrm{Cl}^{-} / \mathrm{HCO}_{3}{ }^{-}$, as demonstrated via transporter expression in Xenopus oocytes, and the activity is dependent on the $\mathrm{SO}_{4}{ }^{2-}$ concentration in the medium [107]. The ability of teleost SLC26a1 to exchange $\mathrm{SO}_{4}{ }^{2-}$ and $\mathrm{Cl}^{-} / \mathrm{HCO}_{3}{ }^{-}$needs to be verified in a similar expression system in the future. The rate of $\mathrm{SO}_{4}{ }^{2-}$ absorption by the intestine also needs to be calculated using an intestinal sac preparation containing different concentrations of $\mathrm{SO}_{4}{ }^{2-}$ in the lumen.

\subsection{Functional coupling of transporters and enzymes (metabolon formation)}

It has been suggested that in mammals, NHEs, AEs, CAII, and CAIVs form a metabolon on the apical membrane in intestinal epithelial cells to facilitate the secretion of $\mathrm{H}^{+}$and $\mathrm{HCO}_{3}{ }^{-}$and the absorption of $\mathrm{Na}^{+}$ and $\mathrm{Cl}^{-}$across the apical membrane [199] (Fig. 8). Physical as well as functional association of NHE3 with CAII has been reported on the brush border membranes of renal proximal tubules, where $>65 \%$ of filtered $\mathrm{Na}^{+}$is reabsorbed [120]. It has also been shown that CAII binds to the C-terminal amino acid sequence (DADD) of AE1 (SLC4a1) and other SLC4-family $\mathrm{HCO}_{3}{ }^{-}$transporters (AE2, AE3, and NBCe1) to form a complex called the bicarbonate transport metabolon (Fig. 8), which maximizes transmembrane $\mathrm{HCO}_{3}{ }^{-}$flux $[152,211]$. In another group of AEs (the SLC26 family), SLC26a6 has such a consensus DADD sequence at the C-terminal region for CAII binding, and both physical and functional associations with the enzyme have been reported (Fig. 8). The association is disrupted by Ang II-induced PKC activation [3]. SLC26a3 does not possess the consensus sequence, and CAII has been shown to be functionally coupled but not physically coupled with SLC26a3 [210].

The physical and functional association of SLC4-family carbonate transporters with membrane-bound CAIV at the extracellular domain of transporters to form metabolons has also been reported [2, 209]. CAIV is anchored to the cell surface via a glycosylphosphatidylinositol domain and catalyzes mainly the reverse reaction to generate $\mathrm{CO}_{2}$ and $\mathrm{H}_{2} \mathrm{O}$ from concentrated $\mathrm{HCO}_{3}{ }^{-}$and $\mathrm{H}^{+}$in the microenvironment (Fig. 8). The generated $\mathrm{CO}_{2}$ can diffuse across the lipid bilayer of the plasma membrane, but the presence of AQP1 greatly accelerates its transport [171]. Water is also transported back into the cells by AQP1, which is activated by CAII bound to the C-terminal DADD motif in the cytoplasmic domain of AQP1 [251].

NHE3 and SLC26a3/6 have been suggested to interact with CFTR for regulation of mutual activity in the mammalian intestine [106] (Fig. 8). PDZ adaptor proteins such as NHERFs are scaffolding proteins that assemble membrane proteins with PDZ-binding motifs at the Cterminal region [44, 123]. Such proteins include NHE3, SLC26-family transporters and CFTR. As NHERF1 NHERF4 have multiple PDZ domains within their structures, they assemble the several abovementioned transporters and anchor them to the plasma membrane (Fig. 8). They also assemble a number of kinases and cytoskeletal molecules to form a multiprotein complex that regulates transporter activity and recycling (trafficking) of endocytic vesicles carrying transporters [123]. It is also suggested that the NHERF-based complex further polymerizes to form a complex metabolon for more active interaction among transporters. The $\mathrm{C}$-terminal sequences, including the PDZ-binding motif of CFTR, are thought to determine its localization on the apical membrane [155, 217].

In intestinal epithelial cells, CFTR is coupled with SLC26 transporters through binding between its Rdomain and the STAS domains of SLC26 proteins on NHERFs [115, 128] (Fig. 8). The interaction of the two transporters is usually mutually activated, resulting in increased $\mathrm{HCO}_{3}{ }^{-}$secretion or $\mathrm{Cl}^{-}$secretion depending upon the tissues examined [106, 115, 212]. After endogenous cAMP stimulation via hormones, anion secretion is enhanced, while $\mathrm{Na}^{+}$absorption is suppressed (see 5). This is explained by inhibition of NHE3 by CFTR bound to NHERF [32]. NHE3 has a PDZ-binding motif to bind to NHERFs but has no STAS domain to bind with the CFTR R-domain. The interaction of NHE3 and SLC26a3 appears to be realized by the subcellular linkage of two NHERFs to form a complex metabolon [124]. These data regarding the interaction were obtained in a heterologous expression system using cultured cells. More recently, however, mutual regulation of CFTR, SLC26a3/6 and NHE3 has been demonstrated 
in vivo in in situ perfused intestines using knockout mice [204].

Based on the data from mammals mentioned above, a possible scheme for $\mathrm{HCO}_{3}{ }^{-}$secretion and carbonate formation in the teleost intestine can be depicted (Fig. 8); this scheme needs to be confirmed in the future. A metabolon is proposed to exist on the apical membranes of enterocytes that consists of NHE3, SLC26a3/6, and CFTR assembled on the scaffolding protein NHERF via their PDZ-binding motifs. The slc9a3r1 (NHERF1) is expressed in the eel intestine and upregulated in the anterior intestine after SW acclimation [228]. Cytosolic CAII and membrane-bound CAIV are connected to transporter assembly for efficient conversion of $\mathrm{HCO}_{3}{ }^{-}+$ $\mathrm{H}^{+} \rightleftharpoons \mathrm{CO}_{2}+\mathrm{H}_{2} \mathrm{O}$. AQP1 also exists near the metabolon for quick recycling of $\mathrm{CO}_{2}$ and $\mathrm{H}_{2} \mathrm{O}$ across the apical membranes of enterocytes (Fig. 8). Grosell et al. [76] suggested that VHA and SLC26a6 form a metabolon on the apical membrane of the marine teleost intestinal epithelium for active $\mathrm{HCO}_{3}{ }^{-}$secretion and $\mathrm{Cl}^{-}$absorption. Thus, it is possible that VHA is also involved in this scheme to increase the efficiency of $\mathrm{H}^{+}$acquisition and to further accelerate the conversion by CAIV and $\mathrm{Mg}$ / $\mathrm{CaCO}_{3}$ formation. The whole scheme needs to be elucidated in teleosts in the future.

\subsection{Trafficking of transporter-tagged cytoplasmic vesicles}

It is well known that AQP2 is stored on endocytic vesicles in renal collecting duct cells and inserted into the apical membrane upon stimulation by vasopressin-induced cAMP production in mammals [102]. This recruitment enables quick regulation of water reabsorption by vasopressin to cope with acute dehydration. Conversely, AQP2 on the plasma membrane is internalized via endocytic vesicles that are stored in the subapical epithelial cell layer for future recruitment. This phenomenon is called vesicle trafficking and is achieved by phosphorylation of transporters and activation of cytoskeletal molecules. In the case of AQP2, PKA is responsible for initial phosphorylation. On the other hand, the scaffolding protein NHERF with PDZ domains is connected to the actin cytoskeleton by linker proteins in the Ezrin/Radixin/Moesin (ERM) protein family and the protein complex with transporters mediates vesicle trafficking $[129,196]$. Therefore, transporters with PDF-binding motifs such as CFTR, NHE3, and SLC26a6 are likely to be under the control of vesicle trafficking (Fig. 8).

Vesicle trafficking also seems to occur in teleost fishes, and the direction of trafficking is dependent upon the osmotic environment. For instance, CFTR-tagged vesicles are recruited to the basolateral membrane for $\mathrm{Cl}^{-}$ absorption when killifish are in FW, while the vesicles are recruited to the apical membrane for $\mathrm{Cl}^{-}$secretion after acclimation to SW, as mentioned above [145]. This suggests that the direction of trafficking is relatively flexible, but such flexibility for CFTR trafificking has been demonstrated only in fishes thus far. A small population of secretory-type cells exists among intestinal epithelial cells in mammals; these cells express high levels of apical membrane CFTR [99]. Prominent CFTR-tagged vesicles are also observed beneath the apical membrane. It seems that cAMP stimulation recruits vesicles to the apical membrane and causes robust $\mathrm{Cl}^{-}$and water secretion, resulting in diarrhea. In contrast, the sorting of CFTRtagged vesicles seems to be more complex, being accomplished not by cAMP alone but by cooperation with other messengers in the killifish intestine [145].

NHEs are a group of transporters involved in intestinal $\mathrm{Na}^{+}$absorption and $\mathrm{H}^{+}$secretion [174]. Among the NHEs, NHE1 and NHE2 are resident-type (nontrafficking) transporters localized on the basolateral and apical membranes, respectively, in intestinal epithelial cells in mammals [280]. Thus, vesicles containing these NHEs are tagged for trafficking and fusion with the plasma membrane soon after protein synthesis. On the other hand, NHE3-containing cytoplasmic vesicles are tagged and inserted into the apical plasma membrane upon stimulation by intracellular messengers [280]. Since nhe 2 and nhe 3 are expressed in significant amounts in the esophagus and intestine in eels and other teleosts, it would be interesting to investigate whether a similar difference in the regulation of trafficking also exists among NHEs in teleost fishes.

\section{Conclusions}

1. Anguillid eels are extraordinarily euryhaline teleosts and offer many advantages for research on the role of the digestive tract in SW acclimation. Although eels are now endangered species, research in cultured eels will enable great progress to be made toward understanding the mechanisms of SW acclimation in the future.

2. The key processes in eels (and marine teleosts) that enable water gain after SW drinking are desalinization by the esophagus without osmotic water loss, bicarbonate secretion for $\mathrm{Mg} / \mathrm{CaCO}_{3}$ precipitation in the intestine, and efficient water/ $\mathrm{NaCl}$ absorption by the intestine using unique transporters.

3. The major transporters responsible for such processes have been illuminated in eels and other marine teleosts. As transcriptomic data on the digestive tracts of eels after transfer from FW to SW are available to the public (DDBJ accession number: DRA004258), genes that are involved in fine-tuning of transporter function will be elucidated in the near future. 
4. Several biological processes in the digestive tract that have not received sufficient attention but need to be investigated are suggested for future studies.

\section{Abbreviations}

AC: Adenylyl cyclase; AE: Anion exchanger; ANP: Atrial natriuretic peptide; AQP: Aquaporin; BNP: B-type natriuretic peptide; CA: Carbonic anhydrase; CFTR: Cystic fibrosis transmembrane conductance regulator; $\mathrm{ClC}$ : $\mathrm{Cl}^{-}$channel; Cnnm: Cyclin M; CNP: C-type natriuretic peptide; DIDS: 4,4'-diisothiocyano2,2'-disulfonic acid; DMA: Dimethyl amiloride; DMSO: Dimethyl sulfoxide; DNDS: 4,4'-dinitrostilbene-2,2'-disulfonic acid; DPC: Diphenylamine-2carboxylic acid; DRA: Downregulated in adenoma; EIPA: Ethylisopropyl amiloride; ENaC: Epithelial $\mathrm{Na}^{+}$channel; FW: Freshwater; GC: Guanylyl cyclase; HCTZ: Hydrochlorothiazide; Isc: Short-circuit current; KCC: $\mathrm{K}^{+}-\mathrm{Cl}^{-}$ cotransporter; LIS: Lateral interspace; $\mathrm{NBC}: \mathrm{Na}^{+}-\mathrm{HCO}_{3}{ }^{-}$cotransporter; NCC: $\mathrm{Na}^{+}-\mathrm{Cl}^{-}$cotransporter; NHE: $\mathrm{Na}^{+} / \mathrm{H}^{+}$exchanger; NHERF: NHE regulatory factor; NKA: $\mathrm{Na}^{+} / \mathrm{K}^{+}$-ATPase; NKCC: $\mathrm{Na}^{+}-\mathrm{K}^{+}-2 \mathrm{Cl}^{-}$cotransporter; NPPB: 5-nitro2-(3-phenylpropylamino)-benzoate; PAT1: Putative anion transporter 1; PD: Potential difference; PDZ: Postsynaptic density-95/discs large/zonula occludens-1; ROMK: Renal outer medullary potassium channel; SAT1: Sulfate anion transporter 1; SLC: Solute carrier; SW: Seawater; STAS: Sulfate transporter antisigma; TAL: Thick ascending limb of Henle's loop; VHA: Vacuolar-type $\mathrm{H}^{+}$-ATPase; VNP: Ventricular natriuretic peptide

\section{Supplementary Information}

The online version contains supplementary material available at https://doi. org/10.1186/s40851-021-00175-X.

Additional file 1: Supplementary Table 1. Primer sequences for quantitative real time PCR

\section{Acknowledgments}

The data described herein for the eel are the fruits of collaborations with Dr. Masaaki Ando (Professor Emeritus at Hiroshima University) and Dr. Christopher A. Loretz (University at Buffalo) for the physiological studies and with Dr. Marty K. S. Wong (Atmosphere and Ocean Research Institute) for the molecular biological studies. The author is grateful to Dr. Loretz and Dr. Martin Grosell of the University of Miami for their valuable comments on the manuscript and for editing the English. Dr. Wong also helped the author make the figures and commented on the manuscript.

\section{Author details}

Professor Emeritus, Atmosphere and Ocean Research Institute, The University of Tokyo, 5-1-5 Kashiwanoha, Kashiwa, Chiba 277-8564, Japan.

\section{Author's contributions}

YT is responsible for all contents of this review. The authors read and approved the final manuscript.

\section{Funding}

The author's works introduced herein were supported by Grants-in-Aid for Scientific Research (A) from the Japan Society for the Promotion of Science (23247010) and for Scientific Research on Innovation Areas 'Genome Science' from the Ministry of Education, Culture, Sports, Science and Technology of Japan (22150002) to YT.

\section{Availability of data and materials}

The RNA-seq datasets used in this review are available at the DDBJ homepage (https://www.ddbj.nig.ac.jp/index-e.html) under accession number DRA004258.

\section{Declarations}

Ethics approval and consent to participate

Not applicable.

\section{Consent for publication}

Not applicable.

\section{Competing interests}

The author declares that he has no competing interests.

Received: 2 September 2020 Accepted: 16 April 2021 Published online: 21 June 2021

\section{References}

1. Alper SL, Sharma AK. The SLC26 gene family of anion transporters and channels. Mol Asp Med. 2013;34:494-515.

2. Alvarez BV, Loiselle FB, Supuran CT, Schwartz GJ, Casey JR. Direct extracellular interaction between carbonic anhydrase IV and the human NBC1 sodium/bicarbonate co-transporter. Biochemistry. 2003;42:12321-9.

3. Alvarez B, Vilas GL, Casey JR. Metabolon disruption: a mechanism that regulates bicarbonate transport. EMBO J. 2005;24:2499-511.

4. Alves A, Gregorio SF, Egger RC, Fuentes J. Molecular and functional regionalization of bicarbonate secretion cascade in the intestine of the European sea bass (Dicentrarchus labras). Comp Biochem Physiol 2019. 2019; 233A:53-64.

5. Ando M. Intestinal water transport and chloride pump in relation to seawater adaptation of the eel, Anguilla japonica. Comp Biochem Physiol. 1975; 52:229-33.

6. Ando M. Potassium-dependent chloride and water transport across the seawater eel intestine. J Membr Biol. 1983;73:125-30.

7. Ando M, Subramanyam MW. Bicarbonate transport systems in the intestine of the seawater eel. J Exp Biol. 1990;150:381-94.

8. Ando $\mathrm{M}, \mathrm{Hara}$ I. Alteration of sensitivity to various regulators in the intestine of the eel following seawater acclimation. Comp Biochem Physiol. 1994; 109A:447-53.

9. Ando M, Takei Y. Guanylin activates $\mathrm{Cl}^{-}$secretion into the lumen of seawater eel intestine via apical $\mathrm{Cl}^{-}$channel under simulated in vivo conditions. Am J Phys. 2015;308:R400-10.

10. Ando $\mathrm{M}$, Kondo $\mathrm{K}$, Takei $\mathrm{Y}$. Effects of eel atrial natriuretic peptide on $\mathrm{NaCl}$ and water transport across the intestine of the seawater eel. J Comp Physiol. 1992;162B:436-9.

11. Ando M, Mukuda T, Kozaka T. Water metabolism in the eel acclimated to sea water: from mouth to intestine. Comp Biochem Physiol. 2003;136B:621-33.

12. Ando M, Wong MKS, Takei Y. Mechanisms of guanylin action on water and ion absorption at different regions of seawater eel intestine. Am J Phys. 2014;307:R653-63.

13. Aoki M, Kaneko T, Katoh F, Hasegawa S, Tsutsui N, Aida K. Intestinal water absorption through aquaporin 1 expressed in the apical membrane of mucosal epithelial cells in seawater-adapted Japanese eel. J Exp Biol. 2003; 206:3495-505.

14. Arshad N, Visweswariah SS. The multiple and enigmatic roles of guanylyl cyclase C in intestinal homeostasis. FEBS Lett. 2012;586:2835-40.

15. Barmeyer $\mathrm{C}$, Ye JH, Sidani S, Geibel J, Binder HJ, Rajendran VM. Characteristics of rat downregulated in adenoma (rDRA) expressed in HEK 293 cells. Pflü Arch. 2007:454:441-50.

16. Bazúa-Valenti S, Castaňeda-Bueno M, Gamba G. Physiological role of SLC12 family members in the kidney. Am J Phys. 2016;311:F131-44.

17. Bengtsson MW, Jedstedt G, Flemström G. Duodenal bicarbonate secretion in rats: stimulation by intra-arterial and luminal guanylin and uroguanylin. Acta Physiol. 2007;191:309-17.

18. Beyenbach KW. Renal handling of magnesium in fish: from whole animal to brush border membrane vesicles. Front Biosci. 2000;5:712-9.

19. Beyenbach KW, Petzel DH, Cliff WH. Renal proximal tubule of flounder. I Physiol Propert Am J Physiol. 1986;250:R608-15.

20. Birukawa N, Ando H, Goto M, Kanda N, Pastene LA, Nakatsuji H, et al. Plasma and urine levels of electrolytes, urea and steroid hormones involved in osmoregulation in cetaceans. Zoological Science. 2005;22:1245-57.

21. Bossus MC, Madsen SS, Tipsmark CK. Functional dynamics of claudin expression in Japanese medaka (Oryzias latipes): response to environmental salinity. Comp Biochem Physiol. 2015;187A:74-85.

22. Boyle D, Clifford AM, Orr E, Chamot D, Goss GG. Mechanisms of cl- uptake in rainbow trout: cloning and expression of slc26a6, a prospective $\mathrm{Cl}^{-} /$ $\mathrm{HCO}_{3}{ }^{-}$exchanger. Comp Biochem Physiol. 2015;180A:43-50.

23. Breves JP, Popp EE, Rothenberg EF, Rosenstein CW, Maffett KM, Guertin RR. Osmoregulatory actions of prolactin in the gastrointestinal tract of fishes. Gen Comp Endocrinol. 2020;298:113589. 
24. Brijs J, Hennig GW, Grans A, Denkens E, Axelsson M, Olsson C. Exposure to seawater increases intestinal motility in euryhaline rainbow trout (Oncorhynchus mykiss). J Exp Biol. 2017;220:2397-408.

25. Buddington RK, Diamond JM. Aristotle revisited: the function of pyloric caeca in fish. Proc Natl Acad Sci U S A. 1986;83:8012-4.

26. Carvalho ASM, Gregório SF, Power DM, Canário AVM, Fuentes J. Water absorption and bicarbonate secretion in the intestine of the sea bream are regulated by transmembrane and soluble adenylyl cyclase stimulation. J Comp Physiol B. 2012;182:1069-80.

27. Carvalho ASM, Gregório SF, Canário AVM, Power DM, Fuentes J. PTHrP regulates water absorption and aquaporin expression in the intestine of the marine sea bream (Sparus aurata, L.). gen. Comp. Endocrinol. 2015;213:24-31.

28. Catalán M, Cornejo I, Figueroa CD, Niemeyer MI, Sepulveda FV, Cid LP. CIC-2 in Guinea pig colon: mRNA, immunolabeling, and functional evidence for surface epithelium localization. Am J Phys. 2002;283:G1004-13.

29. Chang MH, Plata C, Kurita Y, Kato A, Hirose S, Romero MF. Euryhaline pufferfish NBCe1 differs from nonmarine species NBCe1 physiology. Am J Phys. 2012;302:C1083-95.

30. Chasiotis H, Kolosov D, Bui P, Kelly SP. Tight junctions, tight junction proteins and paracellular permeability across the gill epithelium of fishes: a review. Respir Physiol Neurobiol. 2012;184:269-81.

31. Chen L-M, Zhao J, Musa-Aziz R, Pelletier MF, Drummond IA, Boron WF. Cloning and characterization of a zebrafish homologue of human AQP1: a bifunctional water and gas channel. Am J Phys. 2010;299:R1163-74.

32. Clarke LL, Harline MC (1996). CFTR is required for CAMP inhibition of intestinal $\mathrm{Na}^{+}$absorption in a cystic fibrosis mouse model. Am J Physiol. 1996:270:G259-67.

33. Clelland ES, Bui P, Bagherie-Lachidan M, Kelly SP. Spatial and salinity-induced alterations in claudin-3 isoform mRNA along the gastrointestinal tract of the pufferfish Tetraodon nigroviridis. Comp Biochem Physiol. 2010;155A:154-63.

34. Comrie MM, Cutler CP, Cramb G (2001a). Cloning and expression of guanylin from the European eel (Anguilla anguilla). Biochem Biophys Res Comm 2001a;281:1078-1085

35. Comrie MM, Cutler CP, Cramb G. Cloning and expression of two isoforms of guanylate cyclase C (GC-C) from the European eel (Anguilla anguilla). Comp. Physiol. Biochem. 2001b;129B:575-86.

36. Conte FP. Origin and differentiation of ionocytes in gill epithelium of teleost fish. Int Rev Cell Mol Biol. 2012;299:1-25.

37. Cutler CP, Cramb G. Two isoforms of the $\mathrm{Na}^{+} / \mathrm{K}^{+} / 2 \mathrm{Cl}^{-}$cotransporter are expressed in the European eel (Anguilla anguilla). Biochim Biophys Acta. 2002;1566:92-103.

38. Cutler CP, Cramb G. Differential expression of absorptive cation-chloridecotransporters in the intestinal and renal tissues of the European eel (Anguilla anguilla). Comp Biochem Physiol. 2008;149B:63-73.

39. Cutler CP, Martinez A-S, Cramb G. The role of aquaporin 3 in teleost fish. Comp Biochem Physiol. 2007;148A:82-91.

40. Deane EE, Luk JCY, Woo NYS. Aquaporin 1a expression in gill, intestine, and kidney of the euryhaline silver sea bream. Front Physiol. 2011;2:39.

41. de Baaij JHF, Hoenderop JGJ, Bindels RJM. Magnesium in man: implications for health and disease. Physiol Rev. 2015;95:1-46.

42. Diamond JM, Bossert WH. Standing-gradient osmotic flow - a mechanism for coupling of water and solute transport in epithelia. J Gen Physiol. 1967; 50:2061-83.

43. Dixon JM, Loretz CA. Luminal alkalinization in the intestine of the goby. J Comp Physiol. 1986;156B:803-11.

44. Donowitz M, Li X. Regulatory binding partners and complexes of NHE3. Physiol Rev. 2007:87:825-72.

45. Dópido R, Rodríguez C, Gómez T, Acosta NG, Díaz M. Isolation and characterization of enterocytes along the intestinal tract of the gilthead seabream (Sparus aurata L.). Comp Biochem Physiol. 2004;139:21-31.

46. Dymowska AK, Schultz AG, Blair SD, Chamot D, Goss GG. Acid-sensing ion channels (ASICs) are involved in epithelial $\mathrm{Na}^{+}$uptake in rainbow trout (Oncorhynchus mykiss). Am J Phys. 2014;307:C255-65.

47. Englund MB, Chauvigne F, Christensen BM, Finn RN, Cerda J, Madsen SS. Differential expression and novel permeability properties of three aquaporin 8 paralogs from seawater-challenged Atlantic salmon smolts. J Exp Biol. 2013:216:3873-85

48. Esbaugh AJ. Physiological implications of ocean acidification for marine fish: emerging patterns and new insights. J Comp Physiol. 2018;188B:1-13.
49. Esbaugh AJ, Grosell M. Esophageal desalination is mediated by $\mathrm{Na}^{+}, \mathrm{H}^{+}$ exchanger-2 in the gulf toadfish (Opsanus tau). Comp Biochem Physiol. 2014;171A:57-63.

50. Esbaugh AJ, Cutler B. Intestinal $\mathrm{Na}^{+}, \mathrm{K}^{+}, 2 \mathrm{Cl}^{-}$cotransporter 2 plays a crucial role in hyperosmotic transitions of a euryhaline teleost. Physiol Rep. 2016;4: e13028.

51. Evans DH, Piermarini PM, Choe KP. The multifunctional fish gill: dominant site of gas exchange, osmoregulation, acid-base regulation, and excretion of nitrogenous waste. Physiol Rev. 2005;85:97-177.

52. Faggio C, Tirre A, Lando G, Sabatino G, Trischitta F. Carbonate precipitates and bicarbonate secretion in the intestine of sea bass, Dicentrarchus labrax. J Comp Physiol. 2011;181B:517-25.

53. Ferlazzo A, Carvalho ES, Gregorio SF, Power DM, Canario AVM, Trischitta F, et al. Prolactin regulates luminal bicarbonate secretion in the intestine of the sea bream (Sparus aurata L.). J Exp Biol. 2012;215:3836-44.

54. Foran E, Weiner S, Fine M. Biogenic fish-gut calcium carbonate is a stable amorphous phase in the gilt-head seabream, Sparus aurata. Sci Rep. 2013;3:1700.

55. Forte LR. Uroguanylin and guanylin peptides: pharmacology and experimental therapeutics. Pharm Therap. 2004;104:137-67.

56. Forte LR, London RM, Krause WJ, Freeman RH. Mechanisms of guanylin action via cyclic GMP in the kidney. Annu Rev Physiol. 2000;62:673-95.

57. Frizzell RA, Halm DR, Musch MW, Steward CP, Field M. Potassium transport by flounder intestinal mucosa. Am J Phys. 1984;246:F946-51.

58. Fuentes J, Figueiredo J, Power DM, Canario AVM. Parathyroid hormonerelated protein regulates intestinal calcium transport in sea bream (Sparus auratus). Am J Phys. 2006;291:R1499-506.

59. Fuentes J, Power DM, Canario AVM. Parathyroid hormone-related protein-stanniocalcin antagonism in regulation of bicarbonate secretion and calcium precipitation in a marine fish intestine. Am J Phys. 2010; 299:R150-8.

60. Garcia-Hernandez V, Quiros M, Nusrat A. Intestinal epithelial claudins: expression and regulation in homeostasis and inflammation. Ann N Y Acad Sci. 2017;1397:66-79.

61. Geibel JP. Secretion and absorption by colonic crypt. Annu Rev Physiol. 2005:67:471-90.

62. Genz J, McDonald MD, Grosell M. Concentration of $\mathrm{MgSO}_{4}$ in the intestinel lumen of Opsanus beta limits osmoregulation in response to acute hypersalinity stress. Am J Phys. 2011;300:R895-909.

63. Giacomin M, Dal Point G, Eom J, Schulte PM, Wood CM. The effects of salinity and hypoxia on oxygen consumption, ventilation, diffusive water exchange and ionoregulation in the Pacific hagfish (Eptatretus stoutii). Comp Biochem Physiol A. 2019;232:47-59.

64. Giffard-Mena I, Boulo V, Aujoulat F, Fowden H, Castille R, Charmantier G, et al. Aquaporins molecular characterization in the sea-bass (Dicentrachus labrax): the effect of salinity on AQP1 and AQP3 expression. Comp Biochem Physiol. 2007;148A:430-44

65. Goytain A, Quamme GA. Identification and characterization of a novel mammalian $\mathrm{Mg}^{2+}$ transporter with channel-like properties. BMC Genomics. 2005;6:48.

66. Gregório SF, Carvalho ESM, Encarnação S, Wilson JM, Power DM, Canário AVM, et al. Adaptation to different salinities exposes functional specialization in the intestine of the sea bream (Sparus aurata L.). J Exp Biol. 2013;216:470-9.

67. Gregório SF, Luiz-Jarabo I, Carvalho EM, Fuentes J. Increased intestinal carbonate precipitate abundance in the sea bream (Sparus aurata L.) in response to ocean acidification. PLoS One. 2019;14:e021843.

68. Grosell M. Intestinal anion exchange in marine fish osmoregulation. J Exp Biol. 2006:209:2813-27.

69. Grosell M. The role of the gastrointestinal tract in salt and water balance. In: Grosell M, Farrell AP, Brauner CJ, editors. The multifunctional Gut of Fish Fish Physiology Vol. 30. San Diego: Academic Press; 2011. p. 135-164

70. Grosell M. $\mathrm{CO}_{2}$ and calcification processes in fish. In: Grosell M, Munday P, Farrell AP, Brauner CJ, editors. Carbon Dioxide. Fish Physiology vol. 37. San Diego: Academic Press; 2019. p. 133-59.

71. Grosell M, Genz J. Ouabain sensitive bicarbonate secretion and acid absorption by the marine teleost fish intestine play a role in osmoregulation. Am J Phys. 2006;291:R1145-56. 
72. Grosell M, Gilmour KM, Perry SF. Intestinal carbonic anhydrase, bicarbonate, and proton carriers play a role in the acclimation of rainbow trout to seawater. Am J Phys. 2007;293:R2099-111.

73. Grosell M, Wood CM, Wilson RW, Burry NR, Hogstrand C, Rankin C, et al. Bicarbonate secretion plays a role in chloride and water absorption of the European flounder intestine. Am J Phys. 2005;288:R936-46.

74. Grosell M, Laliberte CN, Wood S, Jensen FB, Wood CM. Intestinal $\mathrm{HCO}_{3}{ }^{-}$ secretion in marine teleost fish: evidence for an apical rather than basolateral $\mathrm{Cl}^{-} / \mathrm{HCO}_{3}{ }^{-}$exchanger. Fish Physiol Biochem. 2001;24:81-95.

75. Grosell M, Genz J, Taylor JR, Perry SF, Gilmour KM. The involvement of $\mathrm{H}^{+}$ATPase and carbonic anhydrase in intestinal $\mathrm{HCO}_{3}{ }^{-}$secretion in seawateracclimated rainbow trout. J Exp Biol. 2009a;212:1940-8.

76. Grosell M, Mager EM, Williams C, Taylor JR. High rates of $\mathrm{HCO}_{3}{ }^{-}$secretion and $\mathrm{Cl}^{-}$absorption against adverse gradients in the marine teleost intestine: the involvement of an electrogenic anion exchanger and $\mathrm{H}^{+}$-pump metabolon? J Exp Biol. 2009b;212:1684-96.

77. Guba M, Kuhn M, Forssmann WG, Classen M, Gregor M, Seidler U. Guanylin strongly stimulates rat duodenal $\mathrm{HCO}_{3}{ }^{-}$secretion: proposed mechanism and comparison with other secretagogues. Gastroenterology. 1996;111:1558-68.

78. Günzel D, Yu ASL. Claudins and the modulation of tight junction permeability. Physiol Rev. 2013;93:525-69.

79. Henkel CV, Dirks RP, de Wijze DL, Minegishi Y, Aoyama J, Jansen HJ, et al. First draft genome sequence of the Japanese eel, Anguilla japonica. Gene. 2012;511:195-201.

80. Heuer RM, Grosell M. Physiological impacts of elevated carbon dioxide and ocean acidification on fish. Am J Phys. 2014;307:R1061-84.

81. Hickman CP Jr. Ingestion, intestinal absorption, and elimination of seawater and salts in the southern flounder, Paralichthys lethostigma. Can J Zool. 1968;46:457-66.

82. Hirano T. Some factors regulating water intake by the eel, Anguilla japonica. J Exp Biol. 1974;61:737-47.

83. Hirano T, Mayer-Gostan N. Eel esophagus as an osmoregulatory organ. Proc Natl Acad Sci U S A. 1976;73:1348-50.

84. Hirano T, Utida S. Effects of ACTH and cortisol on water movement in isolated intestine of the eel, Anguilla japonica. Gen Comp Endocrinol. 1968;11:373-80.

85. Hiroi J, McCormick SD. New insights into gill ionocyte and ion transporter function in euryhaline and diadromous fish. Resp Physiol Neurobiol. 2012; 184:257-68.

86. Hirose $\mathrm{S}$, Kaneko T, Naito N, Takei Y. Molecular biology of major components of chloride cells. Comp Biochem Physiol. 2003;136B:593-620.

87. Hu MY, Michael K, Kreiss CM, Stumpp M, Dupont S, Tseng Y-C, et al. Temperature modulates the effects of ocean acidification on intestinal ion transport in Atlantic cod, Gadus morhua. Front Physiol. 2016;7:198.

88. Humbert $W$, Kirsch $R$, Simonneaux V. Is mucus involved in biocrystallization? Study of the intestinal mucus of the seawater eel Anguilla anguilla L. Cell Tissue Res. 1986;245:599-604.

89. Humbert W, Voegel JC, Kirsch R, Simonneaux V. Role of intestinal mucus in crystal biogenesis - an electron-microscopical, diffraction and x-ray microanalytical study. Cell Tissue Res. 1989;255:575-83.

90. Hwang P-P, Lee T-H, Lin L-Y. Ion regulation in fish gills: recent progress in the cellular and molecular mechanisms. Am J Phys. 2011;301:R28-47.

91. Inoue J, Sato Y, Sinclair R, Tsukamoto K, Nishida M. Rapid genome reshaping by multiple-gene loss after whole-genome duplication in teleost fish suggested by mathematical modeling. Proc Natl Acad Sci U S A. 2015;112:14918-23.

92. Inoue K, Takei Y. Asian medaka fishes offer new models for studying seawater adaptation. Comp Biochem Physiol. 2003;136B:635-45.

93. Inoue K, Naruse K, Yamagami S, Mitani H, Suzuki N, Takei Y. Four functionally distinct C-type natriuretic peptides found in fish reveal evolutionary history of the natriuretic peptide system. Proc Natl Acad Sci U S A. 2003;100:10079-84.

94. Inoue K, Sakamoto T, Yuge S, Iwatani H, Yamagami S, Tsutsumi M, et al. Structural and functional evolution of three cardiac natriuretic peptides. Mol Biol Evol. 2005;22:2428-34.

95. Ishibashi K, Kondo S, Hara S, Morishita Y. The evolutionary aspects of aquaporin family. Am J Phys. 2011;300:R566-76.

96. Islam Z, Hayashi N, Yamamoto Y, Doi H, Romero MF, Hirose S, et al. Identification and proximal tubular localization of the $\mathrm{Mg}^{2+}$ transporter, Slc41a1, in a seawater fish. Am J Phys. 2013;305:R385-96.

97. Islam Z, Hayashi N, Inoue H, Umezawa T, Kimura Y, Doi H, et al. Identification and lateral membrane localization of cyclin $\mathrm{M} 3$, likely to be involved in renal $\mathrm{Mg}^{2+}$ handling in seawater fish. Am J Phys. 2014;307:R525-37.
98. Jakab RL, Collaco AM, Ameen NA. Physiological relevance of cell specific distribution patterns of CFTR, NKCC1, NBCe1, and NHE3 along the cryptvillus axis in the intestine. Am J Phys. 2011;300:G82-98.

99. Jakab RL, Collaco AM, Ameen NA. Characterization of CFTR high expresser cells in the intestine. Am J Phys. 2013;305:G453-65.

100. Jampol LM, Epstein FH. Sodium-potassium activated adenosine triphosphatase and osmotic regulation by fishes. Am J Phys. 1970;218:607-11.

101. Jansen HJ, Liem M, Jong-Raadsen SA, Dufour S, Welzien F-A, Swinckls W, et al. Rapid de novo assembly of the European eel genome from nanopore sequencing reads. Sci Rep. 2017;7:7213.

102. Jing HJ, Kwon T-H. Molecular mechanisms regulating aquaporin-2 in kidney collecting duct. Am J Phys. 2016;311:F1318-28.

103. Kamiya M, Utida S. Changes in activity of Na-K activated adenosine triphosphatase in gills during adaptation of the Japanese eel to sea water. Comp Biochem Physiol. 1968:26:675-85.

104. Kasahara $M$, et al. The medaka draft genome and insights into vertebrate genome evolution. Nature. 2007:447:714-9.

105. Katayama Y, Sakamoto T, Saito K, Tsuchimori H, Kaiya H, Watanabe T, et al. Drinking by amphibious fish: convergent evolution of thirst mechanisms during vertebrate terrestrialization. Sci Rep. 2018;8:625.

106. Kato A, Romero MF. Regulation of electroneutral $\mathrm{NaCl}$ absorption by the small intestine. Annu Rev Physiol. 2011;73:261-81.

107. Kato A, Chang MH, Kurita Y, Nakada T, Ogoshi M, Nakazato T, et al. Identification of renal transporters involved in sulfate excretion in marine teleost fish. Am J Phys. 2009;297:R1647-59.

108. Keys A, Willmer E. Chloride secreting cells in the gills of fishes with special reference to the common eel. J Physiol (London). 1932;76:368-78.

109. Kim YK, Ideuchi H, Watanabe S, Park SI, Huh MD, Kaneko T. Rectal water absorption in seawater-adapted Japanese eel Anguilla japonica. Comp Biochem Physiol. 2008;151A:533-41.

110. Kim YK, Watanabe S, Kaneko T, Huh MD, Park SI. Expression of aquaporin 3, 8,10 in the intestines of freshwater-and seawater-acclimated Japanese eels Anguilla japonica. Fish Sci. 2010;76:695-702.

111. Kim YK, Watanabe S, Park SI, Jeong JB, Kaneko T, Park MA, et al. Molecular characterization and gene expression of $\mathrm{Na}^{+}-\mathrm{K}^{+}-2 \mathrm{Cl}^{-}$cotransporter 2 (NKCC2) in the gastrointestinal tract of olive flounder (Paralichythyes olivaceus) during four days after infection with Streptococcus parauberis. Marine Freshwater. Behav Physiol. 2013:46:145-57.

112. Kinoshita M, Murata K, Naruse K, Tanaka M. Transgenesis. In: Murata K, Kinoshita M, Naruse K, Tanaka M, Kamei Y, editors. Medaka: biology, management, and experimental protocols. Chichester: Wiley; 2012. p. 277-96.

113. Kirsch R, Meister MF. Progressive processing of ingested water in the gut of seawater teleost. J Exp Biol. 1982;98:67-81.

114. Kirsch R, Guinier D, Meens R. Water balance in the European eel (Anguilla anguilla L.). role of the esophagus in the utilization of drinking water and a study of the osmotic permeability of the gills (in French). J Physiol Paris. 1975;70:605-26.

115. Ko SB, Zeng W, Dorwart MR, Luo X, Kim KH, Millen L, et al. Gating of CFTR by the STAS domain of SLC26 transporters. Nat Cell Biol. 2004;6:343-50.

116. Kolosov D, Kelly SP. C-type natriuretic peptide regulates the molecular components of the rainbow trout gill epithelium tight junction complex. Peptides. 2010;124:170211.

117. Kolosov D, Bui P, Chasiotis H, Kelly SP. Claudins in teleost fishes. Tiss Barriers. 2013;1:e25391.

118. Konrad M, Schaller A, Seelow D, Pandey AV, Waldegger S, Lesslauer A, et al. Mutations in the tight-junction gene claudin 19 (CLDN19) are associated with renal magnesium wasting, renal failure, and sever ocular involvement. Am J Human Genet. 2006;79:949-57.

119. Krause G, Winkler L, Mueller SL, Haseloff RF, Piontek J, Blasig IE. Structure and function of claudins. Biochim Biophys Acta. 2008;1778:631-45.

120. Krishnan D, Liu L, Wiebe SA, Casey JR, Cordat E, Alexander RT. Carbonic anhydrase II binds to and increases the activity of the epithelial sodiumproton exchanger, NHE3. Am J Phys. 2015;309:F383-92.

121. Krug SM, Schulzke JD, Fromm M. Tight junction, selective permeability, and related disease. Semin Cell Develop Biol. 2014;36:166-76.

122. Kurita $Y$, Nakada T, Kato A, Doi H, Mistry AC, Chang M-H, et al. Identification of intestinal bicarbonate transporters involved in formation of carbonate precipitates to stimulate water absorption in marine teleost fish. Am J Phys. 2008;294:R1402-12.

123. Lamprecht $G$, Seidler U. The emerging role of PDZ adapter proteins for regulation of intestinal ion transport. Am J Phys. 2006;291:G766-77. 
124. Lamprecht G, Heil A, Baisch S, Lin-Wu E, Yun CC, et al. The down regulated in adenoma (dra) gene product binds to the second PDZ domain of the NHE3 kinase a regulatory protein (E3KARP), potentially linking intestinal $\mathrm{Cl}^{-} / \mathrm{HCO}_{3}{ }^{-}$exchange to $\mathrm{Na}^{+} / \mathrm{H}^{+}$exchange. Biochemistry. 2002;41:12336-42

125. Larsen $\mathrm{EH}$, Mobjerg N. $\mathrm{Na}^{+}$recirculation and isosmotic transport. J Membr Biol. 2006;212:1-15.

126. Larsen EH, Willumsen NJ, Mobjerg N, Sorensen JN. The lateral intercellular space as osmotic coupling in isotonic transport. Acta Physiol. 2009;195:171-86.

127. Larsen EH, Deaton LE, Onken H, O'Donnell M, Grosell M, Danzler WH, et al. Osmoregulation and excretion. Compr Physiol. 2014;4:405-573.

128. Lee MG, Wigley WC, Zeng W, Noel LE, Marino CR, Thomas PJ, et al. Regulation of $\mathrm{Cl}^{-} / \mathrm{HCO}_{3}{ }^{-}$exchange by cystic fibrosis transmembrane conductance regulator expressed in NIH 3 T3 and HEK 293 cells. J Biol Chem. 1999;274:3414-21.

129. Li J, Dai Z, Jana D, Callaway DJE, Bu Z. Ezrin controls the macromolecular complexes formed between an adapter protein $\mathrm{Na}^{+} / \mathrm{H}^{+}$exchanger regulatory factor and the cystic fibrosis transmembrane conductance regulator. J Biol Chem. 2005;280:37634-43.

130. Li Z, Lui EY, Wilson JM, Ip YK, Lin Q, Lam TJ, et al. Expression of key ion transporters in the fill and esophageal-gastrointestinal tract of euryhaline Mozambique tilapia Oreochromis mossambicus acclimated to fresh water, seawater and hypersaline water. PLoS One. 2014;9:e87591.

131. Long X, Ma Y, Qi L. Biogenic and synthetic high magnesium calcite - a review. J Struct Biol. 2014;185:1-14.

132. Loo DDF, Wright EM, Zeuthen T. Water pumps. J Physiol (London). 2002:542:53-60.

133. Loretz CA. Electrophysiology of ion transport in teleost intestinal cells. In: Wood CM, Shuttleworth TJ, editors. Cellular and molecular approaches to fish ionic regulation, fish Physiol, vol. 14. New York: Academic Press; 1995. p. 25-56

134. Loretz CA, Bern HA. Ion transport by the urinary bladder of the gobiid teleost, Gillichthys mirabilis. Am J Physiol. 1980;239:R415-23.

135. Loretz CA, Fourtner CR. Functional characterization of a voltage-gated anion channel from teleost fish intestinal epithelium. J Exp Biol. 1988;136:383-403.

136. Loretz CA, Bern HA, Foskett JK, Mainoya JR. The caudal neurosecretory system and osmoregulation in fish. In: Farner DS, Lederis K, editors. Neurosecretion: molecules, cells, systems. New York: Plenum; 1981. p. 319-28.

137. Loretz CA, Pollina C, Kaiya H, Sakaguchi H, Takei Y. Local synthesis of natriuretic peptides in the eel intestine. Biochem Biophys Res Commun. 1977;238:817-22.

138. MacKay WC, Janicki R. Changes in the eel intestine during seawater adaptation. Comp Biochem Physiol. 1979;62A:757-61.

139. Madsen SS, Bujak J, Tipsmark CK. Aquaporin expression in the Japanese medaka (Oryzias latipes) in freshwater and seawater: challenging paradigm of intestinal water transport? J Exp Biol. 2014;217:3108-21.

140. Madsen SS, Weber C, Nielsen AM, Mohiseni M, Bossus MC, Tipsmark CK, et al. Sexual maturation and changes in water and salt transport components in the kidney and intestine of three-spine stickleback (Gasterosteus aculeatus L.). Comp Biochem Physiol. 2015;188A:107-19.

141. Maetz J, Skadhauge E. Drinking rates and gill ionic turn-over in relation to external salinities in the eel. Nature. 1968;217:371-3.

142. Mainoya JR. Effect of peptide hormones on intestinal transport in fish. In: Lofts B, Holmes WN, editors. Current trends in comparative endocrinology, vol. 2. Hong Kong: Hong Kong University Press; 1985. p. 910-3.

143. Mainoya JR, Bern HA. Influence of vasoactive intestinal peptide and urotensin II on the absorption of water and $\mathrm{NaCl}$ by the anterior intestine of the tilapia, Sarotherondon mossambicus. Zool Sci. 1984;1:100-5.

144. Marshall WS, Grosell M. Ion transport, osmoregulation, and acid-base balance. In: Evans DH, Claiborne JB, editors. The physiology of fishes. Boca Raton: CRC Press; 2005. p. 177-230.

145. Marshall WS, Singer TD. Cystic fibrosis transmembrane conductance regulator in teleost fish. Biochim Biophys Acta. 2002;1566:16-27.

146. Marshall WS, Howard JA, Cozzi JRRF, Lynch EM. NaCl and fluid secretion by the intestine of the teleost Fundulus heteroclitus: involvement of CFTR. J Exp Biol. 2002;205:745-58.

147. Marshall WS, Breves JP, Doohan EM, Tipsmark CK, Kelly SP, Robertson GN, et al. Claudin-10 isoform expression and cation selectivity change with salinity in salt-secreting epithelia of Fundlus heteroclitus. J Exp Biol. 2018;221:jeb168906.

148. Marsigliante S, Muscella A, Greco S, Elia MG, Vilella S, Storelli C. Na+/ $\mathrm{K}^{+}$ATPase activity inhibition and isoform-specific translocation of protein kinase C following angiotensin II administration in isolated eel enterocytes. J Endocrinol. 2001;168:339-46.
149. Martinez A-S, Cutler CP, Wilson G, Phillips C, Hazon N, Cramb G. Regulation of expression of two aquaporin homologues in the intestine of the European eel: effects of seawater acclimation and cortisol treatment. Am J Phys. 2005;288:R1733-43.

150. Martos-Sitcha JA, Gregório SF, Carvalho ESM, Canario AVM, Power DM, Mancera $J M$, et al. AVT is involved in the regulation of ion transport in the intestine of the sea bream (Sparus aurata). Gen Comp Endocrinol. 2013;193:221-8.

151. McCormick SD. Endocrine control of osmoregulation in teleost fish. Am Zoo. 2001:41:781-94

152. McMurtrie HL, Cleary HJ, Alvarez BV, Loiselle FB, Sterling D, Morgan PE, et al. The bicarbonate transport metabolon. J Enzy Inhib Med Chem. 2004;19: 231-6.

153. Mekuchi M, Hatta T, Kaneko T. Mg-calcite, a carbonate mineral, constitutes Ca precipitates produced as a byproduct of osmoregulation in the intestine of seawater-acclimated Japanese eel, Anguilla japonica. Fish Sci. 2010;76: 199-205.

154. Mobasheri A, Shakibaei M, Marples D. Immunohistochemical localization of aquaporin 10 in the apical membrane of the human ileum: a potential pathway for luminal water and small solute absorption. Histochem Cell Biol. 2004;121:463-71.

155. Moyer BD, Duhaime M, Shaw C, Denton J, Reynolds D, Karlson KH, et al. The PDZ-interacting domain of cystic fibrosis transmembrane conductance regulator is required for functional expression in the apical plasma membrane. J Biol Chem. 2000;275:27069-74.

156. Musch MW, Orellana SA, Kimberg LS, Field M, Halm DR, Krasny EJ Jr, et al. Na ${ }^{+}$$\mathrm{K}^{+}-\mathrm{Cl}^{-}$co-transport in the intestine of a marine teleost. Nature. 1982;300:351-3.

157. Nagashima K, Ando M. Characterization of esophageal desalination in the seawater eel, Anquilla japonica. J Comp Physiol. 1994;164:47-54.

158. Nakada T, Zandi-Nejad K, Kurita Y, Kudo H, Broumand V, Kwon CY, et al. Roles of SIC13a1 and SIC26a1 sulfate transporters of eel kidney in sulfate homeostasis and osmoregulation in freshwater. Am J Phys. 2005;289:R575-85.

159. Nelson JS, Grande T, Wilson MKV. Fishes of the world. 5th ed. Chichester: Wiley; 2016

160. Nighot PK, Blikslager AT. CIC-2 regulates mucosal barrier function associated with structural changes to the villus and epithelial tight junction. Am J Phys. 2010;299:G449-56.

161. Nobata S, Ando M, Takei Y. Hormonal control of drinking behavior in fishes: insights from studies using eels. Gen Comp Endocrinol. 2013;192:214-21.

162. O'Grady SM. Cyclic nucleotide-mediated effects of ANF and VIP on flounder intestinal ion transport. Am J Phys. 1989;256:C142-6.

163. O'Grady SM, Field M, Nash NT, Rao MC. Atrial natriuretic factor inhibits Na-KCl cotransport in teleost intestine. Am J Phys. 1985;249:C531-4.

164. O'Grady SM, Musch MW, Field M. Stoichimetry and ion affinities of the Na-K$\mathrm{Cl}$ cotransport system in the intestine of the winter flounder (Pseudopleuronectes amaricanus). J Memb Biol. 1986;91:33-41.

165. Oide M, Utida S. Changes in water and ion transport in isolated intestines of the eel during salt adaptation and migration. Mar Biol. 1967;1:102-6.

166. Parmelee JT, Renfro JL. Esophageal desalination of seawater in flounder: role of active sodium transport. Am J Phys. 1983;245:R888-93.

167. Partiseti M, Collura V, Agnel M, Culouscou JM, Graham D. Cloning and characterization of a novel human inwardly rectifying potassium channel predominantly expressed in small intestine. FEBS Lett. 1998;434: 171-6.

168. Pavey SA, Laporte M, Normandeau E, Gaudin J, Letourneau L, Boisvert S, et al. Draft genome of the American eel (Anguilla rostrata). Mol Ecol Resor. 2017;17:806-11.

169. Pelis RM, Renfro JL. Active sulfate secretion by the intestine of winter frounder is through exchange for luminal chloride. Am J Phys. 2003;284:R380-8.

170. Pena-Munzenmayer G, Catalan M, Cornejo I, Figueroa CD, Melvin JE, et al. Basolateral localization of native $\mathrm{CIC}-2$ chloride channels in absorptive intestinal epithelial cells and basolateral sorting encoded by a CBS-2 domain di-leucine motif. J Cell Sci. 2005;118:4243-52.

171. Prasad GV, Coury LA, Finn F, Zeidel ML. Reconstituted aquaporin 1 water channels transport $\mathrm{CO}_{2}$ across membranes. J Biol Chem. 1998;273:33123-6.

172. Raldúa D, Otero D, Fabra M, Cerdà J. Differential localization and regulation of two aquaporin-1 homologs in the intestinal epithelia of the marine teleost Sparus aurata. Am J Phys. 2008;294:R993-1003.

173. Renfro JL. Recent developments in teleost renal transport. J Exp Zool. 1999;283: 653-61.

174. Romero MF, Chen A-P, Parker MD, Boron WF. The SLC4 family of bicarbonate $\left(\mathrm{HCO}_{3}{ }^{-}\right)$transporters. Mol Asp Med. 2013;34:159-82. 
175. Rosenthal R, Milatz S, Krug SM, Oelrich B, Schulzke J-D, Amasheh S, et al. Claudin-2, a component of the tight junction, forms a paracellular water channel. J Cell Sci. 2010;123:1913-21.

176. Rosenthal R, Gunzel D, Piontek J, Krug SM, Ayala-Torres C, Hempel C, et al. Claudin-15 forms a water channel through the tight junction with distinct function compared to claudin-2. Acta Physiol. 2020;228 e13334.

177. Ruhr IM, Bodinier C, Mager EM, Esbaugh AJ, Williams C, Takei Y, et al. Guanylin peptides regulate electrolyte and fluid transport in the Gulf toadfish (Opsanus beta) posterior intestine. Am J Phys. 2014;307:R1167-79.

178. Ruhr IM, Mager EM, Takei Y, Grosell M. The differential role of renoguanylin in osmoregulation and apical $\mathrm{Cl}^{-} / \mathrm{HCO}_{3}{ }^{-}$exchange activity in the posterior intestine of the Gulf toadfish (Opsanus beta). Am J Phys. 2015;309:R399-409.

179. Ruhr I, Takei Y, Grosell M. The role of the rectum in osmoregulation and the potential effect of renoguanylin on SLC26a6 transport activity in the Gulf toadfish (Opsanus beta). Am J Phys. 2016;311:R179-91.

180. Ruhr IM, Schauer KL, Takei Y, Grosell M. Renoguanylin stimulates apical CFTR translocation and decreases $\mathrm{HCO}_{3}{ }^{-}$secretion through PKA activity in the Gulf toadfish (Opsanus beta). J Exp Biol. 2018;221:jeb173948.

181. Ruhr IM, Wood CM, Schauer KL, Wang Y, Mager EM, Stanton B, et al. Is aquaporin-3 involved in water-permeability changes in the killifish during hypoxia and normoxic recovery, in freshwater or seawater? J Exp Zool A. 2020;333:511-25.

182. Ruiz-Jarabo I, Barany-Ruiz A, Jerez-Cepa I, Mancera JM, Fuentes J. Intestinal response to salinity challenge in the Senegalese sole (Solea senegalensis). Comp Biochem Physiol. 2017a;204A:57-64.

183. Ruiz-Jarabo I, Gregório SF, Gaetano P, Trischitta F, Fuentes J. High rates of intestinal bicarbonate secretion in seawater tilapia (Oreochromis mossambicus). Comp Biochem Physiol. 2017b;207A:57-64.

184. Salter MA, Perry CT, Wilson RW. Production of mud-grade carbonates by marine fish: crystalline products and their sedimentary significance. Sedimentology. 2012;59:2172-98.

185. Santos CRA, Estêvão MD, Fuentes J, Cardoso JCR, Fabra M, Passos AL, et al. Isolation of a novel aquaglyceroporin from a marine teleost (Sparus auratus): function and tissue distribution. J Exp Biol. 2004;207:1217-27.

186. Sardet C, Pisam M, Maetz J. The surface epithelium of teleostean fish gills: cellular and junctional adaptations of the chloride cell in relation to salt adaptation. J Cell Biol. 1979;80:96-117.

187. Sattin G, Mager EM, Grosell M. Cytosolic carbonic anhydrase in the Gulf toadfish is important for tolerance to hypersalinity. Comp Biochem Physiol A. 2010;156:169-75.

188. Schauer KL, LeMoine CMR, Pelin A, Corradi N, Warren WC, Grosell M, et al. A Proteinaceous organic matrix regulates carbonate mineral production in the marine teleost intestine. Sci Rep. 2016;6:34494.

189. Schmidt-Nielsen K. Animal Physiology - Adaptation and Environment. 5th ed. Cambridge: Cambridge University Press; 1997. p. 348-9.

190. Schmitz C, Perraud A-L, Johnson CO, Inaba K, Smith MK, Penner R, et al. Regulation of vertebrate cellular $\mathrm{Mg}^{2+}$ homeostasis by TRPM7. Cell. 2003;114:191-200.

191. Schron CM, Knickelbein RG, Aronson PS, Dobbins JW. Evidence for carriermediated $\mathrm{Cl}_{-} \mathrm{SO}_{4}$ exchange in rabbit ileal basolateral membrane vesicles. Am J Phys. 1987;253:G404-10.

192. Schultheis PJ, Clarke LL, Meneton P, Miller ML, Soleimani M, et al. Renal and intestinal absorptive defects in mice lacking the NHE3 $\mathrm{Na}^{+} / \mathrm{H}^{+}$exchanger. Nat Genet. 1998;19:282-5.

193. Schweinfest CW, Spyropoulos DD, Henderson KW, Kim JH, Chapman JM, et al. Slc26a3 (dra)-deficient mice display chloride-losing diarrhea, enhanced colonic proliferation, and distinct up-regulation of ion transporters in the colon. J Biol Chem. 2006;281:37962-71.

194. Scott GR, Baker DW, Schulte PM, Wood CM. Physiological and molecular mechanisms of osmoregulatory plasticity in killifish after seawater. J Exp Biol. 2008a;211:2450-9.

195. Shcheynikov N, Wang Y, Park M, Ko SB, Dorwart M, et al. Coupling modes and stoichiometry of $\mathrm{Cl}^{-} / \mathrm{HCO}_{3}{ }^{-}$exchange by Slc26a3 and Slc26a6. J Gen Physiol. 2006;127:511-24.

196. Short DB, Trotter KW, Reczek D, Kreda SM, Bretscher A, Boucher RC, et al. An apical PDZ protein anchors the cystic fibrosis transmembrane conductance regulator to the cytoskeleton. J Biol Chem. 1998;273:19797-801.

197. Scott GR, Baker DW, Schulte PM, Wood CM. Physiological and molecular mechanisms of osmoregulatory plasticity in killifish after seawater transfer. J Exp Biol. 2008b;211:2450-9.
198. Seale AP, Stagg JJ, Yamaguchi Y, Breves JP, Soma S, Watanabe S, et al. Effects of salinity and prolactin on gene transcript levels of ion transporters, ion pumps and prolactin receptors in Mozambique tilapia intestine. Gen Comp Endocrinol. 2014;206:146-54.

199. Seidler U, Nikolovska K. Slc26 family of anion transporters in the gastrointestinal tract: expression, function, regulation, and role in disease. Compr Physiol. 2019;9:839-72.

200. Seidler U, Rottinghaus I, Hillesheim J, Chen M, Riederer B, et al. Sodium and chloride absorptive defects in the small intestine in Slc26a6 null mice. Pflüg Arch. 2008;455:757-66

201. Shedadeh ZH, Gordon MS. The role of intestine salinity adaptation of the rainbow trout, Salmo gairdneri. Comp Biochem Physiol. 1969;30:397-418.

202. Simon DB, Lu Y, Choate KA, Velazques H, Al-Sabban E, Praga M, et al. Paracellin-1, a renal tight junction protein required for paracellular $\mathrm{Mg}^{2+}$ resorption. Science. 1999;285:103-6.

203. Silva P, Solomon RJ, Epstein FH. The rectal gland of Squalus acanthias: a model for the transport of chloride. Kid Intern. 1996:49:1552-6.

204. Singh AK, Riederer B, Chen M, Xiao F, Krabbenhoft A, Engelhardt R, et al. The switch of intestinal SLC26 exchangers from anion absorptive to $\mathrm{HCO}_{3}{ }^{-}$ secretory mode is dependent on CFTR anion channel function. Am J Phys. 2010;298:C1057-65.

205. Sinke AP, Kortenoeven MLA, de Groot T, Baumgarten R, Devuyst O, Wetzels JFM, et al. Hydrochlorothiazide attenuates lithium-induced nephrogenic diabetes insipidus independently of the sodium-chloride cotransporter. Am J Phys. 2014;306:F525-33.

206. Skadhauge E. Mechanism of salt and water absorption in intestine of eel (Anguilla anguilla) adapted to waters of various salinities. J Physiol (London). 1969;204:135-58.

207. Smith HW. The absorption and excretion of water and salts by marine teleosts. Am J Phys. 1930;93:480-505.

208. Smith CP, Smith PL, Welsh MJ, Frezzell RA, Orellana SA, Field M. Potassium transport by the intestine of the winter flounder Pseudopleuronectes americanus: evidence for $\mathrm{KCl}$ cotransport. Bull Mt Desert Island Biol Lab. 1980;20:92-6.

209. Sterling D, Alvarez BV, Casey JR. The extracellular component of a transport metabolon. Extracellular loop 4 of the human $\mathrm{AE} 1 \mathrm{Cl}^{-} / \mathrm{HCO}_{3}{ }^{-}$exchanger binds carbonic anhydrase IV. J Biol Chem. 2002a;277:25239-46.

210. Sterling D, Brown NJD, Supuran CT, Casey JR. The functional and physical relationship between the DRA bicarbonate transporter and carbonic anhydrase II. Am J Phys. 2002b;283:C1522-9.

211. Sterling D, Reithmeier RA, Casey JR. A transport metabolon. Functional interaction of carbonic anhydrase II and chloride/bicarbonate exchangers. J Biol Chem. 2001;276:47886-94.

212. Stewart AK, Yamamoto A, Nakakuki M, Kondo T, Alper SL, Ishiguro $\mathrm{H}$. Functional coupling of apical $\mathrm{Cl}^{-} / \mathrm{HCO}_{3}{ }^{-}$exchange with CFTR in stimulated $\mathrm{HCO}_{3}{ }^{-}$secretion by Guinea pig interlobular pancreatic duct. Am J Phys. 2009:296:G1307-17.

213. Sundell KS, Sundh H. Intestinal fluid absorption in anadromous salmonids: importance of tight junctions and aquaporins. Front Physiol. 2012;3:e00388.

214. Sundell KS, Bjornsson BT, Itoh H, Kawauchi H. Chum salmon (Oncorhynchus keta) stanniocalcin inhibits in vitro intestinal calcium uptake in Atlantic cod (Gadus morhua). J Comp Physiol. 1992;162:489-95.

215. Sundh H, Nilsen TO, Lindstrom J, Hasselberg-Frank L, Stefansson SO, McCormick SD, et al. Development of intestinal ion-transporting mechanisms during smoltification and seawater acclimation in Atlantic salmon Salmo salar. J Fish Biol. 2014:85:1227-52.

216. Suzuki Y, Itakura M, Kashiwagi M, Nakamura N, Matsuki T, Sakuta $H$, et al. Identification by differential display of a hypertonicity-inducible inward rectifier potassium channel highly expressed in chloride cells. J Biol Chem. 1999;274:11376-82.

217. Swiatecka-Urban A, Duhaime M, Coutermarsh B, Karlson KH, Collawn J, Milewski M, et al. PDZ domain interaction controls the endocytic recycling of the cystic fibrosis transmembrane conductance regulator. J Biol Chem. 2002;277:40099-105.

218. Takei Y. Comparative physiology of body fluid regulation in vertebrates with special reference to thirst regulation. Jpn J Physiol. 2000;50:171-86.

219. Takei Y. Exploring novel hormones essential for seawater adaptation in teleost fish. Gen Comp Endocrinol. 2008;157:3-13.

220. Takei Y. From aquatic to terrestrial life: evolution of the mechanisms for water acquisition. Zool Sci. 2015;32:1-7. 
221. Takei Y, Balment RJ. The neuroendocrine regulation of fluid intake and fluid balance. In: Bernier N, Van Der Kraak G, Farrell AP, Brauner CJ, editors. Fish Neuroendocrinology. Fish Physiology Vol. 28. San Diego: Academic Press; 2009. p. 365-419.

222. Takei $Y$, Loretz CA. The gastrointestinal tract as an endocrine, paracrine and autocrine organ. In: Grosell M, Farrell AP, Brauner CJ, editors. The Multifunctional Gut of Fish. Fish Physiology Vol. 30. San Diego: Academic Press; 2010. p. 261-317.

223. Takei $Y$, Hirano T, Kobayashi H. Angiotensin and water intake in the Japanese eel, Anguilla japonica. Gen Comp Endocrinol. 1979;38:466-75.

224. Takei Y, Hiroi J, Takahashi T, Sakamoto T. Diverse mechanisms of body fluid regulation in teleost fishes. Am J Phys. 2014;307:R778-92.

225. Takei Y, Ogoshi M, Inoue K. A 'reverse' phylogenetic approach for identification of novel osmoregulatory and cardiovascular hormones in vertebrates. Front Neuroendocrinol. 2007;28:143-60.

226. Takei Y, Tsuchida T, Tanakadate A. Evaluation of water intake in seawater adaptation in eels using a synchronized drop counter and pulse injector system. Zool Sci. 1998;15:677-82.

227. Takei Y, Wong MKS, Pipil S, Ozaki H, Iwasaki W, Suzuki Y, et al. Molecular mechanisms underlying active desalination in the esophagus of seawater eels. Am J Phys. 2017;312:R231-44.

228. Takei $Y$, Wong MKS, Ando M. Molecular mechanisms for intestinal $\mathrm{HCO}_{3}{ }^{-}$ secretion and its regulation by guanylin in seawater-acclimated eels. J Exp Biol. 2019;222:jeb203539.

229. Tanaka H, Tamura A, Suzuki K, Tuskita S. Site-specific distribution of claudinbased paracellular channels with roles in biological fluid flow and metabolism. Ann N Y Acad Sci. 2017;1405:44-52.

230. Taylor JR, Grosell M. The intestinal response to feeding in seawater gulf toadfish, Opsanus beta, includes elevated base secretion and increased oxygen consumption. J Exp Biol. 2009;212:3873-81.

231. Taylor JR, Mager EM, Grosell M. Basolateral NBCe1 plays a rate-limiting role in transepithelial intestinal $\mathrm{HCO}_{3}{ }^{-}$secretion, contributing to marine fish osmoregulation. J Exp Biol. 2010;213:459-68.

232. Taylor JR, Cooper CA, Mommsen TP. Implication of GI function for gas exchange, acid-base balance and nitrogen metabolism. In: Grosell M, Farrell AP, Brauner CJ, editors. The Multifunctional Gut of Fish. Fish Physiology Vol. 30. San Diego: Academic Press; 2011. p. 213-59.

233. Tipsmark CK, Madsen SS. Tricellulin, occludin and claudin-3 expression in salmon intestine and kidney during salinity adaptation. Comp Biochem Physiol. 2012;162A:378-85.

234. Tipsmark CK, Nielsen AM, Bossus MC, Ellis LV, Baun C, Andersen TL, et al. Drinking and water handling in the medaka intestine: a possible role of claudin-15 in paracellular absorption. Int J Mol Sci. 2020;21:1853.

235. Tipsmark CK, Sørensen KJ, Hulgard K, Madsen SS. Claudin-15 and -25b expression in the intestinal tract of Atlantic salmon in response to seawater acclimation, smoltification and hormone treatment. Comp Biochem Physiol. 2010a;155A:361-70.

236. Tipsmark CK, Sørensen KJ, Madsen SS. Aquaporin expression dynamics in osmoregulatory tissues of Atlantic salmon during smoltification and seawater acclimation. J Exp Biol. 2010b;213:368-79.

237. Tresguerres M, Levin LR, Buck J, Grosell M. Modulation of $\mathrm{NaCl}$ absorption by $\left[\mathrm{HCO}_{3}{ }^{-}\right]$in the marine teleost intestine mediated by soluble adenylyl cyclase. Am J Phys. 2010;299:R62-71.

238. Trischitta F, Denaro MG, Faggio C, Schettino T. Comparison of $\mathrm{Cl}^{-}$absorption in the intestine of the seawater-adapted and freshwater-adapted eel, Anguilla anguilla-evidence for the presence of a Na-K-Cl cotransport system on the luminal membrane of the enterocyte. J Exp Zool. 1992;263:245-53.

239. Trischitta F, Denaro MG, Faggio C, Mandolfino M, Schettino T. Different effects of CGMP and CAMP in the intestine of the European eel, Anguilla anguilla. J Comp Physiol. 1996;166B:30-6.

240. Tritto S, Gastaldi G, Zelenin S, Grazioli M, Orsenigo MN, Ventura U, et al. Osmotic water permeability of rat intestinal brush border membrane vesicles: involvement of aquaporin-7 and aquaporin- 8 and effect of metal ions. Biochem Cell Biol. 2007;85:675-84.

241. Tsukada T, Rankin JC, Takei Y. Mechanisms underlying hyponatremic effect of atrial natriuretic peptide in seawater eels: physiological significance of drinking and intestinal absorption. Zool Sci. 2005;22:77-85.

242. Tsukamoto K, Nakai I, Tesch WV. Do all freshwater eels migrate? Nature. 1998;396:635-6.

243. Tsukita S, Furuse M, Itoh M. Multifunctional strands in tight junctions. Nat Rev Mol Cell Biol. 2001;2:285-93.
244. Uchiyama $\mathrm{H}$, Hayashi $\mathrm{H}$, Suzuki Y. Functional characterization of $\mathrm{Cl}^{-} / \mathrm{HCO}_{3}{ }^{-}$ exchange in villous cells of the mouse ileum. Biomed Res. 2006;27:265-74.

245. Uesaka T, Yano K, Yamasaki M, Nagashima K, Ando M. Somatostatin-related peptides isolated from the eel gut: effects on ion and water absorption across the intestine of the seawater eel. J Exp Biol. 1994;188:205-16.

246. Uesaka T, Yano K, Sugimoto S, Ando M. Effects of eel neuropeptide $Y$ on ion transport across the seawater eel intestine. Zool Sci. 1996;13:341-6.

247. Usher ML, Talbott C, Eddy FB. Intestinal water transport in juvenile Atlantic salmon (Salmo salar L.) during smolting and following transfer to seawater. Comp Biochem Physiol A. 1991;100:813-8.

248. Veillette PA, Young G. Temporal changes in intestinal $\mathrm{Na}^{+}, \mathrm{K}^{+}$-ATPase activity and in vitro responsiveness to cortisol in juvenile Chinook salmon. Comp Biochem Physiol A. 2004;138:297-303.

249. Veillette PA, Sundell K, Specker JL. Cortisol mediates the increase in intestinal fluid absorption in Atlantic salmon during parr-smolt transformation. Gen Comp Endocrinol. 1995;97:250-8.

250. Veillette PA, White RJ, Specker JL, Young G. Osmoregulatory physiology of pyloric ceca: regulated and adaptive changes in Chinook salmon. J Exp Zool A. 2005;303:608-13.

251. Vilas G, Krishnan D, Lognathan SK, Malhotra D, Liu L, Beggs MR, et al. Increased water flux induced by an aquaporin-1/carbonic anhydrase II interaction. Mol Biol Cell. 2015;26:1106-18.

252. Walder RY, Landau D, Meyer P, Shalev H, Tsolia M, Borochowits Z, et al. Mutation of TRPM6 causes familial hypomagnesemia with secondary hypocalcemia. Nat Genet. 2002;31:171-4.

253. Walsh PJ, Blackwelder PK, Gill A, Danulat E, Mommsen TP. Carbonate deposits in marine fish intestines: a new source of biomineralization. Limnol Oceanogr. 1991;36:1227-32.

254. Watanabe S, Kaneko T, Aida K. Aquaporin-3 expressed in the basolateral membrane of gill chloride cells in Mozambique tilapia Oreochromis mossambicus adapted to freshwater and seawater. J Exp Biol. 2005;208: 2673-82.

255. Watanabe S, Mekuchi M, Ideuchi H, Kim YK, Kaneko T. Electroneutral cation$\mathrm{Cl}^{-}$transporters NKCC $\beta$ and NCC $\beta$ expressed in the intestinal tract of Japanese eel Anguilla japonica. Comp Biochem Physiol. 2011;159A:427-35.

256. Watanabe T, Takei Y. Molecular physiology and functional morphology of $\mathrm{SO}_{4}{ }^{2-}$ excretion by the kidney of seawater-adapted eels. J Exp Biol. 2011; 214:1783-90.

257. Watanabe T, Takei Y. Vigorous $\mathrm{SO}_{4}{ }^{2-}$ influx via the gills is balanced by enhanced $\mathrm{SO}_{4}{ }^{2-}$ excretion by the kidney in eels after seawater adaptation. J Exp Biol. 2012;215:1775-81.

258. Welling PA. Roles and regulation of renal K channels. Annu Rev Physiol. 2016;78:415-35

259. Whittamore JM. Osmoregulation and epithelial water transport: lessons from the intestine of marine teleost fish. J Comp Physiol. 2012;182B:1-39.

260. Whittamore JM, Hatch M. Loss of the anion exchanger DRA (SIC26a3), or PAT1 (SIc26a6), alters sulfate transport by the distal ileum and overall sulfate homeostasis. Am J Phys. 2017;313:G166-79.

261. Wilson JM, LFC C. Morphological diversity of the gastrointestinal tract in fishes. In: Grosell M, Farrell AP, Brauner CJ, editors. The Multifunctional Gut of Fish. Fish Physiology Vol. 30. San Diego: Academic Press; 2011. p. 1-55.

262. Wilson RW, Grosell M. Intestinal bicarbonate secretion in marine teleost fish -source of bicarbonate, $\mathrm{pH}$ sensitivity, and consequences for whole animal acid-base and calcium homeostasis. Biochim Biophys Acta. 1618;2003:163-74.

263. Wilson RW, Gilmour K, Henry R, Wood CM. Intestinal base excretion in the seawater-adapted rainbow trout: a role in acid-base balance? J Exp Biol. 1996;199:2331-43.

264. Wilson RW, Wilson JM, Grosell M. Intestinal bicarbonate secretion by marine teleost fish-why and how? Biochim Biophys Acta. 2002;1566:182-93.

265. Wilson RW, Millero FJ, Taylor JR, Walsh PJ, Christensen V, Jennings S, et al. Contribution of fish to the marine inorganic carbon cycle. Science. 2009;323:359-62.

266. Wong MKS, Takei Y. Changes in plasma angiotensin subtypes in Japanese eel acclimated to various salinities from deionized water to double-strength seawater. Gen Comp Endocrinol. 2012;178:250-8.

267. Wong MKS, Takei Y, Woo NYS. Differential status of the renin-angiotensin system of silver sea bream (Sparus sarba) in different salinities. Gen Comp Endocrinol. 2006;149:81-9.

268. Wong MKS, Ozaki H, Suzuki Y, Iwasaki W, Takei Y. Discovery of osmotic sensitive transcription factors in fish intestine via a transcriptomic approach. BMC Genomics. 2014;15:1134. 
269. Wong MKS, Pipil S, Kato A, Takei Y. Duplicated CFTR isoforms in eels diverged in regulatory structures and osmoregulatory functions. Comp Biochem Physiol. 2016a;199A:130-41.

270. Wong MKS, Pipil S, Ozaki H, Iwasaki W, Suzuki Y, Takei Y. Flexible selection of diversified $\mathrm{Na}^{+} / \mathrm{K}^{+}$-ATPase a-subunit isoforms for osmoregulation in teleosts. Zool Lett. 2016b;2:15.

271. Wong MKS, Tsukada T, Ogawa N, Pipil S, Ozaki H, Suzuki Y, et al. A sodium binding system alleviates acute salt stress during seawater acclimation in eels. Zool Lett. 2017;3:22.

272. Wood CM. Internal special and temporal $\mathrm{CO}_{2}$ dynamics: fasting, feeding, drinking, and alkaline tide. In: Grosell M, Munday P, Farrell AP, Brauner CJ, editors. Carbon Dioxide. Fish Physiology Vol. 37. San Diego: Academic Press; 2019. p. 245-86.

273. Wood CM, Bucking C. The role of feeding in salt and water balance. In: Grosell M, Farrell AP, Brauner CJ, editors. The Multifunctional Gut of Fish Fish Physiology, vol. 30. San Diego: Academic Press; 2011. p. 165-212.

274. Wood CM, Grosell M. Independence of net water flux from paracellular permeability in the intestine of Fundulus heteroclitus, a euryhaline teleost. J Exp Biol. 2012;215:508-17.

275. Yamamoto M, Hirano T. Morphological changes in the esophageal epithelium of the eel, Anguilla japonica, during adaptation to seawater. Cell Tiss Res. 1978:192:25-38.

276. Yamazaki D, Funato Y, Miura J, Sato S, Toyasawa S, Furutani K, et al. Basolateral $\mathrm{Mg}^{2+}$ extrusion via CNNM4 mediates transcellular $\mathrm{Mg}^{2+}$ transport across epithelia: a mouse model. PLoS Genet. 2013;9:e1003983.

277. Yuge S, Takei Y. Regulation of ion transport in eel intestine by the homologous guanylin family of peptides. Zool Sci. 2007;24:1222-30.

278. Yuge S, Inoue K, Hyodo S, Takei Y. A novel guanylin family (guanylin, uroguanylin and renoguanylin) in eels: possible osmoregulatory hormones in intestine and kidney. J Biol Chem. 2003;278:22726-33.

279. Yuge S, Yamagami S, Inoue K, Suzuki N, Takei Y. Identification of two functional guanylin receptors in eel: multiple hormone-receptor system for osmoregulation in fish intestine and kidney. Gen Comp Endocrinol. 2006;149:10-20.

280. Zachos NC, Tse M, Donowitz M. Molecular physiology of intestinal $\mathrm{Na}^{+} / \mathrm{H}^{+}$ exchange. Annu Rev Physiol. 2005;67:411-43.

281. Zeuthen T, Belhage B, Zeuthen E. Water transport by $\mathrm{Na}^{+}$-coupled cotransporters of glucose (SGLT1) and of iodide (NIS). The dependence of substrate size studied at high resolution. J Physiol (London). 2006;570:485-99.

282. Zhang K, Zhang X, Wen H, Xin Q, Fan H, Tian Y, et al. Spotted sea bass (Lateolabrax maculatus) cftr, nkccla, nkcclb and nkcc2: genome-wide identification, characterization and expression analysis under salinity stress. J Ocean Univ China. 2019;18:1470-80.

\section{Publisher's Note}

Springer Nature remains neutral with regard to jurisdictional claims in published maps and institutional affiliations.

Ready to submit your research? Choose BMC and benefit from:

- fast, convenient online submission

- thorough peer review by experienced researchers in your field

- rapid publication on acceptance

- support for research data, including large and complex data types

- gold Open Access which fosters wider collaboration and increased citations

- maximum visibility for your research: over $100 \mathrm{M}$ website views per year

At $\mathrm{BMC}$, research is always in progress.

Learn more biomedcentral.com/submissions 